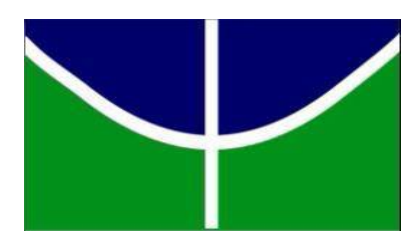

UNIVERSIDADE DE BRASÍLIA - UnB INSTITUTO DE CIÊNCIAS HUMANAS - IH DEPARTAMENTO DE GEOGRAFIA - GEA PROGRAMA DE PÓS-GRADUAÇÃO EM GEOGRAFIA ÁREA DE CONCENTRAÇÃO: GESTÃO AMBIENTAL E TERRITORIAL

\title{
ANÁLISE DA INFLUÊNCIA DAS VARIÁVEIS CLIMÁTICAS NA MORT ALIDADE POR DOENÇAS DO APARELHO CIRCULATÓRIO NO DISTRITO FEDERAL
}

EVONEIS FARIAS NATAL

Dissertação de Mestrado 


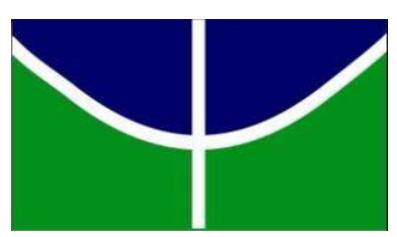

UNIVERSIDADE DE BRASÍLIA - UnB INSTITUTO DE CIÊNCIAS HUMANAS - IH DEPARTAMENTO DE GEOGRAFIA - GEA PROGRAMA DE PÓS-GRADUAÇÃO EM GEOGRAFIA ÁREA DE CONCENTRAÇÃO: GESTÃO AMBIENTAL E TERRITORIAL

\section{ANÁLISE DA INFLUÊNCIA DAS VARIÁVEIS CLIMÁTICAS NA MORTALIDADE POR DOENÇAS DO APARELHO CIRCULATÓRIO NO DISTRITO FEDERAL}

EVONEIS FARIAS NATAL

Orientadora: Prof. ${ }^{a}$ Dr. ${ }^{\text {a }}$ Ruth Elias de Paula Laranja

Dissertação de Mestrado 


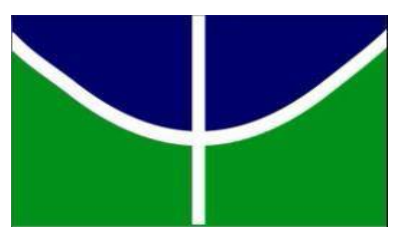

UNIVERSIDADE DE BRASÍLIA - UnB INSTITUTO DE CIÊNCIAS HUMANAS - $\mathbb{H}$

DEPARTAMENTO DE GEOGRAFIA - GEA

PROGRAMA DE PÓS-GRADUAÇÃO EM GEOGRAFIA

ÁREA DE CONCENTRAÇÃO: GESTÃO AMBIENTAL E TERRITORIAL

\section{ANÁLISE DA INFLUÊNCIA DAS VARIÁVEIS CLIMÁTICAS NA MORTALIDADE POR DOENÇAS DO APARELHO CIRCULATÓRIO NO DISTRITO FEDERAL}

\section{EVONEIS FARIAS NATAL}

Dissertação de mestrado apresentada ao Programa de Pós-Graduação em Geografia da Universidade de Brasilia, na área de concentração Gestão Ambiental e Territorial como requisito parcial para obtenção do título de Mestre em Geografia.

Aprovado por:

Professora Dra. Ruth Elias de Paula Laranja - Orientadora

Universidade de Brasilia - UnB - Departamento de Geografia

Professora Dra. Helen da Costa Gurgel - Examinador Interno Universidade de Brasília - UnB - Departamento de Geografia

Professora Dra. Ivone Kamada - Examinador Externo

Universidade de Brasília - UnB - Faculdade de Ciências da Saúde/FS

Brasilia-DF, 05 de Março de 2015. 


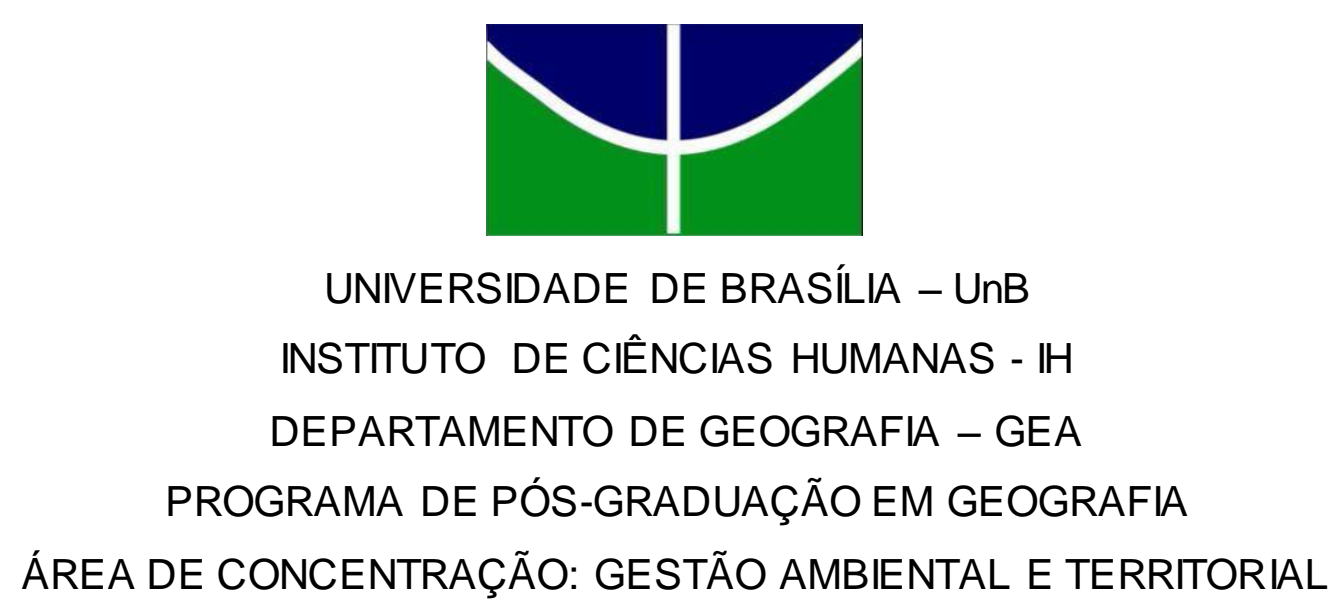

NATAL, EVONEIS FARIAS.

Análise da Influência das Variáveis Climáticas na Mortalidade por Doenças do Aparelho Circulatório no Distrito Federal, 121 páginas, (UnB-GEA, Mestre, Gestão Ambiental e Territorial, 2015).

Dissertação de Mestrado - Universidade de Brasilia. Departamento de Geografia.

1. Clima e Saúde

3. Doenças circulatórias

I.UnB - GEA
2. Variáveis Climáticas

4. Correlação

II. Título (Série)

É concedida à Universidade de Brasília permissão para reproduzir cópias desta dissertação e emprestar ou vender tais cópias somente para propósitos acadêmicos e científicos. O autor reserva outros direitos de publicação e nenhuma parte desta dissertação de mestrado pode ser reproduzida sem a autorização por escrito do autor.

Evoneis Farias Natal 


\section{AGRADECIMENTOS}

Em primeiro a lugar a Deus, nosso pai maior, responsável pelo dom da vida, saúde e paz infinita.

À minha esposa (Eliane) e aos meus filhos (Glenio e Guilherme), por estarem presentes nos momentos difíceis, de alegria, tristeza e por ser a razão da realização dos meus sonhos.

À Professora Ruth Elias de Paula Laranja pela orientação, incentivo e confiança.

A todos os professores do Departamento de Geografia/GEA, em especial aos professores Ercilia T. Steinke, Valdir A. Steinke, Helen da Costa Gurgel, Mário Diniz, Roberto Arnaldo Trancoso e Osmar Abílio que dispuseram de seus conhecimentos e fizeram parte da minha formação acadêmica.

Aos colegas da pós-graduação, em especial aos alunos do doutorado: Isabel, Núbia e Rebeca, e do mestrado: Ane Caroline, Elton, Gilney, Isabel, Ligier, Maribel, Marina, e Natanael que nos momentos difíceis se propuseram a ajudar com palavras de incentivos.

À Secretaria de Estado de Saúde do Distrito Federal pela disponibilização dos dados, em especial aos servidores Mauro, Eduardo e Cássio.

A todos que me ajudaram de forma direta e indireta nessa longa jornada.

Muito obrigado! 
"A vida é uma peça de teatro que não permite ensaios. Por isso, cante, chore, dance, ria e viva intensamente, antes Que a cortina se feche e a peça termine sem aplausos." (Charles Chaplin) 


\section{RESUMO}

Este trabalho constitui em uma colaboração aos estudos de clima e saúde humana, dando ênfase às doenças de origem circulatória. Nesta perspectiva, esta pesquisa objetivou analisar a influência das variáveis climáticas na mortalidade por doenças do aparelho circulatório no Distrito Federal no período de 2003 a 2012. A metodologia utilizada foi a bibliográfica, exploratória e de abordagem quantitativa na qual foram pesquisadas em artigos, revistas cientificas, periódicos, dissertações, teses, livros e sites oficiais o que permitiu melhor direcionamento do tema em questão. Os dados climatológicos - precipitação, pressão atmosférica, temperaturas e umidade relativas do ar - coletados junto à estação climatológica de Brasilia, mantida pelo Instituto Nacional de Meteorologia - e, posteriormente correlacionados através do método de correlação de Pearson com os registros de óbitos por doenças circulatórias registradas pela Secretaria de Estado de Saúde do Distrito Federal e pelo Departamento de Informática do SUS/DATASUS. Foi constatado que nas oscilações das variáveis do clima - temperatura e umidade relativa do ar (diminuição dos valores médios) e pressão atmosférica (aumento dos valores médios) - houve aumento nos registros de óbitos por agravos circulatórios. Dessa forma, é possível concluir que as condições do meio físico ligado ao clima podem contribuir com diversas morbidades e mortalidades, mas, vale ressaltar que outros fatores podem também contribuir com o aumento dos óbitos - condições socioeconômicas (moradia, alimentação, exposição aos poluentes atmosféricos) aliados com fatores fixos preexistentes.

Palavras-Chave: Clima e Saúde, Variáveis Climáticas, Doenças Circulatórias, Correlação. 


\begin{abstract}
This work is in collaboration with climate and human health studies, emphasizing the diseases with circulatory origins In this perspective, this paper analyzes the influence of climatic variables in mortality from circulatory diseases in the Federal District from 2003 to 2012. The methodology used was to literature, exploratory and quantitative approach, in which were surveyed in articles, scientific journals, periodicals, dissertations, theses, books and official sites, enabling better guidance of the subject in question. The climatological data - rainfall, air pressure, temperature and relative humidity - collected from the National Institute of Meteorology and thereafter correlated using Pearson's correlation method with the death records from circulatory diseases provided by database of the State Department of Health of the Federal District and the Department of SUS IT / DATASUS. It was found that the oscillations of the climate variables - temperature and relative humidity (lower mean values) and atmospheric pressure (higher mean values) - there was an increase in the death records by circulatory diseases. Thus, it was concluded that the conditions of the physical linked to climate environment can contribute to many morbidities and mortalities, but it is noteworthy that other factors may also contribute to the increase in admissions and deaths- socioeconomic conditions (housing, food, exposure to air pollutants)allies with preexisting fixed factors.
\end{abstract}

Keywords: Climate and Health, Climate Variables, Circulatory Diseases, Correlation. 


\section{SUMÁRIO}

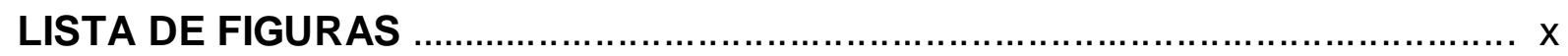

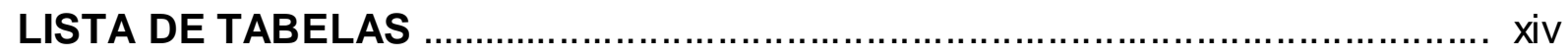

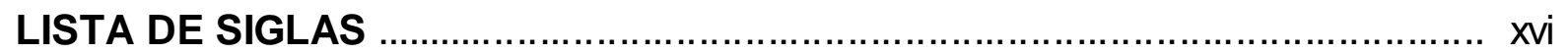

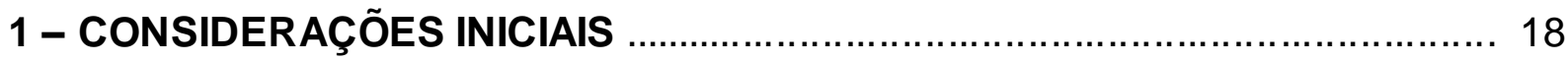

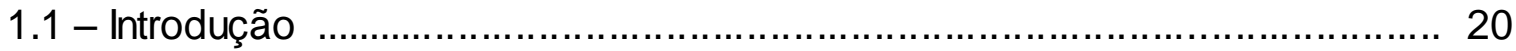

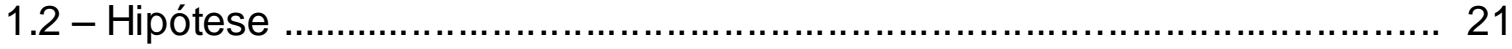

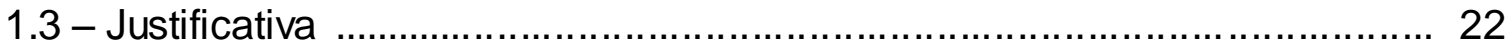

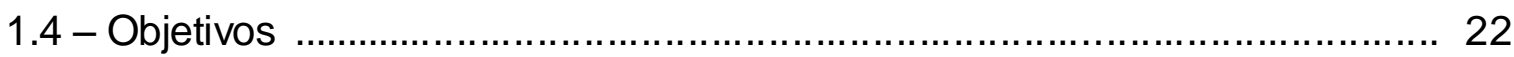

1.4 .1 - Objetivo Geral ............................................................. 22

1.4 .2 - Objetivos Específicos .................................................... 23

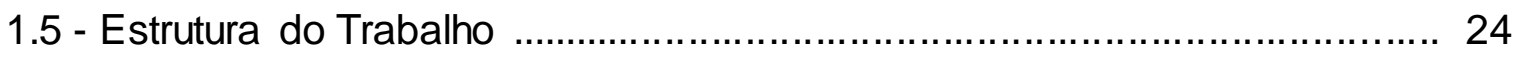

2 - FUNDAMENTAÇÃO TEÓRICA ....................................................... 25

2.1 - Trajetórias da Geografia da Saúde ................................................... 26

2.2 - Saúde, Doenças e Meio Ambiente .................................................... 33

2.3 - Geografia da Saúde e as Tecnologias ................................................. 36

2.4 - Clima e doenças - Visão Fragmentada ......................................... 38

2.5 - Doenças do Aparelho Circulatório ..................................................... 41

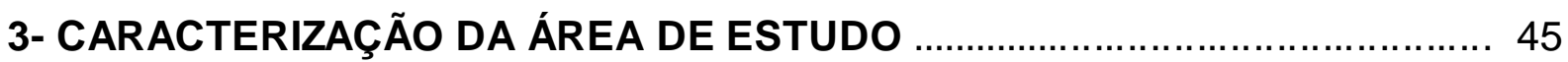

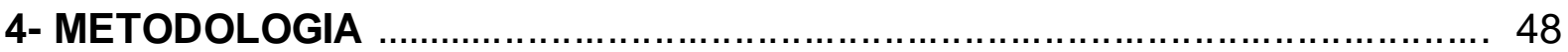

4.1 - Procedimentos Metodológicos ..................................................... 49

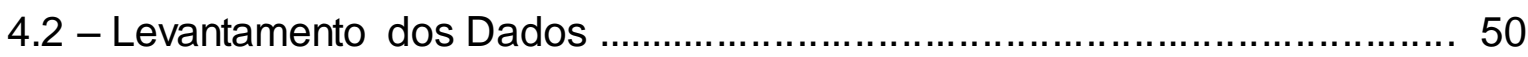

4.2 .1 - Dados da Saúde ..................................................................... 50

4.2 .2 - Dados do Clima ..................................................................... 50

4.3 - Processamento dos Dados ......................................................... 51

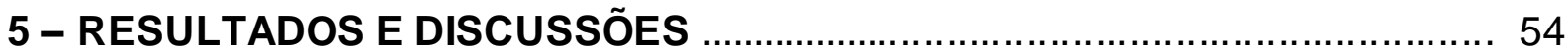


5.1- Levantamento dos óbitos por doenças do aparelho circulatório no Distrito

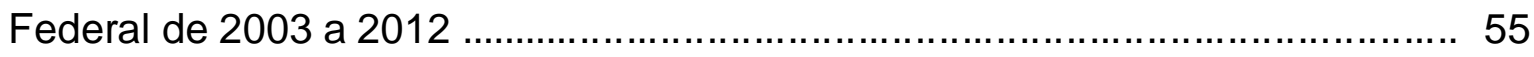

5.2 - Distribuição espacial dos óbitos por doenças do aparelho circulatório nas regiões administrativas (RAs) no Distrito Federal de 2003 a 2012 ..................... 62 5.3 - Correlações Mensais das Variáveis Climáticas com os óbitos por doenças do aparelho circulatório no Distrito Federal de 2003 a 2012 76

6 - CONSIDERAÇÕES FINAIS 108

REFERÊNCIAS BIBLIOGRÁFICAS 112

ANEXOS 119 


\section{LISTA DE FIGURAS}

Figura 01- Fluxograma do Objetivo Geral e Específicos da Pesquisa ............ 23

Figura 02- Tríade Ecológica, segundo Pavlovsky (1930) .............................. 35

Figura 03- Estrutura do Sistema Circulatório ............................................. 41

Figura 04- Transição Epidemiológica de 1930 a 2009 ................................ 42

Figura 05- Mapa das Regiões Administrativas do Distrito Federal ................. 46

Figura 06- Roteiro metodológico da pesquisa ......................................... 53

Figura 07- Média da Mortalidade por Doenças do Aparelho Circulatório, segundo a faixa etária em ambos sexo, Distrito Federal, 2003 a 2012

Figura 08- Mortalidade na população humana pelas principais doenças do aparelho circulatório em ambos sexos, em todo o Distrito Federal, 2003 a 2012

Figura 09- Divisão Administrativa do Distrito Federal, 19 RAs (reconhecidas oficialmente pelo IBGE) Utilizadas na pesquisa

Figura 10- Taxa média anual de óbitos por doenças do aparelho circulatório no Distrito Federal (grupo de 10.000 hab.), ano de 2003, distribuídos por Região Administrativa

Figura 11- Taxa média anual de óbitos por doenças do aparelho circulatório no Distrito Federal (grupo de 10.000 hab.), ano de 2004, distribuídos por Região Administrativa

Figura 12- Taxa média anual de óbitos por doenças do aparelho circulatório no Distrito Federal (grupo de 10.000 hab.), ano de 2005, distribuídos por Região Administrativa

Figura 13- Taxa média anual de óbitos por doenças do aparelho circulatório no Distrito Federal (grupo de 10.000 hab.), ano de 2006, distribuídos por Região Administrativa

Figura 14- Taxa média anual de óbitos por doenças do aparelho circulatório no Distrito Federal (grupo de 10.000 hab.), ano de 2007, distribuídos por Região Administrativa

Figura 15- Taxa média anual de óbitos por doenças do aparelho circulatório 
no Distrito Federal (grupo de 10.000 hab.), ano de 2008, distribuídos por Região Administrativa

Figura 16- Taxa média anual de óbitos por doenças do aparelho circulatório no Distrito Federal (grupo de 10.000 hab.), ano de 2009, distribuídos por Região Administrativa

Figura 17- Taxa média anual de óbitos por doenças do aparelho circulatório no Distrito Federal (grupo de 10.000 hab.), ano de 2010, distribuídos por Região Administrativa

Figura 18- Taxa média anual de óbitos por doenças do aparelho circulatório no Distrito Federal (grupo de 10.000 hab.), ano de 2011, distribuídos por Região Administrativa

Figura 19- Taxa média anual de óbitos por doenças do aparelho circulatório no Distrito Federal (grupo de 10.000 hab.), ano de 2012, distribuídos por Região Administrativa

Figura 20- Taxa média de óbitos por doenças do aparelho circulatório no Distrito Federal (grupo de 10.000 hab.),nos anos pesquisados (2003 a 2012), distribuídos por Região Administrativa

Figura 21- Relações entre as variáveis climatológicas e os óbitos por doenças do aparelho circulatório mensais em 2003, no Distrito Federal

Figura 22- Regressão entre as variáveis climatológicas e os casos de óbitos por doenças do aparelho circulatório na população humana de todas as idades e sexo, em 2003, no Distrito Federal

Figura 23- Relações entre as variáveis climatológicas e os óbitos por doenças do aparelho circulatório mensais em 2004, no Distrito Federal

Figura 24- Regressão entre as variáveis climatológicas e os casos de óbitos por doenças do aparelho circulatório na população humana de todas as idades e sexo, em 2004, no Distrito Federal

Figura 25- Relações entre as variáveis climatológicas e os óbitos por doenças do aparelho circulatório mensais em 2005, no Distrito Federal

Figura 26- Regressão entre as variáveis climatológicas e os casos de óbitos por doenças do aparelho circulatório na população humana de 
todas as idades e sexo, em 2005, no Distrito Federal

Figura 27- Relações entre as variáveis climatológicas e os óbitos por doenças do aparelho circulatório mensais em 2006, no Distrito Federal

Figura 28- Regressão entre as variáveis climatológicas e os casos de óbitos por doenças do aparelho circulatório na população humana de todas as idades e sexo, em 2006, no Distrito Federal

Figura 29- Relações entre as variáveis climatológicas e os óbitos por doenças do aparelho circulatório mensais em 2007, no Distrito Federal

Figura 30- Regressão entre as variáveis climatológicas e os casos de óbitos por doenças do aparelho circulatório na população humana de todas as idades e sexo, em 2007, no Distrito Federal

Figura 31- Relações entre as variáveis climatológicas e os óbitos por doenças do aparelho circulatório mensais em 2008, no Distrito Federal

Figura 32- Regressão entre as variáveis climatológicas e os casos de óbitos por doenças do aparelho circulatório na população humana de todas as idades e sexo, em 2008, no Distrito Federal

Figura 33- Relações entre as variáveis climatológicas e os óbitos por doenças do aparelho circulatório mensais em 2009, no Distrito Federal

Figura 34- Regressão entre as variáveis climatológicas e os casos de óbitos por doenças do aparelho circulatório na população humana de todas as idades e sexo, em 2009, no Distrito Federal

Figura 35- Relações entre as variáveis climatológicas e os óbitos por doenças do aparelho circulatório mensais em 2010, no Distrito Federal

Figura 36- Regressão entre as variáveis climatológicas e os casos de óbitos por doenças do aparelho circulatório na população humana de todas as idades e sexo, em 2010, no Distrito Federal

Figura 37- Relações entre as variáveis climatológicas e os óbitos por doenças do aparelho circulatório mensais em 2011, no Distrito Federal 
Figura 38- Regressão entre as variáveis climatológicas e os casos de óbitos por doenças do aparelho circulatório na população humana de todas as idades e sexo, em 2011, no Distrito Federa

Figura 39- Relações entre as variáveis climatológicas e os óbitos por doenças do aparelho circulatório mensais em 2012, no Distrito Federal

Figura 40- Regressão entre as variáveis climatológicas e os casos de óbitos por doenças do aparelho circulatório na população humana de todas as idades e sexo, em 2012, no Distrito Federal 


\section{LISTA DE TABELAS}

Tabela 01- Principais Fatores de Risco das Doenças do Aparelho Circulatório

Tabela 02- Regiões Administrativas Existentes e suas Respectivas Populações

Tabela 03- Classificação dos valores das correlações do Método de Pearson

Tabela 04- Mortalidade na população humana por Capítulo do CID-10 em ambos os sexos, em todo o Distrito Federal

Tabela 05- Mortalidade por doenças do aparelho circulatório na população humana por sexo, em todo o Distrito Federal

Tabela 06- Mortalidade na população humana por DAC, faixa etária em ambos sexos, em todo o Distrito Federal, 2003 a 2012

Tabela 07- Mortalidade na população humana pelas principais doenças do aparelho circulatório em ambos sexos, em todo o Distrito Federal, 2003 a 2012

Tabela 08- Taxa média anual de óbitos por doenças do aparelho circulatório no Distrito Federal (grupo de 10.000 hab.), 2003 a 2012, distribuídos por Região Administrativa

Tabela 09- Valores dos coeficientes de correlação $(R)$, de determinação $\left(R^{2}\right)$ e classificação $(C)$, encontrados entre as variáveis climatológicas e os números de óbitos mensais por doenças circulatórias ocorridas no Distrito Federal, ano de 2003

Tabela 10- Valores dos coeficientes de correlação $(R)$, de determinação $\left(R^{2}\right)$ e classificação $(C)$, encontrados entre as variáveis climatológicas e os números de óbitos mensais por doenças circulatórias ocorridas no Distrito Federal, ano de 2003

Tabela 11- Valores dos coeficientes de correlação $(R)$, de determinação $\left(R^{2}\right)$ e classificação $(C)$, encontrados entre as variáveis climatológicas e os números de óbitos mensais por doenças circulatórias ocorridas no Distrito Federal, ano de 2005 
Tabela 12- Valores dos coeficientes de correlação $(R)$, de determinação $\left(R^{2}\right)$ e classificação $(C)$, encontrados entre as variáveis climatológicas e os números de óbitos mensais por doenças circulatórias ocorridas no Distrito Federal, ano de 2006

Tabela 13- Valores dos coeficientes de correlação $(R)$, de determinação $\left(R^{2}\right)$ e classificação $(C)$, encontrados entre as variáveis climatológicas e os números de óbitos mensais por doenças circulatórias ocorridas no Distrito Federal, ano de 2007

Tabela 14- Valores dos coeficientes de correlação $(R)$, de determinação $\left(R^{2}\right)$ e classificação (C), encontrados entre as variáveis climatológicas e os números de óbitos mensais por doenças circulatórias ocorridas no Distrito Federal, ano de 2008

Tabela 15- Valores dos coeficientes de correlação $(R)$, de determinação $\left(R^{2}\right)$ e classificação $(C)$, encontrados entre as variáveis climatológicas e os números de óbitos mensais por doenças circulatórias ocorridas no Distrito Federal, ano de 2009

Tabela 16- Valores dos coeficientes de correlação $(R)$, de determinação $\left(R^{2}\right)$ e classificação $(C)$, encontrados entre as variáveis climatológicas e os números de óbitos mensais por doenças circulatórias ocorridas no Distrito Federal, ano de 2010

Tabela 17- Valores dos coeficientes de correlação $(R)$, de determinação $\left(R^{2}\right)$ e classificação (C), encontrados entre as variáveis climatológicas e os números de óbitos mensais por doenças circulatórias ocorridas no Distrito Federal, ano de 2011

Tabela 18- Valores dos coeficientes de correlação $(R)$, de determinação $\left(R^{2}\right)$ e classificação (C), encontrados entre as variáveis climatológicas e os números de óbitos mensais por doenças circulatórias ocorridas no Distrito Federal, ano de 2012 


\section{LISTA DE SIGLAS}

a.C - Antes de Cristo

AIDS / SIDA - Síndrome da Imunodeficiência Adquirida

AVC - Acidente Vascular Cerebral (AVC).

CID 10 - Classificação Estatística Internacional de Doenças e Problemas

Relacionados à Saúde, versão 10.

DAC - Doenças do Aparelho Circulatório

DATASUS - Departamento de Informática do Sistema Único de Saúde

DCNT - Doenças Crônicas Não-Transmissíveis

DF - Distrito Federal

FIOCRUZ - Fundação Osvaldo Cruz.

INMET - Instituto Nacional de Meteorologia

IBGE - Instituto Brasileiro de Geografia e Estatística

MEC - Ministério da Educação.

MS - Ministério da Saúde.

OMS - Organização Mundial da Saúde.

RA - Região Administrativa

SES - Secretaria de Estado de Saúde

SIG - Sistemas de Informações Geográficas

SIH - Sistema de Informações Hospitalares

SIM - Sistema de Informações sobre Mortalidade

SUS - Sistema Único de Saúde

TX - Taxa

WHO - World Heath Organization 


\section{OAPITULOI}

Considerações Iniciais Introdução Hipótese Justificava Objetivos Estrutura da Pesquisa 


\section{1 - CONSIDERAÇÕES INICIAIS}

O ser humano ao longo de sua vida é acometido por várias doenças de diferentes origens. Desde a antiguidade estudos já correlacionavam as enfermidades a vários fatores ligados ao ambiente físico (LACAZ, et. al. 1972).

O clima por apresentar alterações cíclicas diferentes e inesperadas na mesma região favorece a manifestação de determinados agravos à saúde tendo interferência no bem estar dos indivíduos (MURARA, et. al., 2010).

Portanto, ao analisarmos a saúde do homem e sua relação com o meio ambiente, partimos para uma interpretação mais complexa, ou seja, quais as condições ou agentes que favoreceram para a instalação de uma determinada doença podendo ser provocado por um agente químico, físico ou biológico das relações do homem com o ambiente.

Pois, os elementos ligados ao meio físico não são os únicos responsáveis pelo surgimento ou aumento das enfermidades, todavia alguns fatores que determinam as condições de saúde são fixos como os biológicos (sexo, idade, cor, raça e herança genética). Temos ainda, os fatores oriundos do estilo de vida e das questões socioeconômicas no que tange a educação, má alimentação, sedentarismo, tabagismo e o acesso aos serviços voltados para a promoção e recuperação da saúde.

É percebido que as palavras saúde e doença estão presentes no cotidiano das pessoas, mas o que nos faz pensar no processo saúde e doença são duas palavras com significados bastante diferentes, mas que é inerente a vida dos seres vivos.

Visando buscar um conceito mais abrangente de saúde, em 1948, a Organização Mundial de Saúde definiu: "Saúde é o estado de completo bem-estar físico, mental e social e não apenas a ausência de doença".

Esse conceito nos remete a pensar que saúde não pode ser compreendida de maneira abstrata e isolada. Pois, a saúde é entendida de várias formas dependendo da visão que se tenha do ser humano e sua relação com o ambiente, podendo variar de pessoa para outra, de culturas e ao longo do tempo, tornando a saúde bastante subjetiva e de momentos históricos. É o individuo ou a coletividade que considerarão 
ter mais ou menos saúde num determinado momento histórico através dos valores atribuídos a uma situação.

$\mathrm{Na}$ atualidade, o homem convive com diversas doenças de diferentes origens, e expressam a busca individual da cura através dos investimentos das políticas públicas em prol da coletividade. Não podemos limitar a busca pela saúde somente pelas ações do poder público ou delegar aos profissionais de saúde, pois, ela está ao alcance de todos.

Diante de tanto conhecimentos e tecnologia que o homem dispõe, podem melhorar a qualidade de vida das pessoas através de medidas preventivas que possam antecipar as mudanças bruscas do meio físico e social.

Doenças que eram tipicamente de países desenvolvidos como as doenças do aparelho circulatório (cardiovasculares) vêm ganhando crescente importância entre as causas de mortes nos países subdesenvolvidos associadas ao estresse, a hábitos alimentares impróprios, ao tabagismo, à vida sedentária e o aumento da expectativa de vida.

Vale ressaltar que o foco nos cuidados dos pacientes cardíacos nesses países tem sido a tríade: fármacos, atividade física e adequação alimentar já que há um conhecimento muito incipiente da estreita relação da saúde do homem com o ambiente físico no qual está inserido.

Não há a preocupação em analisar a mudança na qualidade de vida dos pacientes com as variáveis climáticas e ambientais mesmo sabendo que o controle dos fatores de risco é imprescindível para a redução das complicações fatais nos episódios de doenças. 


\section{1 - INTRODUÇÃO}

As Doenças do sistema circulatório estão ligadas a todo o mecanismo do coração envolvendo as veias, artérias, alguns órgãos que são responsáveis por: filtrar, bombear, oxigenar e distribuir o sangue para todo o corpo (MS, 2003).

As doenças do aparelho circulatório (DAC) constituem-se em um dos mais importantes problemas de saúde pública da atualidade, sendo as principais doenças crônicas não transmissíveis (DCNTs ${ }^{1}$ ) responsáveis pela mortalidade e Morbidade em todas as regiões do Brasil (MS, 2011).

Conforme destaca a WHO (World Health Organization, 2009), a morbidade e a mortalidade por doenças do aparelho circulatório atingem tanto os países desenvolvidos quanto em países emergentes, em 2030 morrerão 23,6 milhões de pessoas ao ano devido a alguma forma de agravo das doenças do aparelho circulatório, este agravo já supera, por exemplo, as mortes por malária, HIV/AIDS e tuberculose.

Segundo dados do Ministério da Saúde (2011), as doenças cardiovasculares são responsáveis por $29,4 \%$ de todas as mortes registradas no País em um ano. Isso significa que mais de 308 mil pessoas faleceram, principalmente, de infarto e acidente vascular cerebral (AVC). A alta frequência do problema coloca o Brasil entre os 10 países com maior índice de mortes por doenças cardiovasculares (MS, 2011).

De acordo com os dados da Secretaria de Estado de Saúde/DF, o quantitativo de mortes relacionadas às doenças cardiovasculares cresceu de forma significativa nos últimos anos, numa análise estatística de 2000 a 2010 (CODEPLAN, 2012).

As doenças cardiovasculares vêm ganhando novos patamares com seus valores aumentando a cada ano, ficando evidente a amplitude que este problema social tem atualmente.

No Brasil, acometem cerca de $75 \%$ da população adulta sendo que os casos ocorrem desde a adolescência (MOURA, et.al., 2007). As doenças do aparelho circulatório não distinguem cor, raça, sexo ou idade. São oriundas de vários fatores,

\footnotetext{
${ }^{1}$ São doenças multifatoriais que se desenvolvem no decorrer da vida e são de longa duração. Atualmente, elas são consideradas um sério problema de saúde pública, e já são responsáveis por $63 \%$ das mortes no mundo, segundo estimativas da Organização Mundial de Saúde (WHO, 2009).
} 
desde a má alimentação, sedentarismo, tabagismo, hereditariedade, mudanças de estilo de vida, etc.

Para o Ministério da Saúde (2006) com a revolução industrial e tecnológica ocorreram mudanças drásticas entre a interação do homem e o meio ambiente, fazendo necessário refletir sobre o surgimento de diversas enfermidades. Desde a antiguidade Hipócrates ${ }^{2} 400$ a.C , o pai da medicina, já mostrava esta relação entre o meio ambiente - saúde/doença - homem - através de sua famosa obra "Dos ares, das águas e dos lugares" esta obra já registrara, naquela época, a preocupação humana com a relação entre os fatores ambientais e o surgimento das doenças (LACAZ, et. al.,1972).

Nesta perspectiva, torna-se viável analisar a influência das variáveis climáticas nos registros de óbitos por Doenças do Aparelho Circulatório no Distrito Federal visando aprimorar os conhecimentos sobre a saúde da população humana do Distrito Federal.

Espera-se que as informações e resultados obtidos com o trabalho possam contribuir de forma interdisciplinar para que os gestores da saúde possam formular políticas públicas mais eficientes na demanda dos pacientes com enfermidades do aparelho circulatório.

\section{2 - HIPÓTESE}

Estudos em países Asiáticos (LEE, et. al. 2010; Y.LI et. al. 2011) e Europeus (DILAVERIS et. al. 2006; GOERRE et. al. 2007) apontam que os elementos climáticos e as mudanças ambientais têm interferências de forma direta ou indireta no aumento de várias doenças humanas, e até mesmo no aumento da mortalidade.

As alterações do clima podem provocar um aumento significativo do número de casos de uma grande variedade de doenças ou agravar o quadro dos pacientes no leito e até levar ao óbito (OLIVEIRA, 2005).

\footnotetext{
2 Hipócrates Viveu entre 400 a.C - 377, considerado o pai da medicina, em sua obra mais importante "Dos ares, das águas e dos Lugares", considerado o primeiro tratado de saúde pública, de geografia médica, de climatologia e fisioterapia.
} 
Neste sentido, a pesquisa parte da seguinte hipótese: As variáveis climáticas podem contribuir com a variabilidade dos óbitos por doenças do aparelho circulatório no Distrito Federal?

\section{3 - JUSTIFICATIVA}

Especificamente, no Brasil existem poucos trabalhos que mostram a existência da correlação das doenças com os elementos climáticos e as pesquisas existentes são trabalhos dissociados, não permitindo uma visão holística da relação das doenças humanas com as variáveis climáticas. Não há a preocupação em analisar a mudança na qualidade de vida dos indivíduos com as variáveis climáticas e ambientais, mesmo sabendo que o controle dos fatores de risco é imprescindível para a redução das complicações fatais nos episódios de doenças.

Neste contexto, torna-se relevante a busca de reafirmar a importância da Geografia na compreensão do processo saúde-doença e tornar possível o diálogo entre os profissionais da geografia e os da área de saúde.

\section{4 - OBJETIVOS}

\subsection{1 - Objetivo Geral}

Este trabalho constitui em uma colaboração aos estudos de clima e saúde humana com ênfase às doenças de origem circulatória.

Esta pesquisa tem como objetivo geral analisar a influência das variáveis climáticas (precipitação pluviométrica; pressão atmosférica; umidade relativa e temperatura do ar máxima, mínima e média) na mortalidade por doenças do aparelho circulatório na população humana do Distrito Federal no período de 2003 a 2012, série temporal de 10 anos (figura 01). 


\subsection{2 - Objetivos Específicos}

> Analisar estatisticamente os casos de mortalidade por doenças do aparelho circulatório no Distrito Federal de 2003 a 2012;

> Identificar as variáveis climáticas (precipitação pluviométrica; pressão atmosférica; umidade relativa do ar e temperatura do ar máxima, mínima e média) que mais se correlacionam com as doenças do aparelho circulatório;

$>\quad$ Compreender a relação mensal entre o clima e os casos de mortalidade por doenças do aparelho circulatório.

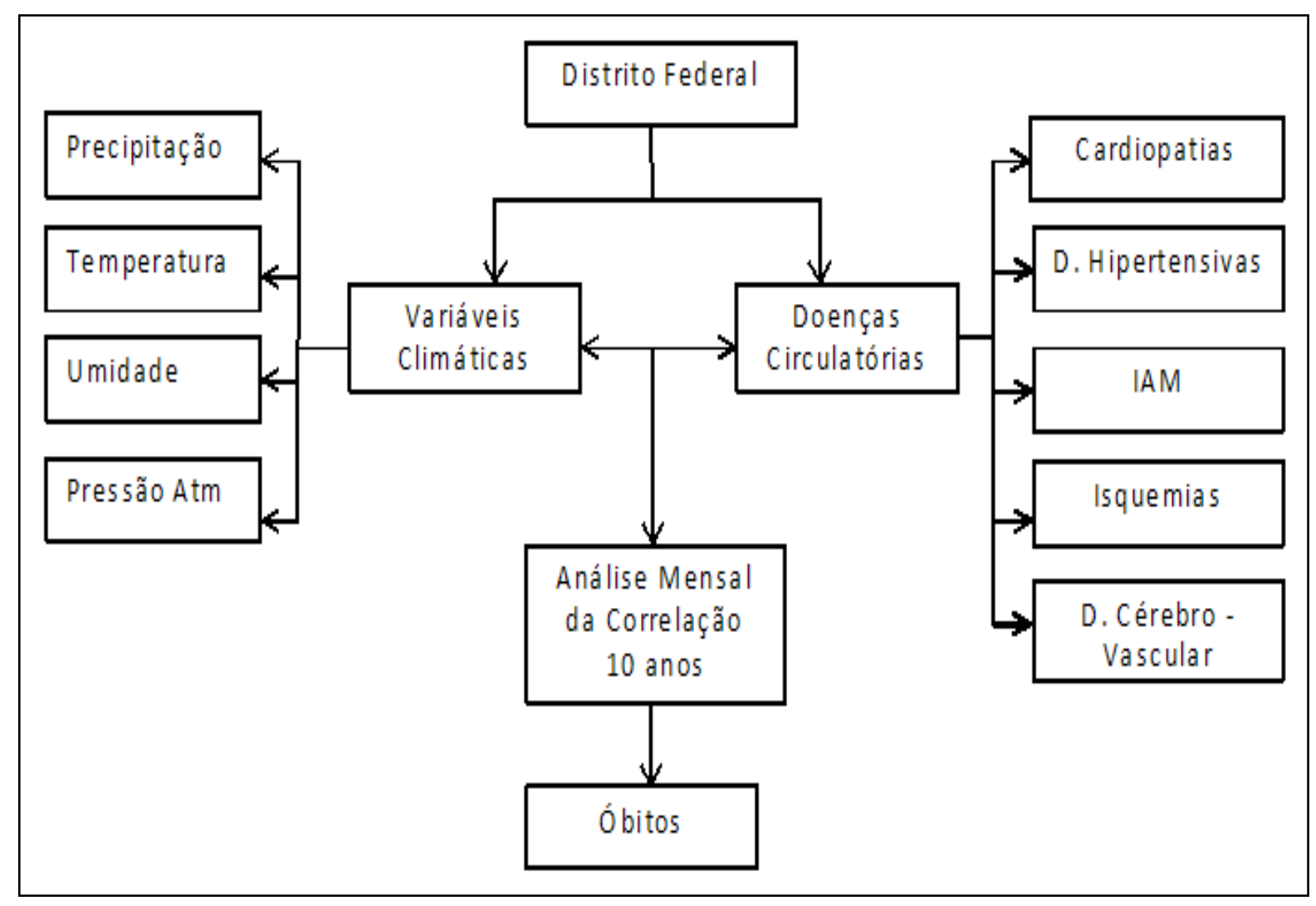

Figura 01 - Fluxograma do Objetivo Geral e Específicos da Pesquisa. Elaboração: NATAL, 2015. 


\section{5 - ESTRUTURA DA PESQUISA}

Para desenvolver o referido estudo, o trabalho foi dividido em 06 (seis) capítulos, estruturado em:

Capítulo I - Apresenta-se o tema e as considerações Iniciais, Introdução, a justificativa, Hipótese e a sistematização dos objetivos da pesquisa.

Capítulo II - Expõe uma revisão bibliográfica: resgaste descritivo da geografia da saúde no mundo e no Brasil, conceitos básicos de saúde, levando em consideração o vasto número de fatores que influenciam a saúde das populações, posteriormente serão tratados as doenças do aparelho circulatório e os vários fatores determinantes que favorecem a doença.

Capítulo III - Caracterização da Área de Estudo: Nesta etapa foi descrita a caracterização da área de estudo, o Distrito Federal, localização geográfica, dados climáticos, divisão administrativa e dados populacionais e econômicos da área pesquisada.

Capítulo IV - Procedimentos Metodológicos: Neste capítulo descrevemos os procedimentos metodológicos e instrumentos utilizados para efetivação da pesquisa, como: a coleta de dados, o material cartográfico, as técnicas e tratamento dos dados.

Capítulo V - Análise e Discussão dos Resultados: foram analisadas as variáveis climáticas através de método de correlação de Pearson que favoreceram para o comportamento da mortalidade das doenças do aparelho circulatório através dos dados de saúde e clima levantados dos anos pesquisados (2003 a 2012).

Capítulo VI - Apresentamos as considerações finais da pesquisa. 


\section{OAPITULOII}

Fundamentação Teórica 


\section{2 - FUNDAMENT AÇÃO TEÓRICA}

\section{1 - Trajetórias da Geografia da Saúde}

Desde a antiguidade os estudiosos já preocupavam com essa relação do homem e o meio ambiente - Hipócrates - 480 a.C, pai da medicina, em sua famosa obra "Dos ares, das águas e dos lugares" já se preocupava com a relação: homem saúde - ambiente. Em sua obra, já registrava a preocupação humana com a relação entre os fatores ambientais e o surgimento das doenças (LACAZ et. al., 1972).

Para Correa (2011), a inter-relação entre as doenças e o meio-ambiente já era percebida desde a Antiguidade Clássica, onde a Escola Hipocrática (Grécia, Séc. $V$ a.C) relacionava as doenças, especialmente as endêmicas e seus focos ao meio ambiente.

A teoria de Hipócrates foi bastante criticada por atribuir as doenças a determinados locais, assim remetia o pensamento do determinismo geográfico ${ }^{3}$. Na verdade Hipócrates sugeria a necessidade de conhecer tanto o espaço físico quanto as influencias sociais, culturais e o estilo de vida que as pessoas estavam inseridas.

Antes as enfermidades eram atribuídas a agentes invisíveis e sobrenaturais, Hipócrates exercendo atividades médicas da época, observador e conhecedor do funcionamento do ser humano, começou a mudar os conceitos das causas de doenças, atribuindo ao meio físico e social com as condições fisiológicas do ser humano.

Hipócrates parte do princípio que as origens das doenças estavam relacionadas às forças da natureza que estão dentro e fora das pessoas, atribuindo às causas naturais no processo saúde e doença, que a saúde era uma combinação equilibrada entre os 04 (quatro) elementos da natureza: terra, água, ar e fogo. $\mathrm{Na}$ concepção ontológica, defende que as doenças são entidades exteriores ao organismo que o invadem para se localizarem em varias das suas partes (MYERS \& BENSO, 1992).

Nessa época, difundiram uma teoria através dos conceitos de Hipócrates que

\footnotetext{
${ }^{3}$ Friedrich Ratzel (1844-1904) pensador alemão, foi atribuído aos seus conceitos o determinismo geográfico, em que o homem seria produto do meio, ou seja, as condições naturais é que determinam a vida em sociedade. O homem seria escravo do seu próprio espaço.
} 
as doenças eram ocasionadas pela natureza, ou seja, o meio físico, e atribuíram às epidemias as condições climáticas, particularmente aos ventos e ao frio (LIMA NETO, 2000; PARAGUASSU-CHAVES, 2001, UJVARI, 2003).

Ainda, segundo Ujvari (2003) Hipócrates postulou que doenças como diarreias e febre quartã (malária ou mal dos ares) viessem das águas de regiões insalubres de pântanos, devendo as pessoas evitar a moradia em locais alagados e pantanosos. Com esta relação entre as doenças e as águas de locais insalubres foi possível criar medidas de prevenção de determinadas moléstias causadas pelo consumo ou moradia aos arredores desses locais que serviam de criadouros para os agentes transmissores.

Hipócrates mesmo não sendo um geógrafo, mas com seus conceitos empíricos de dimensão espacial e localidade das ocorrências de certas moléstias, já demonstrava a importância de entender a relação humana com o meio natural no processo saúde-doença. Mesmo, vivendo num momento histórico que não havia tecnologias modernas para visualizar as bactérias que provocavam a diarreia, nem o agente causador da malária que habitavam os mosquitos dos terrenos alagados, as suas conclusões foram de grande importância para a sociedade e os médicos de sua época, começaram a interpretar os efeitos que o meio ambiente antes despercebido causava ao organismo humano (UJVARI, 2003).

Para Ujvari (2003) as teorias apresentadas por Hipócrates houve a ruptura do surgimento das doenças na concepção mítica ${ }^{4}$ para a naturalização da saúde, dando início a Geografia Médica, no qual a saúde e as doenças eram resultado de uma relação das populações com o meio ambiente e do estilo de vida.

Nesta época os conhecimentos geográficos começaram a fazer parte da filosofia grega e do ensino da medicina, serviam na anamnese dos pacientes a respeito de onde e como viviam informações importantes na confecção dos diagnósticos (ARMSTRONG, 1983). A Geografia Médica passou a fazer parte do ensino da medicina no momento em que pacientes foram indagados a respeito de onde viviam (JUNQUEIRA, 2009).

Com as informações obtidas referentes à moradia, ao estilo de vida, insalubridades e demais fatores que poderiam estar ocasionando determinadas doenças, os pacientes eram orientados a mudar os seus estilos de vida ou até

\footnotetext{
${ }^{4}$ Concepção entre os seres e as coisas, entre o sujeito e os objetos, processava a obediência aos seres divinos e semidivinos, detentores dos poderes que regiam o curso dos eventos cósmicos ehumanos.
} 
mesmo de ambiente, ou seja, mudar de um lugar para outro com as condições ambientais diferentes.

Mesmo pautado que a saúde e a doença estão relacionadas às inter-relações dos seres humanos com o meio que o cercam, ainda nos dias atuais perduram essa dualidade entre a materialidade e o plano espiritual.

Para Le Goff (1991) são valores criados a cerca dos fatores sobrenaturais impregnados na cultura dos povos, como superstições, medos, sentimentos de culpa, aos astros e demais mistérios que estão indissoluvelmente ligados às expressões da doença.

Com o surgimento de várias epidemias ${ }^{5}$ que acabara com várias populações do império romano, a geografia médica passou por alguns declínios, dando ênfase a cura religiosa de domínio da igreja e abandonando a medicina clássica. Neste sentido, a doença torna um ato do pecado e que os males do corpo só poderiam ser curados por intervenção divina.

Nos séculos XV e XVI a geografia médica começa uma nova ascensão com as viagens dos europeus nos outros continentes, trazendo informações valiosas de suas observações nos diferentes lugares e descrevendo os métodos locais de tratamento, e os comportamentos de cada cultura com determinadas enfermidades.

Para Porter (1992) os médicos europeus começavam a encarar a conquista da doença como uma derivação do domínio humano sobre o ambiente. Já havia a preocupação de calcular a morbidade em climas quentes e frios, contextos urbanos e rurais.

Os médicos iniciaram uma catalogação dos endereços dos pacientes com as enfermidades, iniciando a espacialização das doenças. A distribuição espacial das doenças ficou conhecida como as Topografias Médicas, pois faziam descrições detalhadas de cidades, vilas, bairros e distritos particulares, tratando das condições de saúde, informações meteorológicas, hidrográficas, descrições de plantas e o modo de vida dos habitantes locais (PEITER, 2005).

Com os trabalhos de catalogação a Geografia Médica criou uma rede de informações das doenças e tratamentos, foram traduzidos para uma linguagem cientifica com o propósito de compartilhar com toda a comunidade médica. Esse

\footnotetext{
${ }^{5}$ Caracteriza pela incidência de grande número de casos de uma doença em curto período de tempo, exemplo: doença infecciosa transmissível que ocorre numa região se espalha rapidamente entre pessoas de outras regiões, originando ali um grande número de casos da doença (vírus ebola).
} 
trabalho só foi possível graças a vários profissionais de diversas áreas (geógrafos, historiadores, médicos, etc.) e, principalmente, aos viajantes exploradores e os nativos de cada região.

Esses detalhes em relação à moradia, às cidades, aos distritos e aos países eram adquiridos com as viagens de médicos Europeus a colônias da Ásia, África e América que descreviam informações das pessoas, dos lugares, as doenças que os afligiam, os métodos locais de tratamentos e as crenças sobre sua causa. Esses relatos ficaram conhecidos como um levantamento médico-geográfico, porém, geralmente não possuíam uma exatidão quanto à localização e à temporalidade dos eventos (JUNQUEIRA 2009).

À medida que essas viagens tornaram-se mais frequentes, com a conquista das navegações pelos colonizadores europeus, mais informações eram levantadas pelos religiosos, comerciantes e exército.

Para Costa e Teixeira (1999) a aproximação entre o saber médico e a geografia foi impulsionada graças aos descobrimentos de novas terras pelos colonizadores, surgiu a necessidade de se conhecer as doenças das terras conquistadas visando à proteção de seus colonizadores e o desenvolvimento das atividades comerciais.

Portanto, os conhecimentos sobre determinadas moléstias eram também de extrema importância nas conquistas de novas terras conforme aborda ParaguassuChaves (2001):

\footnotetext{
"No período correspondente as grandes viagens e com a descoberta de novos países... entre os séculos XVI e XVII, levaram os colonizadores à necessidade do conhecimento das moléstias das regiões colonizadas, para sua proteção ou de seu comercio" (PARAGUASSU-CHAVES, 2001, p. 43).
}

As grandes ciências da época já eram usadas em prol do homem em dominar novas terras, obter conquistas e proteger seus desbravadores de moléstias desconhecidas.

No século XIX, John Snow (1855), médico sanitarista, abordou a distribuição espacial da cólera na Inglaterra associando à distribuição de fontes de abastecimento de água nas regiões afetadas. Pois, as fezes estavam contaminando a água que era usada pelas pessoas na ingestão, lavagem e na confecção de suas refeições.

Até o século XIX, a Geografia Médica foi sendo construída pelos médicos que 
desconheciam os agentes etiológicos microbianos das doenças, foram criando métodos preventivos com a ideia de que se o homem dominasse o ambiente e poderia controlar as doenças, conforme afirma Peiter (2005):

Até meados do século XIX a Geografia Médica foi, portanto, um campo de conhecimento construído por médicos que desconheciam os agentes etiológicos microbianos das doenças. Estes médicos buscavam informações no ambiente físico (clima, temperatura, relevo, vegetação, etc.) para as suas práticas (diagnóstico e terapêutica) (PEITER, 2005, p.8).

Portanto, com o descobrimento das bactérias e parasitas por Louis Pasteur (1822-1895) e Robert Koch (1843-1910) ocorreu uma série de transformações nos conhecimentos do ramo da Medicina sendo denominado esse período de revolução bacteriológica.

Para Peiter (2005) e Lima Neto (2000) foi um período de reformulação na concepção do processo saúde-doença fato que refletia no ensino da medicina e no campo de atuação dos médicos.

Com essa revolução no campo da medicina os ensinamentos de Hipócrates sobre a influência do meio físico sobre o homem e as doenças foram sendo esquecidas. Assim, a medicina passou a se dedicar, exclusivamente, ao corpo humano, perdendo o interesse pelo ambiente.

No século XX, na década de 30 e 40 a geografia reaproxima novamente das ciências médicas graças aos trabalhos do parasitologista Pavlovsky (1939) e do geografo Max Sorre (1943), voltam a estabelecer relação das doenças com as influências do meio físico. Pavlovsky, em seus estudos em torno das doenças endêmicas estabelece os fatores climáticos sendo uns dos agentes causadores das tais endemias.

Neste contexto se estabelece o paradigma da Tríade Ecológica (homem agente - ambiente) desenvolvido em sua obra "A Teoria dos Focos Naturais das Doenças Transmissíveis" o que traz novamente a vertente ambiental (SILVA, 1997).

Os trabalhos do geógrafo Max Sorre eram considerados mais abrangentes que os de Pavlovsky. Pois, Sorre desenvolveu o conceito de "complexo patogênico", permitindo de forma mais abrangente abordar uma grande variedade de doenças infecciosas e parasitárias, o que a teoria de Pavlovsky não possibilitava (FERREIRA, 1991).

No Brasil, destacamos o médico sanitarista Afrânio Peixoto que desenvolveu vários estudos na saúde publica, as relações entre o clima, o homem e a cultura. 
Além de considerar a importância das condições de higiene e salubridade na propagação das doenças, Afrânio Peixoto dava grande ênfase no clima em destaque em sua obra "Clima e Saúde, 1938".

Nesta obra, ele descreveu suas análises das relações dos tipos de clima e as variações sazonais com as morbidades, endemias e epidemias, e ainda ressaltou que a partir destas conclusões em relação às condições climáticas, certas enfermidades poderiam ser facilitadas e outras inibidas ou até mesmo extintas (PEIXOTO, 1938).

A Geografia da Saúde no Brasil ganha ênfase a partir da década de 1950 com interesses geopolíticos, com as pesquisas nas doenças presentes nas áreas em que havia o movimento de interiorização e integração do território brasileiro (ANADRADE et al., 2010)

Nas décadas seguintes, 70 e 80 , a geografia médica no Brasil ganha destaque com os trabalhos "Introdução à Geografia Médica no Brasil" (LACAZ et al., 1972), "Ensaios Médicos Sociais" (PESSOA, 1978) e Geografia da Fome (JOSUÉ DE CASTRO, 1980).

Apesar da importância de estudos da geografia no espaço geográfico a cerca da saúde e os fatores do meio físico que possibilitam o surgimento e a disseminação de várias doenças relacionadas, principalmente, aos fatores climáticos. Ao compararmos a outras vertentes da geografia ainda continua incipiente, sendo que os referidos estudos possuem extrema relevância na espacialidade nas ofertas de serviços de saúde.

Neste sentido, Peiter (2005) aborda a falta de materiais e publicações na área da geografia da saúde:

\footnotetext{
Atualmente, não há no Brasil publicações especializadas em Geografia da Saúde e raramente se encontram artigos de Geografia da Saúde em periódicos de Geografia. Poucos artigos sobre o assunto podem ser encontrados nos periódicos da área da saúde (em particular de Saúde Pública), o que reduz muito o retorno dos conhecimentos da Geografia Médica para a própria Geografia (PEITER, 2005, p.16).
}

Portanto, há um grande desafio de romper os ensinos tradicionais dos cursos de geografia cuja separação entre a geografia física e a humana é nítida, sendo que todos os campos possuem extrema importância e de forma integrado.

Para Guimarães (2001), com os movimentos de renovação do pensamento geográfico brasileiro dos últimos vinte anos vêm possibilitando a discussão de tais 
temas a partir da introdução de uma série de novas questões teóricas e metodológicas. Afinal, o desenvolvimento das ciências buscam melhores condições para o ser humano. As maiores preocupações da ciência no limiar do século XXI estão relacionadas com as condições da existência humana (FARIA \& BORTOLOZZI, 2009).

Assim, torna importante buscar novos diálogos em prol da atual sociedade frente a novas endemias e epidemias que desenvolvem de forma rápida com 0 dinamismo do capitalismo e do processo globalizado vigente. Uma das características principais do mundo globalizado tornou possíveis os fluxos de vírus e bactérias que podem se alastrar rapidamente nas diversas regiões do globo e produzir grandes epidemias (CASTELLS, 2002).

Para Santiago (2011), a geografia da Saúde possui extrema importância na evolução da saúde nas populações através da análise da distribuição de agravos à saúde, do aprimoramento das técnicas de seu respectivo sistema, tornando-se útil no rastreamento, mapeamento e racionalização de determinadas doenças, estudando seus respectivos desenvolvimentos bem como a caracterização das condições típicas de ocorrência de determinado mal.

A geografia da Saúde com toda importância ao longo do desenvolvimento econômico e social humano, ganha reconhecimento oficial no cenário mundial a partir do congresso internacional de Lisboa em 1949, a Organização Mundial de Saúde (OMS) reconheceu a sua importância graças à nova definição de saúde "saúde é o estado de completo bem-estar físico, psíquico e social e não meramente a ausência de enfermidades".

Em 1976, no congresso da União Geográfica Internacional (UGI) o termo "Geografia Médica" passa a ser utilizada Geografia da Saúde (VIEITES e FREITAS, 2007).

Para Santa Rosa (2010), os estudos da geografia da saúde, ao contrário da geografia médica e medicina geográfica, possuem uma abordagem mais crítica em que a análise das doenças é trabalhada com os fatores ambientais e sociais de risco. 


\section{2 - Saúde, Doença e Meio Ambiente}

Ao longo dos anos a Geografia vem estudando o espaço geográfico natural e humanizado no qual o homem faz parte $e$ interage de diferentes formas $e$ intensidades. Sendo esse sensível a diversas condições ambientais do meio que o cerca, afetando o seu bem estar e o seu modo de vida.

Estudar o espaço e as relações com a saúde do homem é um dos grandes desafios da geografia em validar o seu papel sobre o modelo biomédico dominante.

Mesmo havendo registro do estudo da Geografia vinculado aos conhecimentos da saúde desde a antiguidade (GUIMARÃES, 2001) ainda é preciso romper algumas barreiras e preconceitos.

Neste sentido, Vaz (2008) aborda que:

A geografia da saúde e médica, tem tido certa dificuldade em afirmar seu potencial de estudo, bem como, suas inúmeras áreas que permite ao geógrafo a sistematizar estudos capazes de orientarem no planejamento e na gestão de serviços de saúde (VAZ, 2010, p.8).

Para Nossa (2008) a geografia assume-se como ciência contributiva na discussão da temática saúde - doença sendo desejável a aproximação do real ao social.

A relação entre a produção do espaço e a saúde do homem envolve diversos aspectos físicos e sociais, nos quais os aspectos sociais da saúde incluem as condições mais gerais de uma sociedade (socioeconômicas, culturais e ambientais), que se relacionam com as condições de vida e trabalho de seus membros, como habitação, saneamento, ambiente de trabalho, serviços de saúde e educação.

É preciso romper a concepção metodológica do ensino da geografia física e humana, não podemos criar uma barreira invisível entre ambas, pois o homem esta presente de forma indissociável.

Desta forma, a geografia pode contribuir nos estudos de forma unificada entre natureza e sociedade, Faria e Bortolozzi (2009):

"A Geografia se apresenta, de um lado, como a ciência do estudo das relações entre a sociedade e a natureza, e, portanto, se vê fortalecida e desempenha um papel fundamental nas análises ambientais nas diversas escalas, e de outro, como a ciência do estudo do espaço e, nesse caso, irá ao encontro das necessidades enfrentadas pela Epidemiologia (FARIA \& BORTOLOZZI, p. 32, 2009)". 
Neste contexto, surge a preocupação com as questões ambientais de forma integrada com as questões da saúde e não simplesmente a degradação ambiental. Um novo paradigma na sociedade - o desenvolvimento sustentável - um novo valor estratégico que busca a saúde e uma melhor qualidade de vida.

A busca da sustentabilidade alicerça-se em dois princípios ou diretrizes gerais. O primeiro, de que o desenvolvimento seja orientado para a transformação das realidades e fundamentado no equilíbrio entre a natureza e a cultura, superando a ruptura entre o sujeito e o objeto (AUGUSTO, $p$ 179, 2003).

Ainda, segundo Augusto (2003):

"O desenvolvimento sustentável surge a partir do momento que os sinais da crise ambiental ficam nítidos no âmbito global (efeito estufa; aquecimento dos mares; comprometimento da camada de ozônio) e na saúde individual (intoxicações químicas; câncer; malformação congênita; doenças neurológicas, imunológicas e respiratórias; estresse; dependência de drogas; violência) são evidentes e reconhecidos amplamente (AUGUSTO, $p$ 179, 2003)".

Com esses desequilíbrios da natureza começaram a afetar a saúde da população humana em diversos perfis epidemiológicos afetando a qualidade de vida da atual população e podendo comprometer as futuras gerações.

As atividades humanas sobre o meio ambiente causam vários impactos na saúde do homem em diferentes escalas. Com a destruição dos ecossistemas, contaminação do solo e água com a disposição inadequada dos resíduos industriais, juntamente com moradia inadequada e má condições de trabalhos interagem com maior intensidade com a saúde dos grupos populacionais vulneráveis (BARCELLOS e QUITÉRIO, 2006).

Segundo estimativa da Organização Mundial de Saúde (OMS, 2002), 30\% os danos à saúde estão relacionados aos fatores ambientais decorrentes do saneamento básico inadequado, poluição do ar, exposição a substâncias químicas, fatores biológicos e desastres naturais.

No entanto, surgem preocupações com as populações expostas às condições ambientais adversas, a necessidade de intervir a esses problemas e apontar soluções plausíveis de forma integradora com a realidade de todos envolvidos.

Para Lemos e Lima (2002) é no espaço geográfico que se desenvolvem as interações entre os diferentes segmentos das sociedades humanas e destas com a natureza. Essa interação do homem com o meio não sendo harmoniosa poderá 
trazer resultados negativos, diversos impactos ambientais e a disseminação de várias doenças.

No século XX, Pavlovsky (parasitologista russo) desenvolveu a teoria dos focos naturais no qual as doenças tinham seu foco na tríade da Ecologia:

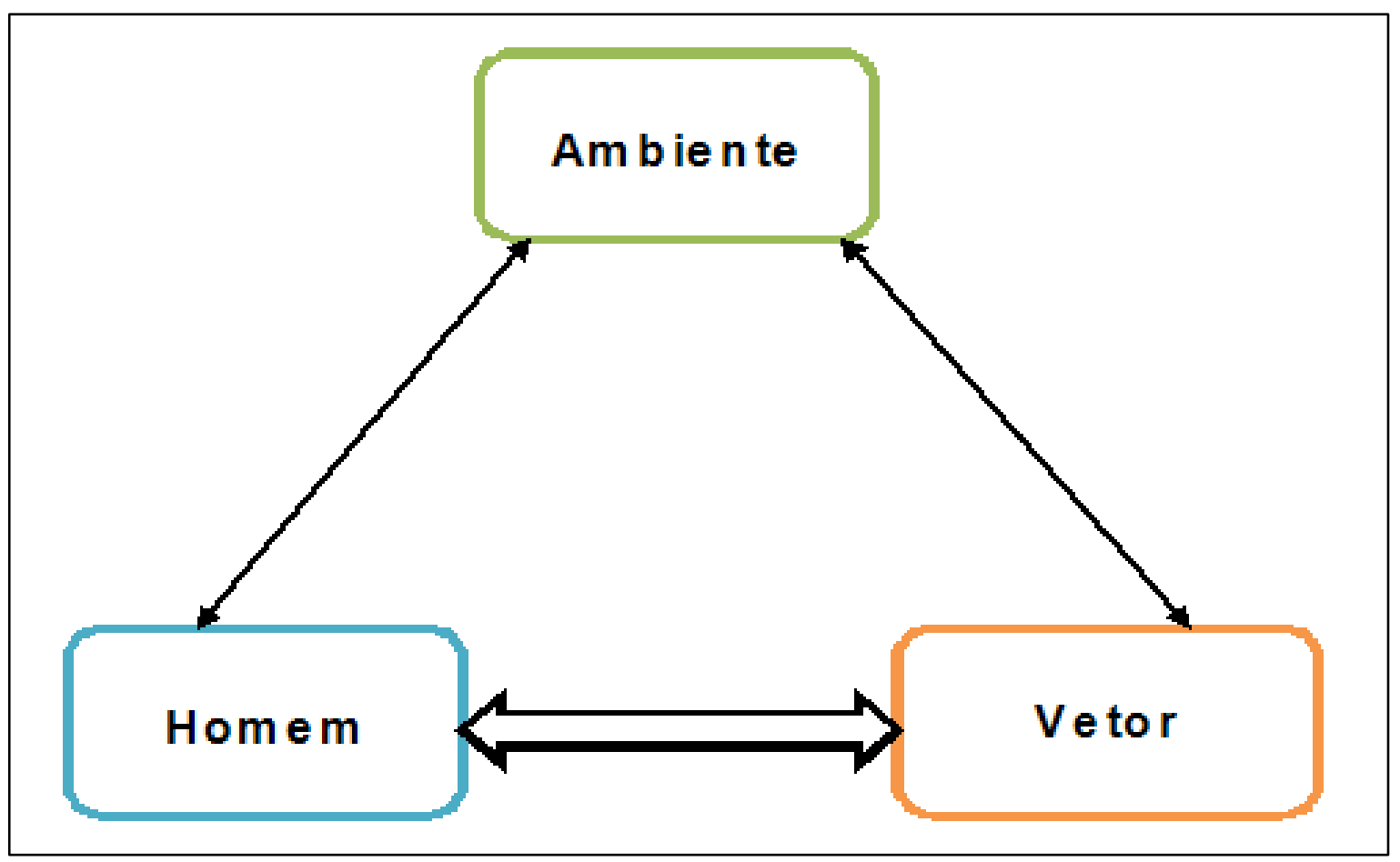

Figura 02 - Tríade Ecológica, segundo Pavlovsky (1930).

Elaboração: NATAL, 2015.

Tal teoria defende que o homem ao desbravar áreas naturais para fins agrícolas ou exploração dos recursos naturais, alterou o equilíbrio e resultou em várias doenças causadas por vetores.

Para Santos e Freitas (2001) seguindo essa teoria naturalista, o ambiente possui as condições favoráveis à circulação de agentes independente da ação do homem. Essa teoria abrange as doenças causadas pelos vetores, resultante dos fluxos de energia e que a doença seria consequência do desequilibrio causado por esses fluxos no sistema.

Em paralelo com esse conceito, na França, "Sorre" desenvolveu um conceito semelhante "o complexo patogênico" em que no espaço poderá haver possibilidade de ocorrer doenças (JUNQUEIRA, 2009). Essa proposta se desenvolveu num

\footnotetext{
${ }^{6}$ Formulado pelo geógrafo francês Max. Sorre, compreende além do homem e do agente causal da doença, seus vetores e todos os seres que condicionam ou comprometem sua existência.
} 
período em que a sociedade mundial tornaria urbano/industrial, aumentando os fluxos migratórios causando diversos impactos ambientais e a disseminação de várias doenças.

Os fluxos vão ocorrer em diferentes intensidades de acordo com a organização de cada sociedade, pois o espaço geográfico é "um conjunto indissociável de sistemas de objetos (fixos) e de ações (fluxos) que apresentam ao longo de sua história (SANTOS, 1988)".

Segundo Santos (1988) o espaço geográfico é o resultado histórico da reprodução social que gera necessidades e organização espacial, é também resultante dos conflitos da vivência e este espaço é percebido por referências socioculturais e pela afetividade construída pelo homem ao longo dos tempos.

Portanto, nessa concepção de espaço geográfico, ou seja, transformação do espaço natural em humanizado. É preciso criar um conjunto de ações que proporcionem o conhecimento e a detecção de qualquer mudança nos fatores determinantes e condicionantes do meio ambiente que interferem na saúde da população humana.

\section{3 - Geografia da Saúde e as Tecnologias}

Com os avanços tecnológicos, o geoprocessamento ${ }^{7}$ surge como uma ferramenta prática e eficaz no trato de diversas doenças que acometem o ser humano. Tendo em vista que os Sistemas de Informações Geográficas (SIG) contribuem de forma efetiva para estudos e análises do espaço geográfico com suas ferramentas computacionais.

Para Câmara e Davis (2001) essas ferramentas computacionais possibilitam realizar análises complexas, ao integrar dados de várias fontes e ao criar bancos de dados georreferenciados.

A utilização dos SIG na geografia da saúde possibilita armazenar e manipular de forma integrada informações inerentes aos componentes do espaço geográfico. Utilizando os conceitos de Milton Santos sobre espaço geográfico podemos agregar

\footnotetext{
${ }^{7}$ É o tratamento das informações geográficas ou de dados georreferenciados por meio de softwares específicos e cálculos. O Geoprocessamento incorpora tecnologia de última geração, envolvendo desde satélites de observação da Terra, técnicas de mensuração por sistema de posicionamento (GPS), até sofisticados progra mas e equipamentos de informática.
} 
as tecnologias existentes para que possamos ter uma assistência melhor na promoção da saúde e prevenção de doenças, além disso é preciso conhecer a população que ocupa um determinado espaço geográfico.

Magalhães (2012) aborda que:

\begin{abstract}
A análise da distribuição das variáveis no espaço e no tempo são aspectos fundamentais nas pesquisas na área da Geografia da Saúde, possibilitando verificar a ocorrência do padrão espacial das doenças, dos serviços de saúde e do ambiente relacionado a esses dois. Como produto na análise espacial, os mapas, possuem em ultima instância a finalidade de identificar os riscos. Apesar de apresentarem aparentemente um aspecto estático, refletem sinteticamente à complexidade das variáveis envolvidas, permitindo conhecer mais detalhadamente as condições de saúde da população no que concerne a situações de morbi-mortalidade, podendo relacioná-las com suas possíveis causas, considerando-se que estas são passíveis de se cartografar no território (MAGALHÃES, 2102, p 64).
\end{abstract}

Com os avanços científicos e tecnológicos nas diversas áreas do conhecimento, como na medicina, na geografia e demais, podemos utilizá-los para entender melhor o processo saúde-doença e suas relações com o espaço geográfico.

A partir da década de 80 com o lançamento de vários satélites no espaço e o surgimento de novas técnicas, as geotecnologias ficaram mais presentes nos estudos em diversas áreas, surgindo novas possibilidades de apoio à análise climática (STEINKE et. al., 2010).

O uso dos SIG auxiliam nessa abordagem tanto na Geografia Física como na geografia Humana dentro das pesquisas desenvolvidas na área de saúde. Os SIG poderão ser utilizados de várias formas em conjunto com demais áreas de pesquisas. As definições de SIG refletem, cada uma à sua maneira, a multiplicidade de usos e visões possíveis desta tecnologia e apontam para uma perspectiva interdisciplinar de sua utilização (CAMÂRA et. al., 1997).

Portanto, podemos utilizar os SIG para monitorar em uma determinada população aos fatores de risco em relação às mudanças do clima. Também podemos utilizá-lo no planejamento dos serviços de saúde em relação à distribuição de serviços essenciais a um determinado público. 


\section{4 - Clima e Doenças - Visão Fragmentada}

Os seres humanos possuem enorme capacidade de adaptação às condições do meio em que estão inseridos. Porém, as alterações do meio natural começam a ter significado para o homem a partir do momento que estas afetam o seu bem-estar e seu modo de vida. Já o clima com variações inesperadas podem provocar ao homem e ao meio social efeitos diversos de maneira direta a saúde humana (FONSECA, 2004).

Estudos que buscam relacionar o clima e a saúde precisam ser mais detalhados, enfocando vários fatores ambientais e socioeconômicos que alteram a qualidade de vida nos indivíduos.

O grande desafio da geografia é validar seu papel no cenário atual, e romper o modelo biomédico dominante. A geografia assume a responsabilidade de aproximação do real, validando metodologias de análise que acrescentam maior compreensão às necessidades humanas. A geografia assume-se como ciência contributiva na discussão da temática saúde - doença (NOSSA, 2008).

Ainda, segundo Nossa (2008) é necessária a adequada validação de uma pluralidade interpretativa dos diferentes sintomas discorridos pelos indivíduos na tradução da sua doença e na construção da sua definição de saúde, tendo como ponto de reflexão as fronteiras apertadas e conformadas pelo arsenal interpretativo. Não desqualifica o sinal clínico como base de identificação e sustentação de diagnóstico e decisão terapêutica.

Neste contexto, não só a geografia vem ponderar sua importância ao modelo dominante, mas as demais ciências sociais (sociologia, antropologia e psicologia) desenvolvem papel fundamental no contexto social e no conhecimento cientifico, validando metodologias de análises que as tornam mais próximas da compreensão das necessidades humanas.

Estudos que mostram a influência do tempo e do clima em enfermidades não podem ser negligenciados. É preciso romper essa barreira dominante do diagnóstico e avançar em estudos a respeito da influência dos elementos do clima sobre a manifestação de diversas doenças na população humana, tendo a geografia com seus conhecimentos na climatologia, geoprocessamento de suma importância na prevenção e no mapeamento de diversas enfermidades com o uso de diversos 
recursos tecnológicos.

Em outros países, vem sendo desenvolvidas diversas pesquisas que correlacionam os fatores ambientais e as variações do clima com aumento dos óbitos na população humana resultantes de diversas enfermidades, sendo que a mortalidade por doenças do aparelho circulatório vem ganhando destaque nas pesquisas em países da Europa e Ásia (DILAVERIS et al. 2006; GOERRE et al. 2007; LEE et al. 2010; Y. Ll et al. 2011 e VASCONCELOS et al. 2013).

Portanto, estas pesquisas que correlacionam a influência do tempo e do clima sobre a saúde humana, por exemplo, nas enfermidades cardiovasculares e respiratórias, mostram que aumenta o número de pessoas afetadas com a elevação ou a diminuição das temperaturas. Os estudos ainda apontam média e forte correlação entre os eventos climáticos e as doenças, tendo como parâmetro ambiental de exposição nas pesquisas, a temperatura relativa do ar e os índices de conforto térmico.

Dilaveris et. al (2006), pesquisaram o impacto das variáveis meteorológicas sobre as mortes diárias e mensais causadas por infarto agudo do miocárdio (IAM) ,em Atenas, no período de 2001. Para este estudo utilizaram os dados da declaração de óbito da região de Atenas, os dados diários da temperatura, pressão atmosférica e umidade relativa do ar. No ano pesquisado teve o registro de 3126 óbitos, a variação sazonal no número de mortes foi significativa, com a média de óbitos diários por Infarto Agudo do Miocárdio (IAM) no inverno, sendo 31,8\% maior do que no verão, a variação mensal foi mais evidenciada para as pessoas mais velhas.

Goerre et. al ( 2007), avaliaram o impacto das variáveis essenciais do tempo e do clima sobre a incidência de infartos do miocárdio, período de 1990 a 1994, Suíça. Para este estudo utilizaram a incidência diária de infartos do miocárdio, os dados epidemiológicos e meteorológicos foram correlacionados por análise multivariada com base em um modelo linear generalizado assumindo a-link-função de $\log$ e uma distribuição de Poisson. Tiveram de resultados que a pressão alta ambiente, gradientes de pressão alta e atividade vento forte foram associados com um aumento na incidência do total das internações (6.560) por infarto do miocárdio, independentemente da região geográfica.

Lee et. al (2010), investigaram a associação entre os parâmetros meteorológicos e as internações hospitalares por IAM na cidade de Daegu-Coreia, 
no período de novembro de 2005 a outubro de 2007. Neste estudo incluíram as internações mensal, semanal e diária, e os seguintes parâmetros meteorológicos (temperatura do ar, velocidade do vento, insolação, índice themo-hidrológico), utilizaram o modelo de regressão Poisson, foram registrados no período pesquisado 2.136 casos de internação por IAM. Conclusões: A incidência de internações por IAM mostra variações sazonais e mensais, e os parâmetros meteorológicos têm uma influência significativa, principalmente no sexo feminino com a idade mais jovem $(<$ 65 anos).

Y. Li et al. (2011), investigaram a distribuição sazonal da ACS (síndrome coronariana aguda) em Pequim e elucidaram as relações entre ACS ocorrência e parâmetros climáticos em um ambiente pré-hospitalar, no período de 01 de agosto de 2005 a 31 de julho de 2007. Neste analisaram, retrospectivamente, os prontuários eletrônicos do pré-hospitalares, utilizaram o método de regressão Poisson. Durante o período de estudo de 02 anos, um total de 7.037 eventos de ACS foram identificados, incluindo 4135 pacientes do sexo masculino $(58,8 \%)$ e 2.902 do sexo feminino (41,2\%). Variações significativas foram observadas no mensal ( $P$ b 0,001) e sazonal $(P$ b, 001) a distribuição de ACS. A maior incidência sazonal ocorreu no inverno e menor no outono.

Vasconcelos et. al (2013), identificaram a contribuição do tempo frio para doenças cardiovasculares em Portugal. A análise de regressão de Poisson baseadas em modelos aditivos generalizados foi aplicada para estimar a influência de um índice de homem-biometeorológico (PET) com internações diárias por infarto do miocárdio. Os principais resultados revelaram um efeito negativo do tempo frio em infartos agudos do miocárdio em Portugal. Para cada queda em PET durante o inverno, houve um aumento de até 2,2\% (95\% Cl 1/4 0,9\%; 3,3\%) em internações diárias.

Estes estudos de vários centros universitários cardiológicos, demostram a preocupação desses países em compreender outros fatores associados aos agravos a saúde humana derivados do ambiente e identificar os grupos vulneráveis.

Visto que estudos que correlacionam as variáveis do clima e a saúde não serem recentes, vem ganhando destaque nas últimas décadas, seja, pela necessidade de compreender melhor os efeitos da urbanização, das alterações ambientais e das mudanças climáticas.

No Brasil, estudos com a finalidade de compreender os efeitos que as 
variáveis climáticas e ambientais possam vir a afetar a saúde e o bem-estar do ser humano vem ganhando novos patamares e interesses nas universidades e nos centros de pesquisas.

\section{5 - Doenças do Aparelho Circulatório}

Considera-se doenças do aparelho circulatório - DAC (CID-10-códigos 100 a 199), todas as doenças que compõem o sistema circulatório (anexo 01) nas quais se destacam, principalmente: hipertensão, coronariana, cerebrovascular, vascular periférica, insuficiência cardíaca, cardíaca reumática, a cardiopatia congênita e as cardiomiopatias (MS, 2006).

O sistema circulatório é composto por um sistema complexo composto pelo coração e os vasos sanguíneos. O principal órgão desse sistema é o coração que bombeia o sangue de forma que ele possa chegar até as extremidades do corpo e voltar para o coração (MS, 2003).

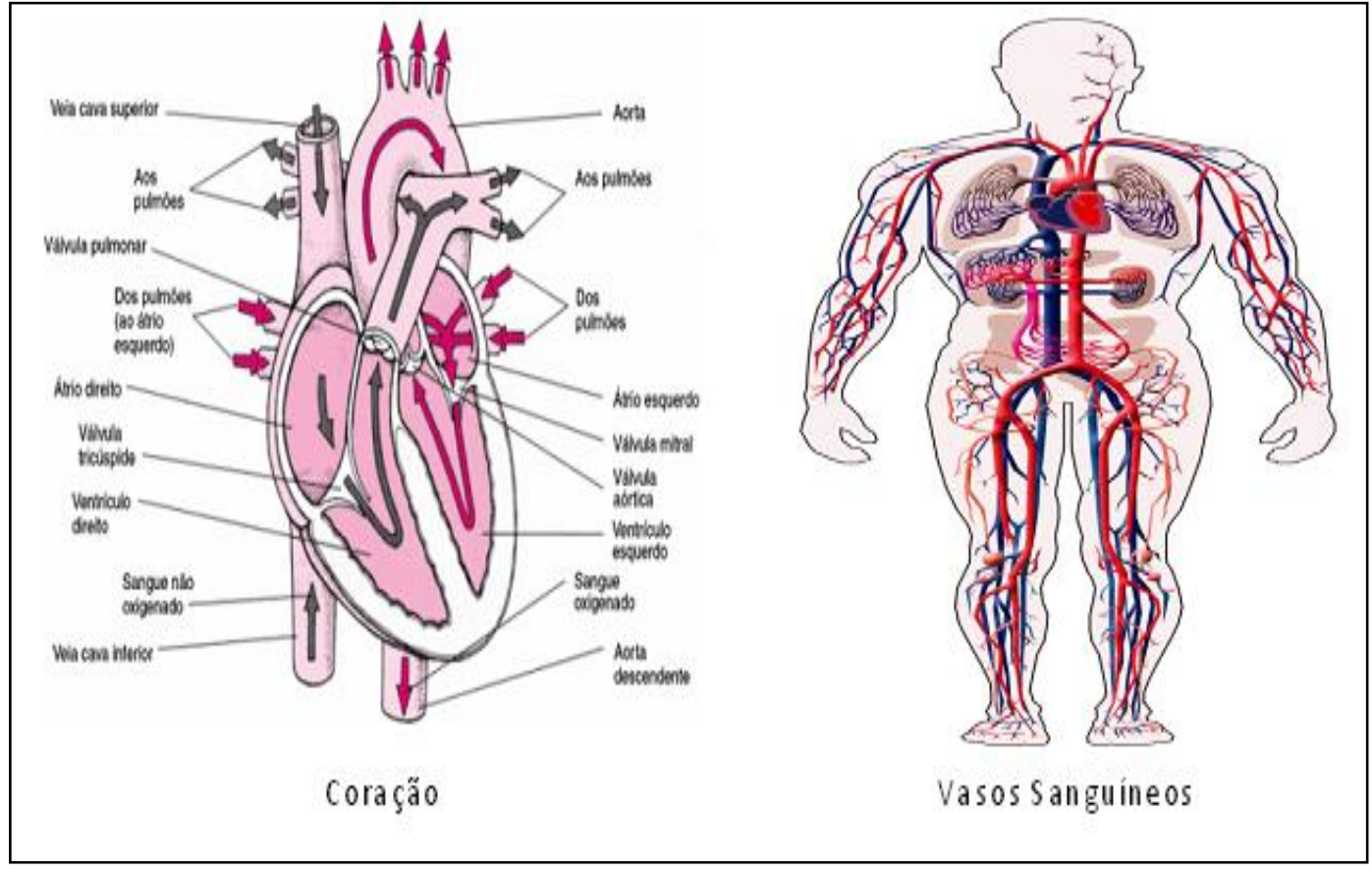

Figura 03: Estrutura do Sistema Circulatório - Fonte: Netter (2000) Organização: NATAL, 2015.

O coração é constituído por fibras musculares que são encarregadas de bombear o sangue por todo o corpo através do sistema arterial e retornar pelo sistema venoso. As artérias são estruturas elásticas dotadas de camada muscular 
que se contrai (vasoconstrição) ou relaxa (vasodilatação) de acordo com as necessidades ou algum evento extremo que for submetido (MS, 2003).

Segundo o MS (2006), a principal causa de morte por doenças do aparelho circulatório é combinação de vários fatores internos e externos, resultando num desgaste progressivo, tendo como resultado o funcionamento precário, e sendo o público alvo dessas enfermidades os mais idosos.

Nas últimas décadas a revolução tecnológica e industrial, que trouxe consequências econômicas e sociais, houve uma mudança drástica no perfil de morbimortalidade da população, com grande predomínio das doenças e mortes devido às doenças crônicas não transmissíveis (DCNT), passando a haver um predomínio das doenças circulatórias, neoplasias e de causas externas (MS, 2006).

O Brasil vem passando por muitas transformações nas últimas décadas, desde a implantação do Sistema Único de Saúde (SUS) e a mudança do seu perfil epidemiológico, reduzindo a morbimortalidade por doenças infecciosas, passando a haver um predomínio das doenças circulatórias, neoplasias e de causas externas.

De acordo com o Ministério da Saúde (2004a) a mudança do perfil epidemiológico no Brasil nos últimas décadas é expressa na permanência da principal causa de morte pelas doenças do aparelho circulatório e pela diminuição da importância das doenças parasitárias.

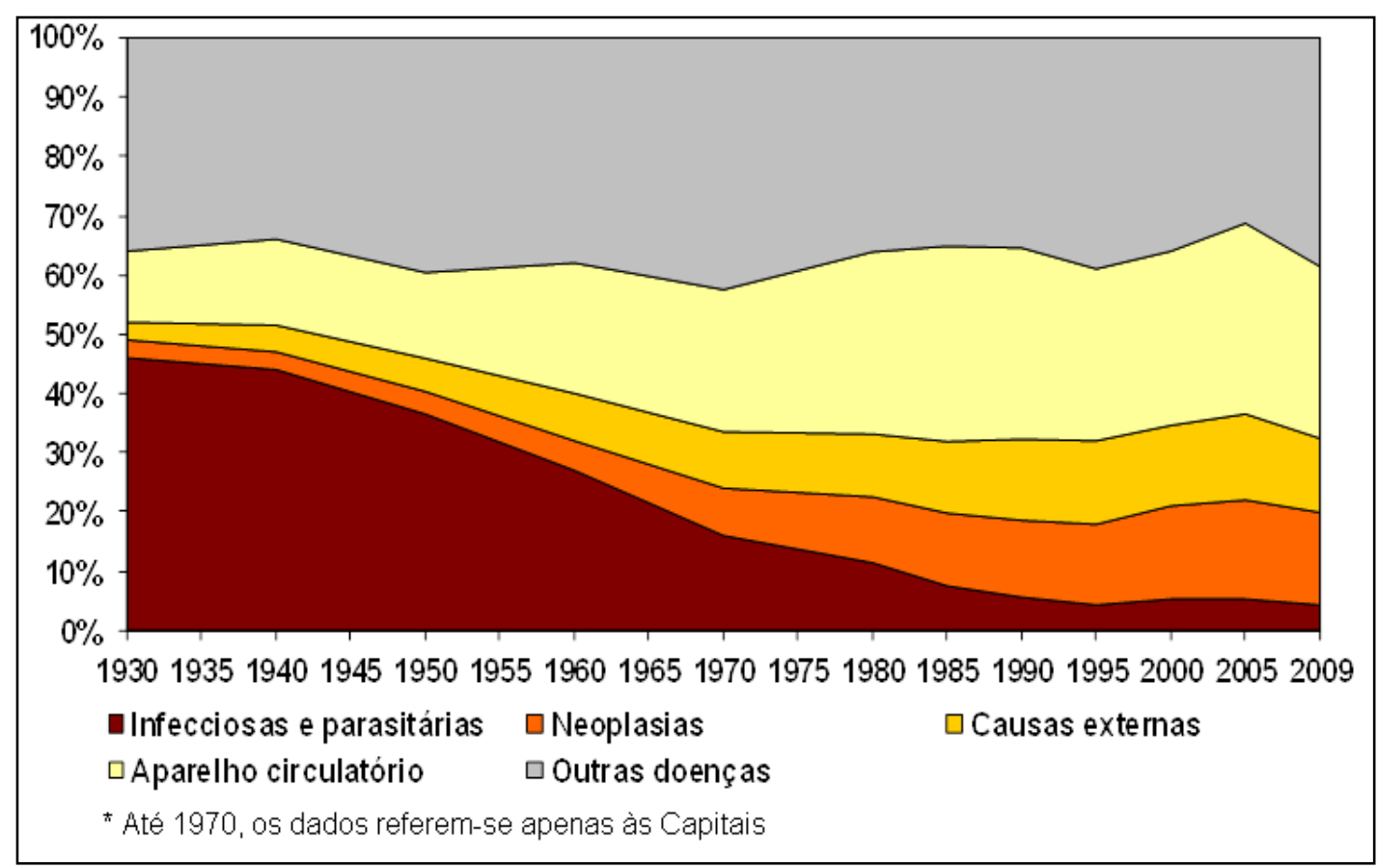

Figura 04 - Transição Epidemiológica de 1930 a 2009. Fonte: Barbosa da Silva e cols. In: Rouquairol \& Almeida Filho: Epidemiologia \& Saúde, 2003 pp. 293. Atualizado por CGIAE/DASIS/SVS. 
As doenças do aparelho circulatório (DAC) tornaram um grande problema mundial na saúde pública nos últimos anos pelo seu elevado número de morbidade, onerando o sistema de saúde pública pela duração da internação, pelo alto custo dos medicamentos e procedimentos cirúrgicos (MS, 20006).

As doenças do aparelho circulatório no Brasil na visão médica e do órgão regulador de saúde no Brasil - Ministério da Saúde - são resultados da associação do estilo de vida e dos fatores fixos (sexo, idade e fatores genéticos), consequentemente, a morbidade é associada a esses fatores (MS, 2006).

Seguindo esses parâmetros da origem das doenças do aparelho circulatório, o Ministério da Saúde (2006) desenvolveu um manual com os principais fatores de risco:

Tabela 01 - Principais Fatores de Risco das Doenças Aparelho Circulatório

- História familiar de DAC prematura (familiar 1․ grau sexo masculino <55 anos e sexo feminino <65 anos);

- Tabagismo;

- Hipercolesterolemia (LDL-c elevado);

- Hipertensão arterial sistêmica;

- Diabete Melito;

- Obesidade (IMC > $\left.30 \mathrm{~kg} / \mathrm{m}^{2}\right)$;

- Gordura abdominal;

- Sedentarismo;

- Dieta pobre em frutas e vegetais;

- Estresse psico-social;

- Homem $>45$ anos e mulher $>55$ anos

Fonte: Ministério da Saúde (2006).

Organização: NATAL, 2015.

No entanto, os fatores considerados de risco definidos pelo Ministério da Saúde (2006) relacionam-se com questões de ordem comportamental ou de estilo de vida, tais como: fumo, bebidas alcoólicas, alimentação excessiva, falta de exercícios, que poderão aumentar a tensão arterial, os níveis de colesterol, o excesso de peso e diabetes, todavia, não aborda a relação com os fatores do meio físico.

O Ministério da Saúde (2006) no manual de medidas preventivas dão maior enfoque preventivo nas mudanças de estilos de vida e ,por fim, quanto maior o risco de mortalidade a necessidade de intervenção terapêutica com o uso de fármacos. 
Todavia, existem alguns estudos (MURARA et. al., 2010) realizados de forma independente no Brasil que mostram estatisticamente a existência de outros fatores ambientais que podem aumentar a morbidade e mortalidade por doenças do aparelho circulatório.

Nesses estudos, são pesquisados os elementos do clima (precipitação, pressão atmosférica, temperatura máxima, média e mínima e umidade relativa do ar) com maior influência no aumento dos casos de internações e óbitos por doenças do aparelho circulatório.

Murara et. al (2010) pesquisaram a influência do clima na mortalidade por doenças do aparelho circulatório em Presidente Prudente - SP, no período de 2000 a 2007, os resultados apontaram maior concentração de óbitos nos dias com maior amplitude térmica e baixa umidade relativa do ar. 


\section{OAPITULOII}

Caracterização da Área de Estudo 


\section{3 - CARACTERIZAÇÃO DA ÁREA DE ESTUDO}

A região pesquisada é o Distrito Federal, localizado na região centro oeste do Brasil, no Planalto Central, possui uma área de $5.814 \mathrm{~km}^{2}$. Atualmente, é dividida em 31 Regiões Administrativas (RAs). Porém, reconhecida oficialmente 19 RAs pelo IBGE (figura 09 ) por falta de definição e aprovação na Câmara Legislativa do Distrito Federal das poligonais das regiões administrativas criadas recentemente.

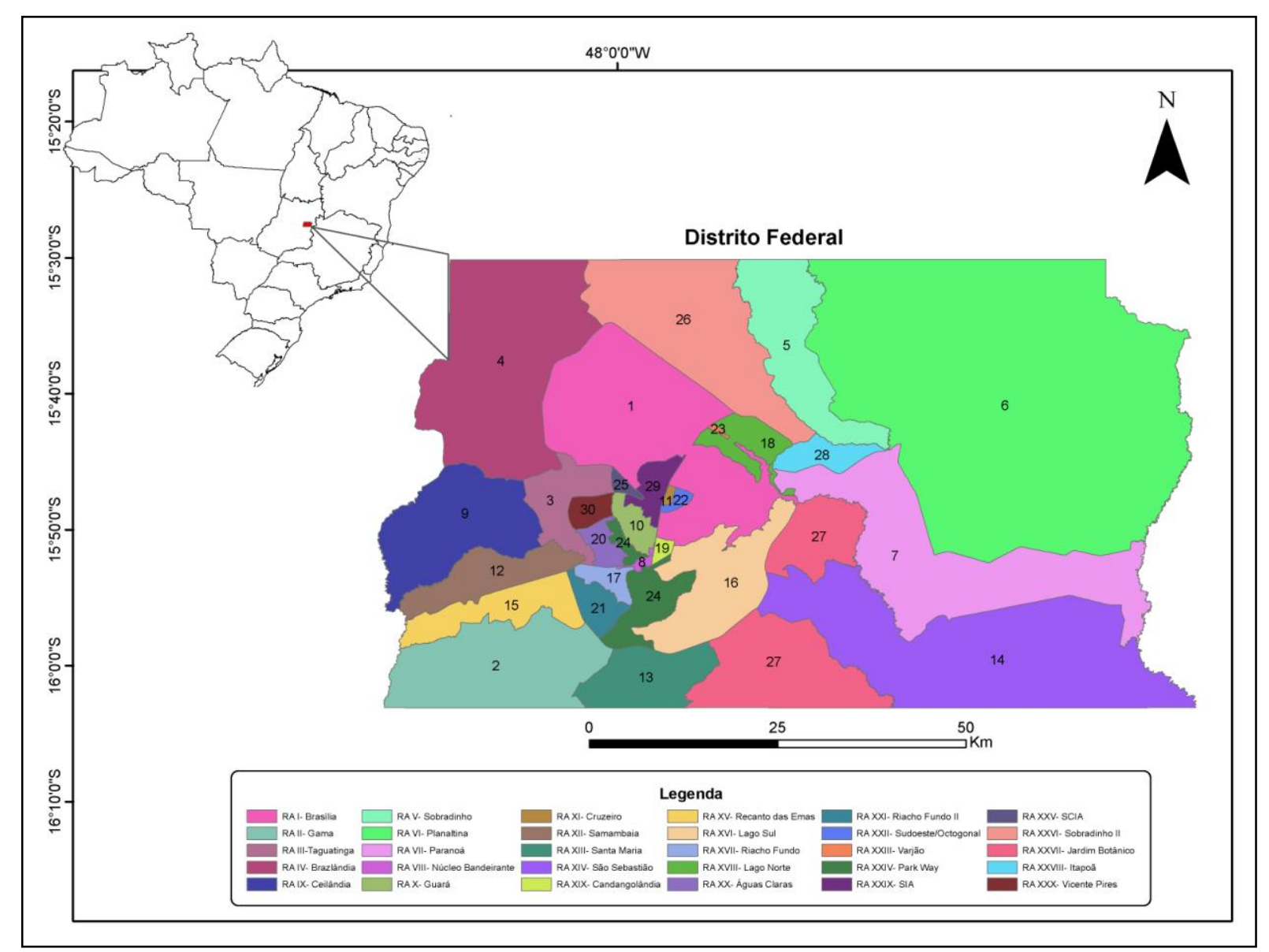

Figura 05: Mapa das Regiões Administrativas do Distrito Federal Fonte: CODEPLAN (2010). Organização: NATAL, 2015.

Segundo o IBGE (2010) o Distrito Federal possui uma população de 2.570.160 habitantes (404 hab. $\mathrm{KM}^{2}$ ). A Região Administrativa de Ceilândia tem o maior número de habitantes (402.729 hab.) e o SIA (2.488 hab.) com o menor número de habitantes (tabela 02). 
Tabela 02 - Regiões Administrativas Existentes e suas Respectivas Populações.

\begin{tabular}{|c|c|c|c|}
\hline \multicolumn{4}{|c|}{$\begin{array}{r}\text { População das Regiões Administrativas do Distrito F } \\
\text { Área Metropolitana }\end{array}$} \\
\hline Região Administrativa & População Total & Região Administrativa & População Total \\
\hline Aguas Claras & 102.076 & Planaltina & 171.303 \\
\hline Brasília (Asa Norte/Sul) & 208.66 & Recanto das Emas & 122.279 \\
\hline Brazlândia & 57.542 & Riacho Fundo & 35.545 \\
\hline Candangolândia & 15.924 & Riacho Fundo II & 36.309 \\
\hline Ceilândia & 402.729 & Samambaia & 199.533 \\
\hline Cruzeiro & 31.379 & Santa Maria & 118.782 \\
\hline Gama & 136.063 & São Sebastião & 87.283 \\
\hline Guará & 107.226 & SCIA - Estrutural & 30.388 \\
\hline Itapoã & 51.501 & SIA & 2.488 \\
\hline Jardim Botânico & 23.124 & Sobradinho & 60.209 \\
\hline Lago Norte & 32.903 & Sobradinho II & 98.409 \\
\hline Lago Sul & 29.537 & Sudoeste/Octogonal & 49.696 \\
\hline Núcleo Bandeirante & 22.810 & Taguatinga & 199.715 \\
\hline Paranoá & 43.870 & Varjão & 8.724 \\
\hline Park Way & 20.995 & Vicente Pires & 63.192 \\
\hline Total & 2.570 .160 & & \\
\hline
\end{tabular}

Fonte: IBGE (2010), CODEPLAN (2010).

Organização: NATAL, 2015.

O clima no Distrito Federal, de acordo com a classificação de Strahler, é tropical de altitude, com 02 (duas) estações distintas: quente-úmida (outubro a abril), quente-seca (maio a setembro) com ausência de chuvas e diminuição da umidade relativa do ar a partir de junho, variando de $70 \%$ a $20 \%$ ou abaixo. A temperatura média anual é de cerca de $20^{\circ} \mathrm{C}$, podendo chegar aos $29,7^{\circ} \mathrm{C}$ de média nas máximas em setembro, e aos $12,5^{\circ} \mathrm{C}$ de média nas mínimas nas madrugadas de inverno em julho. Apresenta altitude entre 750 e 1349 metros, seu ponto mais alto é a colina do Rodeador, que possui 1349 m e está localizada a noroeste do Parque Nacional de Brasilia. 


\section{OAPITULOIY}

Metodologia 


\title{
4- METODOLOGIA
}

\section{1 - Procedimentos Metodológicos}

Trata-se de um estudo descritivo transversal e de abordagem quantitativa dos óbitos por doenças do aparelho circulatório (CID-10-códigos 100 a 199) nos indivíduos residentes no Distrito Federal - DF, no período de janeiro de 2003 a dezembro de 2012. Os dados serão apresentados a partir da estatística descritiva buscando identificar a classificação da relação entre as variáveis pesquisadas.

Esta pesquisa propõe analisar a influência do clima nos óbitos por doenças do aparelho circulatório, sendo um dos fatores que podem aumentar as internações e mortalidade da população. Parte do pressuposto que os elementos do clima (temperatura do ar, umidade relativa do ar, precipitação e pressão atmosférica) sofrem alterações cíclicas e podem contribuir com o aumento dos óbitos por doenças do aparelho circulatório no Distrito Federal.

O grande desafio é definir a metodologia a ser usada, nesta pesquisa utilizou a do tipo exploratória, descritiva e bibliográfica. Para Gil (2008):

\begin{abstract}
"As pesquisas exploratória tem como principal finalidade desenvolver, esclarecer e modificar conceitos e ideias, como vistas na formulação de problemas mais precisos ou hipóteses pesquisáveis para estudos posteriores. A pesquisa descritiva tem como objetivo primordial a descrição das características de determinada população ou fenômeno ou o estabelecimento de relações variáveis (GIL, 2008, p. 44 e 45)".
\end{abstract}

Ainda, segundo Gil (2008) a pesquisa bibliográfica é desenvolvida a partir de material já elaborado, constituído ,principalmente ,de livros e artigos científicos.

No entanto, a pesquisa bibliográfica tem o intuito de elencar as diversas colocações referentes ao tema pesquisado. Neste trabalho especifico está sendo utilizada uma ampla e profunda revisão bibliográfica nas produções acadêmicas existentes relacionadas à Geografia da saúde, climatologia, saúde, meio ambiente, doenças do aparelho circulatório e as consequências que as mudanças climáticas e ambientais causam na população humana de forma geral, buscou subsídios nas diversas vertentes da geografia que possam contribuir na prevenção, mapeamento e monitoramento de diversas doenças transmissíveis e não transmissíveis, mas especificamente, as doenças do aparelho circulatório.

Portanto, a fim de atingir os objetivos propostos, verificar a hipótese acerca de 
que as variáveis climáticas podem contribuir com o aumento da mortalidade por doenças do aparelho circulatório no Distrito Federal, foi realizada primeiro a análise descritiva das variáveis do clima e das doenças do aparelho circulatório e em seguida a técnica de análise estática exploratória para integração das mesmas.

Para Gil (2008) é importante identificar os nexos entre as variáveis através do contato com os fatos empíricos para obter respostas significativas. Para responder a hipótese inicial da pesquisa é preciso buscar as variáveis necessárias que possibilitam sua mensuração.

\section{2 - Levantamento dos Dados}

É uma pesquisa de levantamento retrospectivo, de natureza descritiva e análise quantitativa, foram adquiridos os dados de saúde a partir do banco de dados da Secretaria de Estado de Saúde - SES/DF e do Departamento de Informática do SUS (DATASUS) no período de 2003 a 2012 (dados mensais).

Os dados do clima foram coletados da estação climatológica 83377 em Brasilia, mantida pelo Instituto Nacional de Meteorologia - INMET, através do seu site Oficial (www.inmet.gov.br).

\subsection{1 - Dados de Saúde}

Os dados apresentados foram oriundos do Sistema de informações Hospitalares $(\mathrm{SH})$ geridos pela Secretaria de Estado de Saúde do Distrito Federal e DATASUS - Secretaria Executiva do Ministério da Saúde de 2003 a 2012. Para analisar a correlação e espacialização dos dados do clima com os agravos de doenças circulatórias foram coletados os registros de óbitos de pacientes de todas as idades por região administrativa.

O Sistema de informações Hospitalares (SIH) e DATASUS - Secretaria Executiva do Ministério da Saúde utilizam da 10a Revisão da Classificação Internacional de Doenças (CID 10), para as Doenças do Aparelho Circulatório (DAC) utiliza o código 100-199, Capítulo IX.

\subsection{2 - Dados do Clima}

Coletados da estação climatológica 83377 de Brasília, fica localizada na latitude: -15ำ7 S, Longitude: $-47^{\circ}-49^{`} \mathrm{~W}$ e 1159 metros de altitude com relação ao 
nível do mar. Realizado a tabulação e análise dos dados mensais dos elementos climáticos (precipitação, temperatura máximas, médias e mínimas, pressão atmosférica e umidade relativa do ar). Com os dados levantados, foi possível organizar e gerar gráficos de distribuição das médias e totais mensais. Para os dados mensais, o recorte temporal é de 2003 a 2012.

\section{3 - Processamento dos Dados}

Após o levantamento dos dados da saúde (óbitos por doenças do aparelho circulatório) e do clima (precipitação, pressão atmosférica, temperaturas máxima, média e mínima, e umidade relativa do ar) foi realizado o processo de tabulação e tratamento dos mesmos com a utilização de planilha eletrônica do EXCEL (marca registrada da Microsoft Corporation).

Para representação cartográfica dos dados espaciais, estatísticos e fazer análise e a distribuição espacial na área pesquisa foi utilizado o software livre DIVAGIS - Versão 7.4.0.1.

O software DIVA-GIS é um Sistema de Informação Geográfica (SIG) que possibilita uma análise da distribuição dos elementos pesquisados num determinado espaço geográfico.

Para calcular o coeficiente de a correlação estatística entre os objetos propostos do estudo - Óbitos por DAC e Variáveis Climáticas - foi realizado através do cálculo do Coeficiente de Correlação Linear de Pearson, de acordo com a fórmula:

$$
r=\frac{\left[N\left(\sum X Y\right)-\left(\sum X\right)\left(\sum Y\right)\right]}{\sqrt{\left[N\left(\sum X^{2}\right)-\left(\sum X\right)^{2}\right]\left[N\left(\sum Y^{2}\right)-\left(\sum Y\right)^{2}\right]}}
$$

r - representa o coeficiente de correlação linear;

$\mathbf{N}$ - representa o número de pares de dados presentes;

$\boldsymbol{\Sigma}$ - somatório;

$\boldsymbol{\Sigma} \mathbf{X}$ - somatório de todos os valores $\mathrm{X}$; 
$\Sigma X 2$ - indica que se eleva ao quadrado cada valor de $\mathrm{X}$ e se soma os resultados;

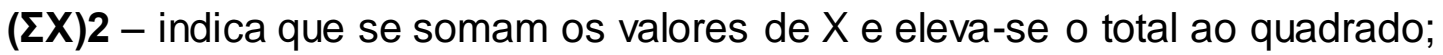
$\boldsymbol{\Sigma} X Y$ - indica que se multiplica cada valor de $X$ pelo correspondente valor de $\mathrm{Y}$ e somam-se todos esses produtos.

X - Variável independente - Dados das variáveis climáticas (precipitação, pressão Atmosférica, temperatura máxima, média e mínima e umidade relativa do ar).

Y- Variável dependente - Dado das doenças do aparelho circulatório (óbitos).

Para determinar os valores de classificação da correlação linear $r$ de $X$ e $Y, o$ grau de medida varia de 1,0 (correlação direta) a $-1,0$ (correlação inversa), sendo o valor zero correspondente a ausência de correlação linear. Abaixo apresenta os valores de correlação de forma detalhada apresentada por Cavalcante (2003):

Tabela 03 - Classificação dos valores das correlações do Método de Pearson

\begin{tabular}{c|c|c}
\hline $\mathbf{R}$ & $\mathbf{R}^{\mathbf{2}}$ & Classificação \\
\hline 0 & 0 & Nula \\
\hline $0,00-0,30$ & $0,00-0,09$ & Fraca \\
\hline $0,30-0,60$ & $0,09-0,36$ & Média \\
\hline $0,60-0,90$ & $0,36-0,81$ & Forte \\
\hline $0,90-0,99$ & $0,81-0,99$ & Fortíssima \\
\hline 1 & 1 & Perfeita \\
\hline
\end{tabular}

Fonte: Cavalcante (2003).

Na Figura 06,0 roteiro utilizado para desenvolver esse trabalho de pesquisa, foram divididas em 04 etapas descritas passo a passo no roteiro metodológico. 


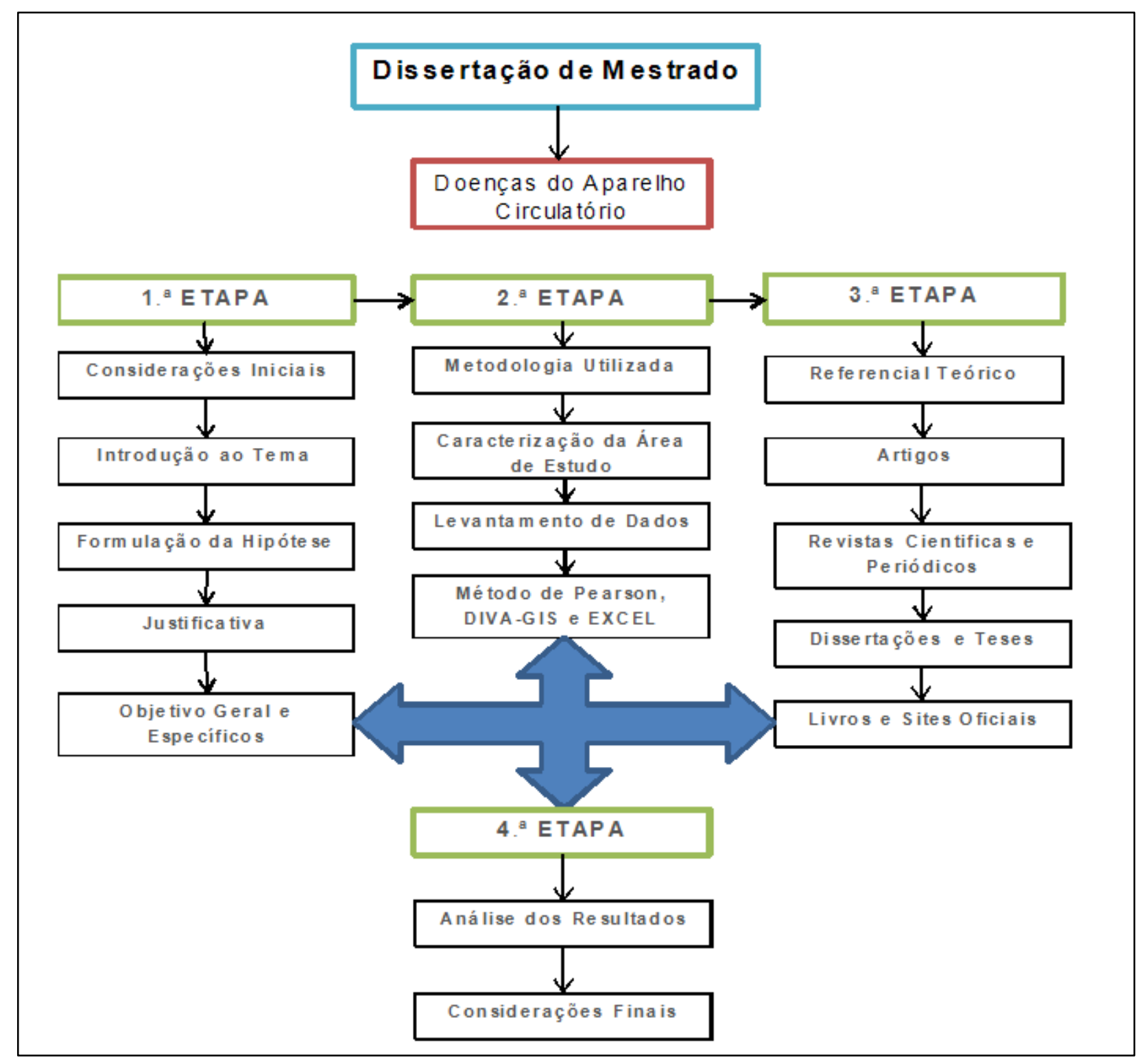

Figura 06 - Roteiro metodológico da pesquisa.

Elaboração: NATAL, 2015. 


\section{OAPITULOY}

Resultados e Discussões 


\section{5 - RESULTADOSE DISCUSSÕES}

\section{1- Levantamento dos óbitos por doenças do aparelho circulatório no Distrito}

Federal de 2003 a 2012.

As doenças crônicas representam a principal causa de mortalidade e incapacidade no mundo inteiro tendo, principalmente, as doenças circulatórias, diabetes, obesidade, câncer e as doenças respiratórias em destaques como apontadas pela Organização Pan-Americana da Saúde (2003).

No período pesquisado de janeiro de 2003 a dezembro de 2012 foram registrados 28.247 Óbitos por Doenças do aparelho circulatório no Distrito Federal, distribuídos nas 19 regiões administrativas reconhecidas pelo IBGE (figura 09).

A partir da análise dos dados pode-se descrever conforme a Tabela 04, as principais causas de óbitos da população humana no Distrito Federal nos 10 (dez) anos pesquisados. Em primeiro lugar são as doenças do aparelho circulatório (27,8\%), segundo lugar as neoplasias/câncer $(18,0 \%)$ em terceiro lugar as causas externas $(17,7 \%)$ e em quarto lugar as doenças do aparelho respiratório (8,2\%).

Ao passar para avalição por sexo e idade, o sexo masculino predominou a incidência nos casos de óbitos por doenças do aparelho circulatório (Tabela 05), já o fator idade é percebido que a partir dos 40 anos a chance é bem maior de ser acometido por alguma do sistema circulatório, sendo a faixa de 70 a 80 anos a de maior risco entre os óbitos por doenças do aparelho circulatório (Tabela 06).

A Tabela 04 mostra a distribuição da frequência das principais causas de óbitos ocorridos em todo Distrito Federal nos anos pesquisados (2003 a 2012). 
Tabela 04 - Mortalidade na população humana por Capítulo do CID-10 em ambos os sexos, em todo o Distrito Federal.

\begin{tabular}{|c|c|c|c|c|c|c|c|c|c|c|c|}
\hline \multirow{2}{*}{$\begin{array}{ll} & \text { CID-10 } \\
\text { Capítulo }\end{array}$} & \multicolumn{11}{|c|}{ ANO DE OCORRENCIA } \\
\hline & $\begin{array}{r}2003 \\
481\end{array}$ & $\begin{array}{c}2004 \\
476\end{array}$ & $\begin{array}{c}2005 \\
484\end{array}$ & $\begin{array}{c}2006 \\
478\end{array}$ & $\begin{array}{c}2007 \\
472\end{array}$ & $\begin{array}{c}2008 \\
469\end{array}$ & $\begin{array}{c}2009 \\
435\end{array}$ & 2010 & $\begin{array}{r}2011 \\
472\end{array}$ & $\begin{array}{c}2012 \\
488\end{array}$ & $\begin{array}{l}\text { Total } \\
4743\end{array}$ \\
\hline \multirow{2}{*}{ I. Algum as doenças infecciosas e parasitárias } & $5,3 \%$ & $5,0 \%$ & $5,1 \%$ & $5,0 \%$ & $4,8 \%$ & $4,6 \%$ & $4,2 \%$ & $4,5 \%$ & $4,2 \%$ & $4,3 \%$ & $4,7 \%$ \\
\hline & 1457 & 1592 & 1586 & 1753 & 1783 & 1847 & 1946 & 2047 & 2136 & 2198 & 18345 \\
\hline \multicolumn{12}{|l|}{ II. Neoplasias (tumores) } \\
\hline & 35 & 33 & 32 & 36 & 36 & 41 & 56 & 45 & 67 & 51 & 432 \\
\hline \multirow{2}{*}{ III. Doenças sangue órgãos hemat e transt im unitár } & $0,4 \%$ & $0,3 \%$ & $0,3 \%$ & $0,4 \%$ & $0,4 \%$ & $0,4 \%$ & $0,5 \%$ & $0,4 \%$ & $0,6 \%$ & $0,5 \%$ & $0,4 \%$ \\
\hline & 450 & 475 & 496 & 445 & 518 & 532 & 499 & 591 & 587 & 571 & 5.164 \\
\hline \multirow[t]{2}{*}{ IV. Doenças endócrinas nutricionais e metabólicas } & $4,9 \%$ & $4,9 \%$ & $5,3 \%$ & $4,7 \%$ & $5,3 \%$ & $5,2 \%$ & $4,8 \%$ & $5,4 \%$ & $5,2 \%$ & $5,0 \%$ & $5,1 \%$ \\
\hline & 95 & 118 & 144 & 121 & 120 & 135 & 130 & 152 & 167 & 148 & 1.330 \\
\hline \multirow[t]{2}{*}{ V. Transtornos mentais e comportamentais } & $1,0 \%$ & $1,2 \%$ & $1,5 \%$ & $1,3 \%$ & $1,2 \%$ & $1,3 \%$ & $1,2 \%$ & $1,4 \%$ & $1,5 \%$ & $1,3 \%$ & $1,3 \%$ \\
\hline & 141 & 191 & 201 & 239 & 226 & 224 & 253 & 287 & 310 & 296 & 2.368 \\
\hline \multirow[t]{2}{*}{ VI. Doenças do sistema nervoso } & $1,6 \%$ & $2,0 \%$ & $2,1 \%$ & $2,5 \%$ & $2,3 \%$ & $2,2 \%$ & $2,4 \%$ & $2,6 \%$ & $2,8 \%$ & $2,6 \%$ & $2,3 \%$ \\
\hline & 0 & 1 & 2 & 1 & 2 & 1 & 0 & 0 & 1 & 1 & 9 \\
\hline \multirow[t]{2}{*}{ VII. Doenças do olho e anexos } & $0,0 \%$ & $0,0 \%$ & $0,0 \%$ & $0,0 \%$ & $0,0 \%$ & $0,0 \%$ & $0,0 \%$ & $0,0 \%$ & $0,0 \%$ & $0,0 \%$ & $0,0 \%$ \\
\hline & 0 & 0 & 1 & 0 & 0 & 0 & 0 & 0 & 0 & 0 & 1 \\
\hline \multirow[t]{2}{*}{ VIII.Doenças do ouvidoe da apófise m astóide } & $0,0 \%$ & $0,0 \%$ & $0,0 \%$ & $0,0 \%$ & $0,0 \%$ & $0,0 \%$ & $0,0 \%$ & $0,0 \%$ & $0,0 \%$ & $0,0 \%$ & $0,0 \%$ \\
\hline & 2538 & 2799 & 2700 & 2678 & 2776 & 2837 & 2890 & 2990 & 2997 & 3042 & 28.247 \\
\hline \multirow{2}{*}{ IX. Doenças do aparelho circulatório } & $27,9 \%$ & $29,1 \%$ & $28,6 \%$ & $28,2 \%$ & 28,1 & $27,6 \%$ & $27,6 \%$ & $27,6 \%$ & $26,6 \%$ & $26,9 \%$ & $27,8 \%$ \\
\hline & 604 & 693 & 717 & 705 & 814 & 861 & 860 & 946 & 1066 & 1020 & 8.286 \\
\hline \multirow[t]{2}{*}{ X. Doenças do aparelho respiratório } & $6,6 \%$ & $7,2 \%$ & $7,6 \%$ & $7,4 \%$ & $8,3 \%$ & $8,4 \%$ & $8,2 \%$ & $8,7 \%$ & $9,5 \%$ & $9,0 \%$ & $8,2 \%$ \\
\hline & 455 & 496 & 478 & 479 & 489 & 577 & 543 & 537 & 625 & 616 & 5.295 \\
\hline \multirow[t]{2}{*}{ XI. Doenças do aparelho digestivo } & $5,0 \%$ & $5,2 \%$ & $5,1 \%$ & $5,0 \%$ & $5,0 \%$ & $5,6 \%$ & $5,2 \%$ & $4,9 \%$ & $5,6 \%$ & $5,4 \%$ & $5,2 \%$ \\
\hline & 2 & 8 & 9 & 7 & 12 & 7 & 7 & 9 & 13 & 17 & 91 \\
\hline \multirow[t]{2}{*}{ XII. Doenças da pele e do te cido subcutâneo } & $0,0 \%$ & $0,1 \%$ & $0,1 \%$ & $0,1 \%$ & $0,1 \%$ & $0,1 \%$ & $0,1 \%$ & $0,1 \%$ & $0,1 \%$ & $0,2 \%$ & $0,1 \%$ \\
\hline & 33 & 54 & 42 & 55 & 41 & 47 & 62 & 67 & 67 & 62 & 530 \\
\hline \multirow{2}{*}{ XIII.Doenças sist osteomuscular e tec conjuntivo } & $0,4 \%$ & $0,6 \%$ & $0,4 \%$ & $0,6 \%$ & $0,4 \%$ & $0,5 \%$ & $0,6 \%$ & $0,6 \%$ & $0,6 \%$ & $0,5 \%$ & $0,5 \%$ \\
\hline & 145 & 132 & 150 & 121 & 140 & 169 & 185 & 182 & 203 & 169 & 1.596 \\
\hline \multirow[t]{2}{*}{ XIV. Doenças do aparelho geniturinário } & $1,6 \%$ & $1,4 \%$ & $1,6 \%$ & $1,3 \%$ & $1,4 \%$ & $1,6 \%$ & $1,8 \%$ & $1,7 \%$ & $1,8 \%$ & $1,5 \%$ & $1,6 \%$ \\
\hline & 10 & 20 & 19 & 21 & 17 & 26 & 23 & 20 & 19 & 19 & 194 \\
\hline \multirow[t]{2}{*}{ XV. Gravidez parto e puerpério } & $0,1 \%$ & $0,2 \%$ & $0,2 \%$ & $0,2 \%$ & $0,2 \%$ & $0,3 \%$ & $0,2 \%$ & $0,2 \%$ & $0,2 \%$ & $0,2 \%$ & $0,2 \%$ \\
\hline & 350 & 324 & 332 & 321 & 276 & 286 & 293 & 311 & 294 & 303 & 3.090 \\
\hline \multirow[t]{2}{*}{ XVI. Algum as afec originadas no período perinatal } & $3,8 \%$ & $3,4 \%$ & $3,5 \%$ & $3,4 \%$ & $2,8 \%$ & $2,8 \%$ & $2,8 \%$ & $2,9 \%$ & $2,6 \%$ & $2,7 \%$ & $3,0 \%$ \\
\hline & 189 & 217 & 189 & 203 & 160 & 170 & 187 & 197 & 160 & 162 & 1.834 \\
\hline \multirow{2}{*}{ XVII. Malf cong deformid e anomalias cromossômicas } & $2,1 \%$ & $2,3 \%$ & $2,0 \%$ & $2,1 \%$ & $1,6 \%$ & $1,7 \%$ & $1,8 \%$ & $1,8 \%$ & $1,4 \%$ & $1,4 \%$ & $1,8 \%$ \\
\hline & 387 & 339 & 221 & 214 & 238 & 207 & 172 & 104 & 129 & 94 & 2.105 \\
\hline \multirow[t]{2}{*}{ XVIII. Sint sinais e achad anorm ex clín e laborat } & $4,3 \%$ & $3,5 \%$ & $2,3 \%$ & $2,2 \%$ & $2,4 \%$ & $2,0 \%$ & $1,6 \%$ & $1,0 \%$ & $1,1 \%$ & $0,8 \%$ & $2,1 \%$ \\
\hline & 1723 & 1641 & 1622 & 1636 & 1746 & 1848 & 1918 & 1878 & 1940 & 2051 & 18.003 \\
\hline $\mathrm{XX}$. Causas exter nas de $\mathrm{m}$ or bidade e mortalidade & $18,9 \%$ & $17,1 \%$ & $17,2 \%$ & $17,2 \%$ & $17,7 \%$ & $18,0 \%$ & $18,3 \%$ & $17,3 \%$ & $17,2 \%$ & $18,1 \%$ & $17,7 \%$ \\
\hline Total & 9095 & 9609 & 9425 & 9513 & 9866 & 10284 & 10459 & 10851 & 11253 & 11308 & 101.663 \\
\hline
\end{tabular}

Fonte: MS/SVS/CGIAE - Sistema de Informações sobre Mortalidade - SIM, 2003 a 2012.

Elaboração: NATAL, 2015. 
As doenças do Aparelho Circulatório (DAC) apresentaram-se, tradicionalmente, como a principal causa de óbito do Distrito Federal como visto na Tabela 04 que mostra a mortalidade proporcional dos grupos de causas mais freqüentes, no período de 2003 a 2012.

Como observado, as Doenças do Aparelho Circulatório mantêm-se ao longo do tempo como a principal causa de morte no DF, mantendo-se percentuais de mortalidade proporcional ,praticamente, estáveis durante o período de 2003 a 2012 . Nos dez anos pesquisados não houve alteração significativa nas causas de mortalidade.

A Tabela 05 mostra a distribuição da mortalidade por doenças do aparelho circulatório entre os sexos, há uma predominância no sexo masculino, responsável por 15.248 (54\%) e o sexo feminino de 12.999 (46 \%) dos óbitos em todo Distrito Federal nos anos pesquisados (2003 a 2012). A maior mortalidade no sexo masculino foi observada em todo o período analisado, 2003 a 2012, porém, observa-se um discreto aumento do número de óbitos para o sexo feminino nos últimos anos pesquisados.

Tabela 05 - Mortalidade por doenças do aparelho circulatório na população humana por sexo, em todo o Distrito Federal.

\begin{tabular}{|c|c|c|c|c|c|c|c|c|c|c|c|}
\hline Capítulo CID-10 & \multicolumn{11}{|c|}{ ANO DE OCORRËNCIA } \\
\hline $\begin{array}{l}\text { IX. Doenças do aparelho } \\
\text { circulatório }\end{array}$ & 2003 & 2004 & 2005 & 2006 & 2007 & 2008 & 2009 & 2010 & 2011 & 2012 & Total \\
\hline Feminino & $\begin{array}{r}1.110 \\
43,7 \%\end{array}$ & $\begin{array}{c}1264 \\
45,2 \%\end{array}$ & $\begin{array}{c}1259 \\
46,6 \%\end{array}$ & $\begin{array}{c}1223 \\
45,7 \%\end{array}$ & $\begin{array}{c}1251 \\
45,1 \%\end{array}$ & $\begin{array}{c}1317 \\
46,4 \%\end{array}$ & $\begin{array}{c}1373 \\
47,5 \%\end{array}$ & $\begin{array}{c}1404 \\
47,0 \%\end{array}$ & $\begin{array}{l}1383 \\
46,1\end{array}$ & $\begin{array}{c}1415 \\
46,5 \%\end{array}$ & $\begin{array}{c}12.999 \\
46 \%\end{array}$ \\
\hline
\end{tabular}

Fonte: MS/SVS/CGIAE - Sistema de Informações sobre Mortalidade - SIM, 2003 a 2012.

Elaboração: NATAL, 2015.

A Tabela 06 e a Figura 07 - mostram que os óbitos por doenças do aparelho circulatório aumentam na população idosa, observam-se que os óbitos por DAC atingem, principalmente, os grupos etários de maior idade. 
Tabela 06 - Mortalidade na população humana por DAC, faixa etária em ambos sexos, em todo o Distrito Federal, 2003 a 2012. Capítulo CID-10 : IX Doenças do aparelho circulatório

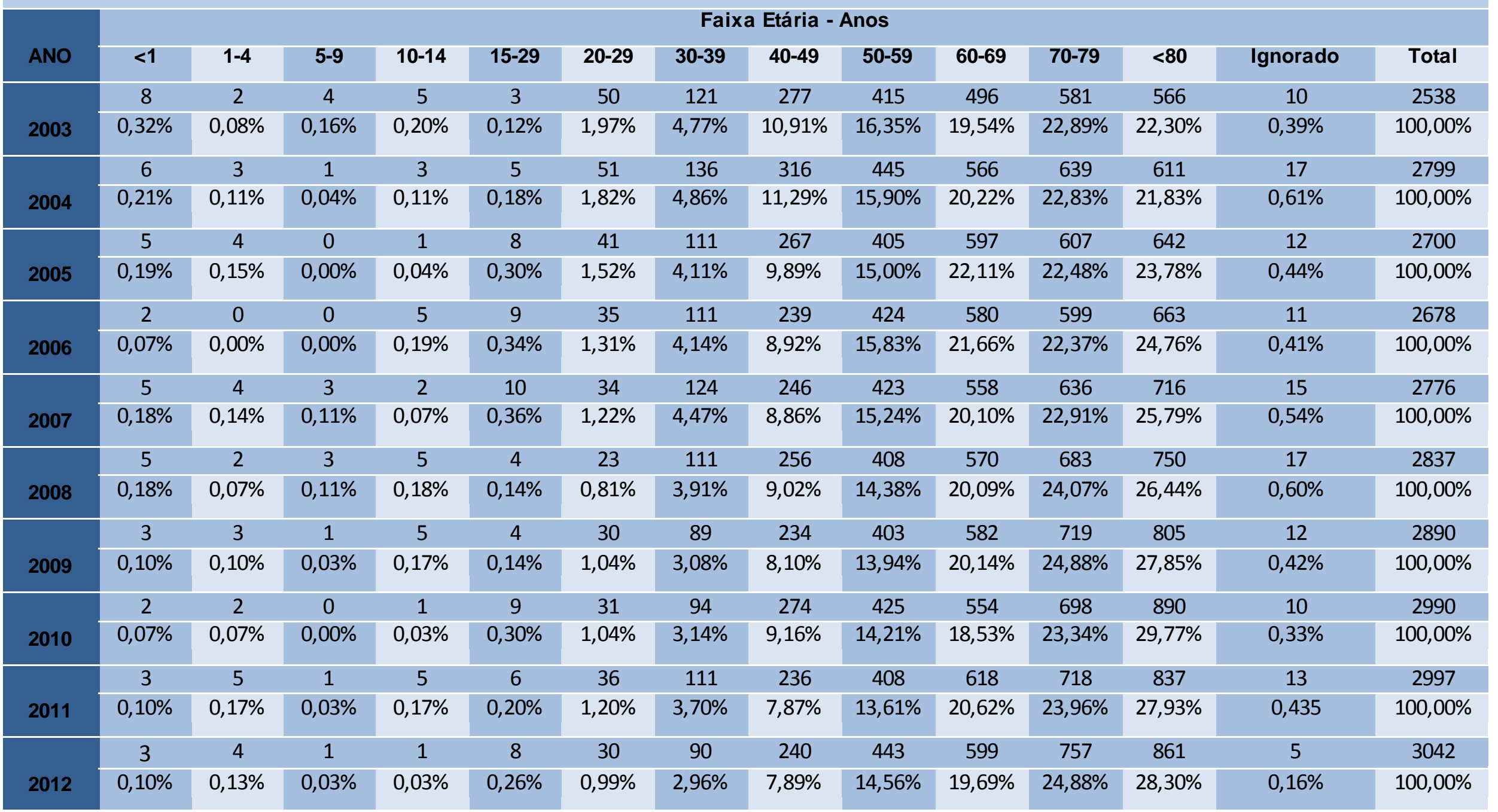

Fonte: MS/SVS/CGIAE - Sistema de Informações sobre Mortalidade - SIM, 2003 a 2012.

Elaboração: NATAL, 2015. 


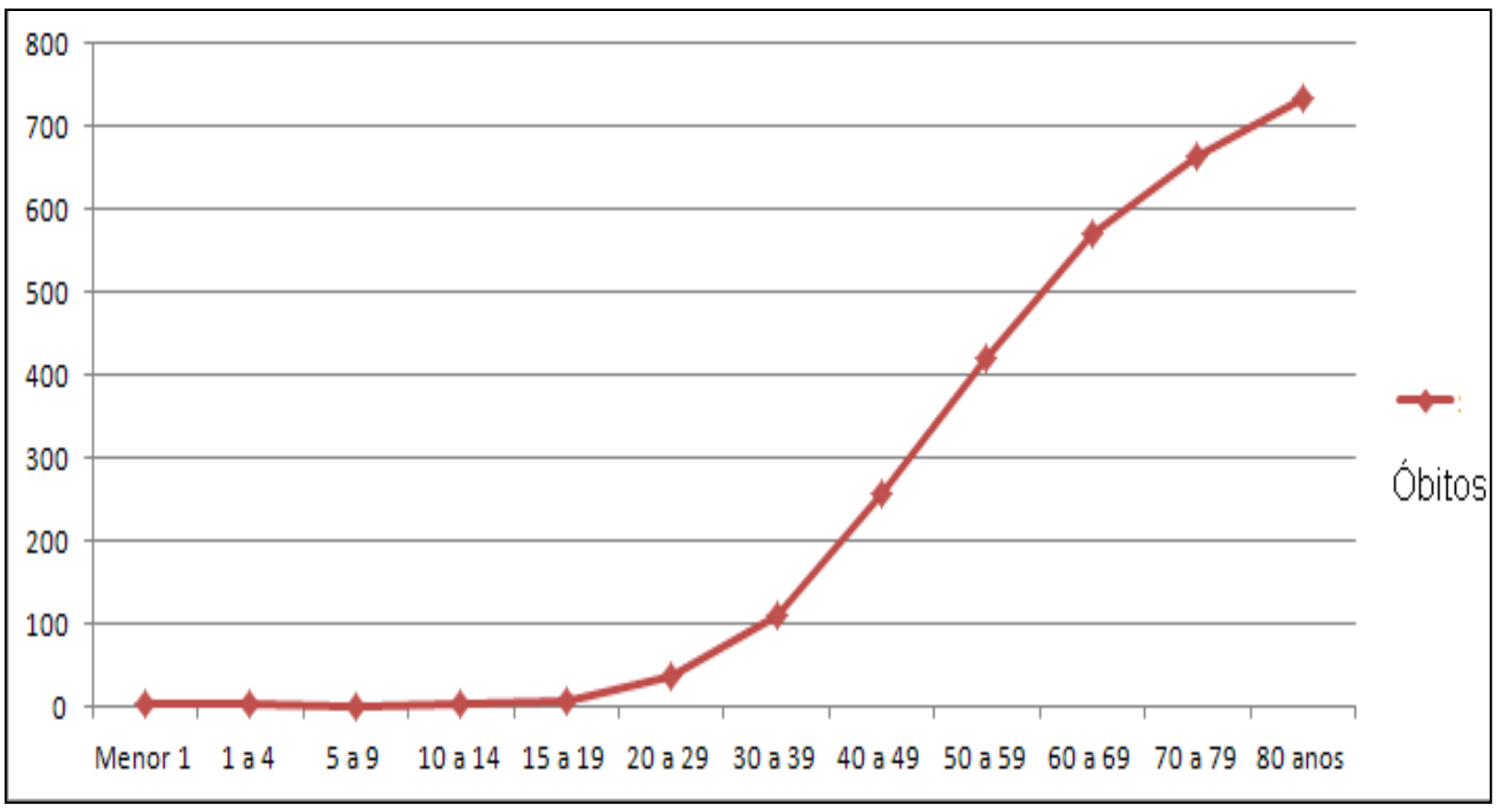

Figura 07 - Média da Mortalidade por Doenças do Aparelho Circulatório, segundo a faixa etária em ambos sexo, Distrito Federal, 2003 a 2012. Fonte: MS/SVS/CGIAE/SIM, 2003 a 2012. Elaboração: NATAL, 2015.

A Tabela 06 e a Figura 07, mostram a crescente mortalidade nos grupos com maior idade em ambos os sexos. O crescimento é verificado a partir dos 40 anos, chegando ao nível máximo na faixa etária acima de 70 anos com uma mortalidade proporcional média de $26 \%$ nos óbitos por doenças do aparelho circulatório. A distribuição do coeficiente de mortalidade mostra um risco superior para a população acima dos 80 anos com uma mortalidade proporcional média superior de $28 \%$.

Segundo o IBGE (2010), o perfil da população brasileira mudou, expressivamente, nos últimos 50 anos. O país possui ,aproximadamente, 20 milhões de pessoas com 60 anos ou mais.

No Distrito Federal, existem 197.613 habitantes nessa faixa etária, percentualmente, $7,69 \%$ da população do DF é composta por pessoas idosas (CODEPLAN, 2012). 
A Tabela 07, mostra a distribuição das principais doenças do aparelho circulatório que acometem a população humana no Distrito Federal nos anos pesquisados (2003 a 2012), a saber: Cardiomiopatias, Doenças Hipertensivas, Infarto Agudo do Miocárdio (IAM), Doenças Isquêmicas do Coração, Doenças Cerebrovasculares, e Demais Doenças do Aparelho Circulatório.

Tabela 07 - Mortalidade na população humana pelas principais doenças do aparelho circulatório em ambos sexos, em todo o Distrito Federal, 2003 a 2012.

\begin{tabular}{|c|c|c|c|c|c|c|c|c|c|c|c|}
\hline Capítulo CID-10 & \multicolumn{11}{|c|}{ ANO DE OCORRÊNCIA } \\
\hline IX Doenças do Aparelho Circulatório & 2003 & 2004 & 2005 & 2006 & 2007 & 2008 & 2009 & 2010 & 2011 & 2012 & Total \\
\hline \multirow[t]{2}{*}{ Cardiomiopatias } & 325 & 326 & 352 & 289 & 356 & 323 & 330 & 275 & 193 & 155 & 2.924 \\
\hline & $12,8 \%$ & $11,6 \%$ & $13,0 \%$ & $10,8 \%$ & $12,8 \%$ & $11,4 \%$ & $11,4 \%$ & $9,2 \%$ & $6,4 \%$ & $5,1 \%$ & $10,4 \%$ \\
\hline \multirow[t]{2}{*}{ Doenças Hipertensivas } & 275 & 273 & 286 & 236 & 252 & 253 & 264 & 273 & 263 & 236 & 2.611 \\
\hline & $10,8 \%$ & $9,8 \%$ & $10,6 \%$ & $8,8 \%$ & $9,1 \%$ & $8,9 \%$ & $9,1 \%$ & $9,1 \%$ & $8,8 \%$ & $7,8 \%$ & $9,2 \%$ \\
\hline \multirow[t]{2}{*}{ Infarto Agudo do Miocárdio (IAM) } & 400 & 518 & 439 & 467 & 459 & 457 & 505 & 534 & 552 & 574 & 4.905 \\
\hline & $15,8 \%$ & $18,5 \%$ & $16,3 \%$ & $17,4 \%$ & $16,5 \%$ & $16,1 \%$ & $17,5 \%$ & $17,9 \%$ & $18,4 \%$ & $18,9 \%$ & $17,4 \%$ \\
\hline \multirow[t]{2}{*}{ Doenças Isquêmicas do Coração } & 231 & 195 & 218 & 173 & 153 & 154 & 179 & 175 & 227 & 206 & 1.911 \\
\hline & $9,1 \%$ & $7,0 \%$ & $8,1 \%$ & $6,5 \%$ & $5,5 \%$ & $5,4 \%$ & $6,2 \%$ & $5,9 \%$ & $7,6 \%$ & $6,8 \%$ & $6,8 \%$ \\
\hline \multirow[t]{2}{*}{ Doenças Cérebro-Vasculares } & 785 & 821 & 784 & 838 & 866 & 944 & 861 & 906 & 904 & 872 & 8.581 \\
\hline & $30,9 \%$ & $29,3 \%$ & $29,0 \%$ & $31,3 \%$ & $31,2 \%$ & $33,3 \%$ & $29,8 \%$ & $30,3 \%$ & $30,2 \%$ & $28,7 \%$ & $30,4 \%$ \\
\hline \multirow[t]{2}{*}{ Demais DAC } & 522 & 666 & 621 & 675 & 690 & 706 & 751 & 827 & 858 & 999 & 7.315 \\
\hline & $20,6 \%$ & $23,8 \%$ & $23,0 \%$ & $25,2 \%$ & $24,9 \%$ & $24,9 \%$ & $26,0 \%$ & $27,7 \%$ & $28,6 \%$ & $32,8 \%$ & $25,9 \%$ \\
\hline Total & 2.538 & 2.799 & 2.700 & 2.678 & 2.776 & 2.837 & 2.890 & 2.990 & 2.997 & 3.042 & 28.247 \\
\hline
\end{tabular}

Fonte: MS/SVS/CGIAE - Sistema de Informações sobre Mortalidade - SIM, 2003 a 2012

Elaboração: NATAL, 2015. 
A Tabela 07 e a Figura 08 mostram que a principal causa de óbitos corresponde às doenças Cérebro-Vasculares (30,4\%), seguido do Infarto Agudo do Miocardo (IAM) com 17,4\% do percentual em média dos anos de 2003 a 2012. Os óbitos por doenças cardiomiopatias apresentam diminuição nos anos de 2011 e 2012. Porém, observa-se um aumento discreto nos óbitos por Infarto Agudo do Miocárdio (IAM) nos últimos 03 anos pesquisados.

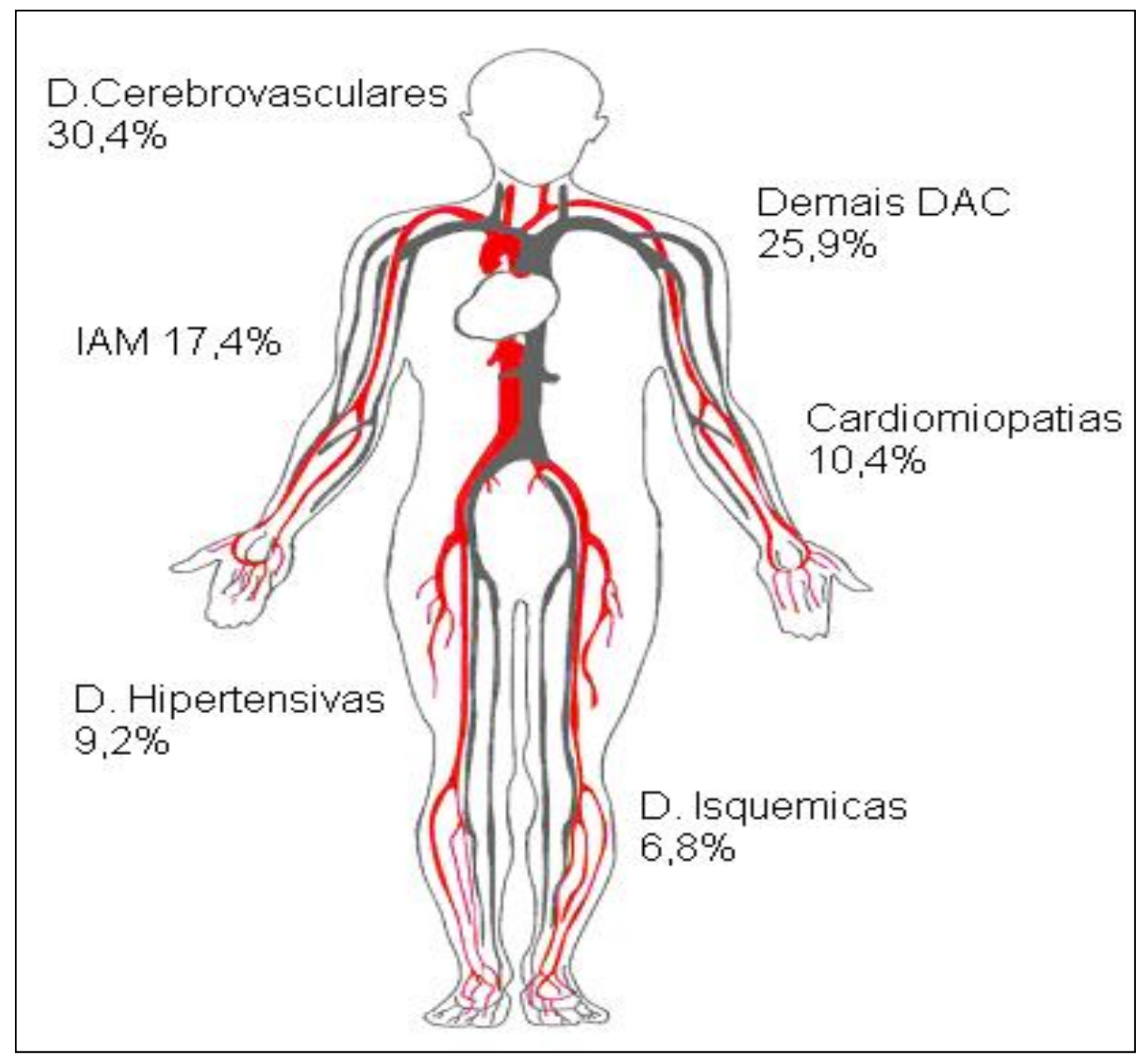

Figura 08 - Mortalidade na população humana pelas principais doenças do aparelho circulatório em ambos sexos, em todo o Distrito Federal, 2003 a 2012. Fonte: MS/SVS/CGIAE/SIM, 2003 a 2012. Elaboração: NATAL, 2015. 


\section{2 - Distribuição espacial dos óbitos por doenças do aparelho circulatório nas}

regiões administrativas (RAs) no Distrito Federal de 2003 a 2012.

O Distrito Federal possui atualmente 31 (trinta e uma) Regiões Administrativas, porém, neste trabalho para espacialização da mortalidade por doenças do aparelho circulatório foi utilizada a divisão administrativa reconhecida pelo IBGE (Regiões Administrativas de 27/01/1994 e 06/05/2003 de 19 RAs), por falta de definições das poligonais e aprovação da Câmara Legislativa do DF, (Figura 09).

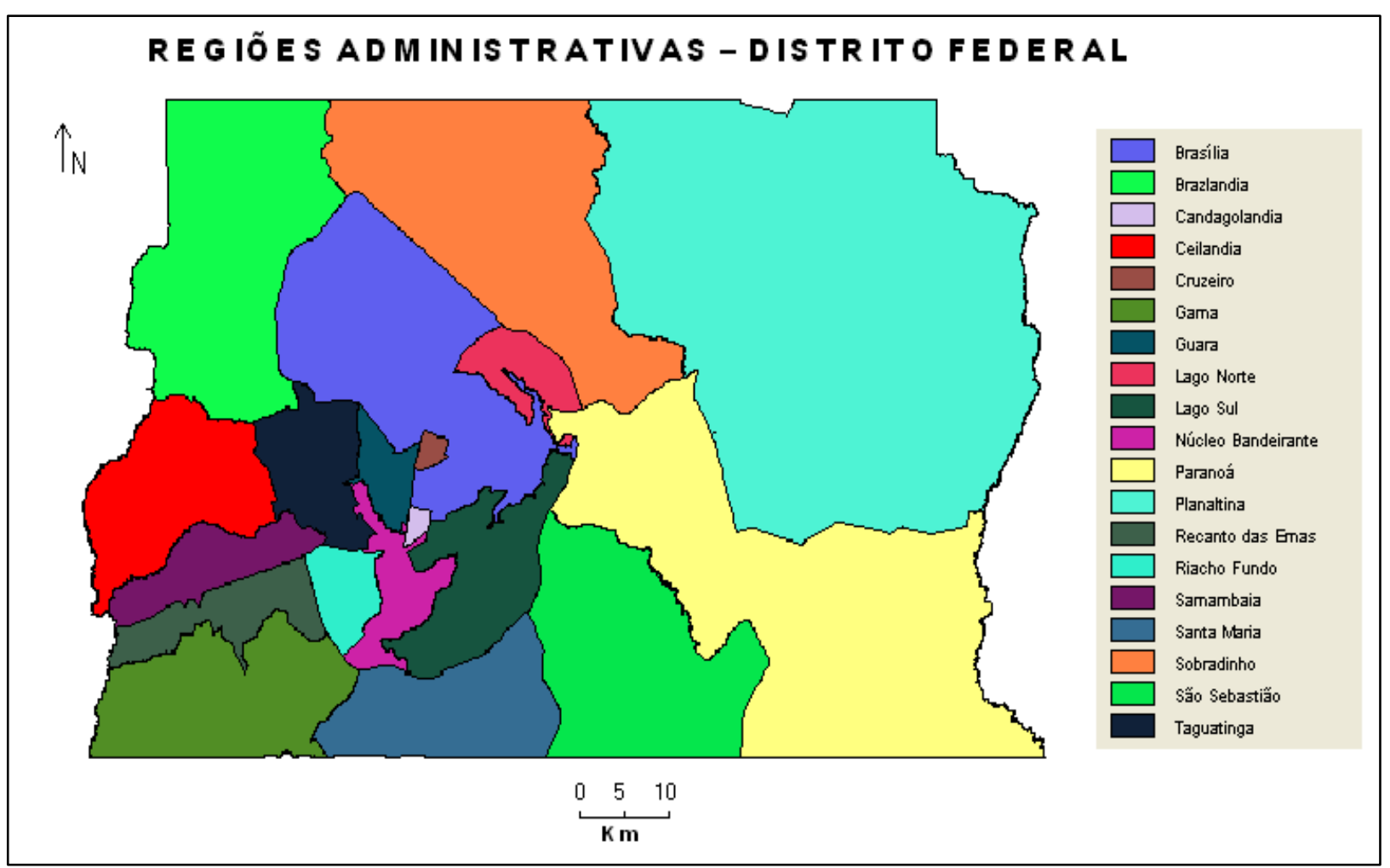

Figura 09 - Divisão Administrativa do Distrito Federal, 19 RAs (reconhecidas oficialmente pelo IBGE), utilizadas na pesquisa. Fonte: IBGE, CODEPLAN (2010). Elaboração: NATAL, 2015.

Neste trabalho utilizamos percentual para os óbitos por doenças do aparelho circulatório para cada grupo de 10.000 habitantes, foram distribuídos por local de residência.

Na Figura 10, apresentamos a distribuição espacial dos óbitos por doenças do aparelho circulatório por Região Administrativa do Distrito Federal, no ano de 
2003, adotando a divisão política antiga das 19 (dezenove) Regiões Administrativas utilizada pela Secretaria de Estado de Saúde-DF.

DISTRIB UIÇAO ESPACIAL DAS TAXAS DE MORTALIDADE POR DAC -2003

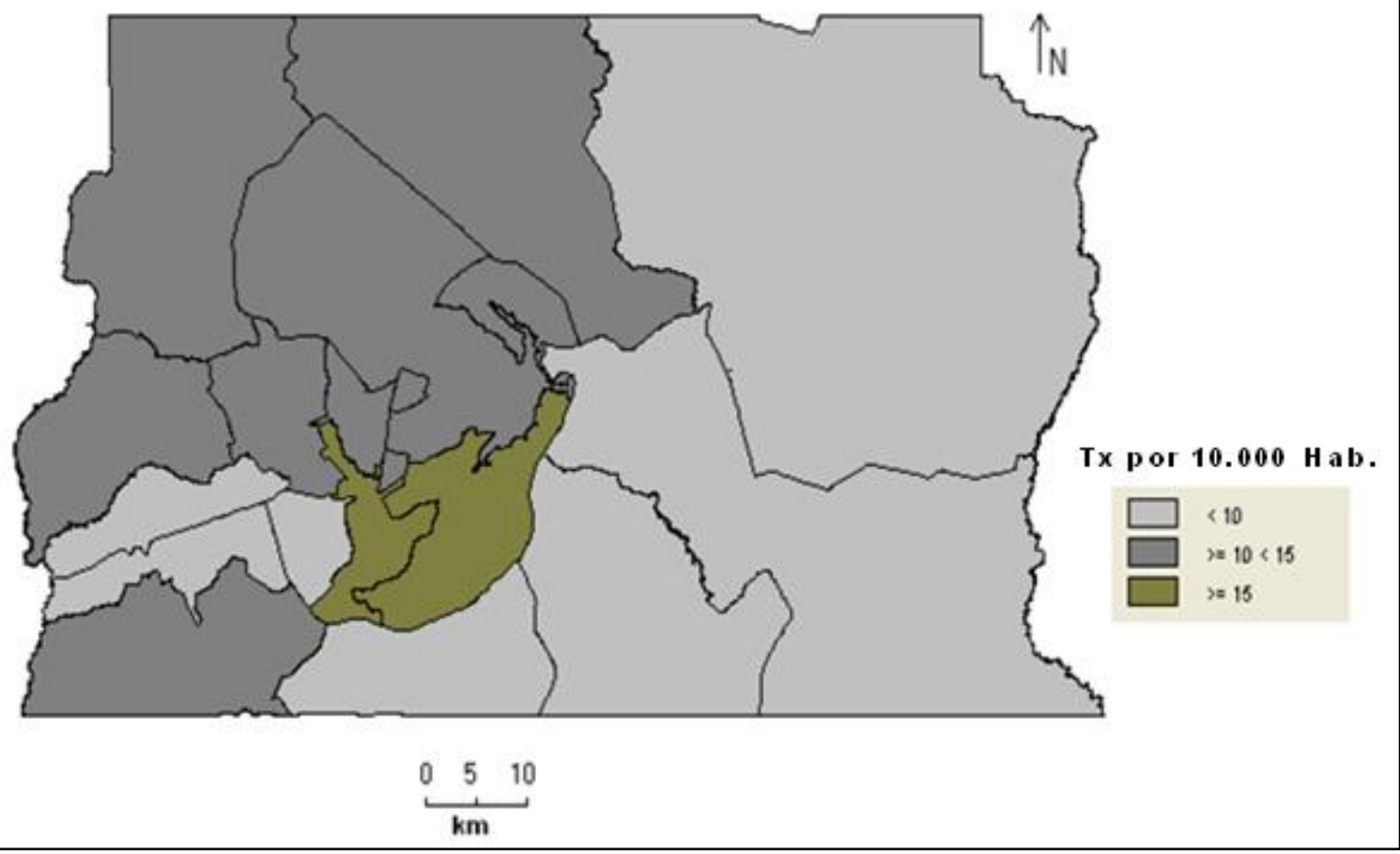

Figura 10 - Taxa média anual de óbitos por doenças do aparelho circulatório no Distrito Federal (grupo de 10.000 hab.), ano de 2003, distribuídos por Região Administrativa. Fonte de dados: SES/DF, CODEPLAN, MS/SVS/CGIAE/SIM, IBGE.

Elaboração: NATAL, 2015.

Em 2003 ,ocorreram 2.538 óbitos por doenças do aparelho circulatório, analisando a Figura 10, verifica-se que Lago Sul e Núcleo Bandeirante são as Regiões Administrativas que apresentaram maiores taxas de óbitos por doenças do aparelho circulatório em pacientes de todas as idades, no ano de 2003. O Lago Sul apresentou uma taxa média anual de 19,3 casos por grupo de 10.000 habitantes e Núcleo Bandeirante de 18,2 casos por 10.000 habitantes. Neste mesmo período as RAs do Gama (14,6 \%), Guara (14,4\%) e Candangolândia (13,2 \%) apresentaram uma taxa média anual alta em relação as demais regiões administrativas (Tabela 08).

Na Figura 11, apresentamos a distribuição espacial dos óbitos por doenças do aparelho circulatório por Região Administrativa do Distrito Federal, no ano de 2004, adotando a divisão política antiga das 19 (dezenove) Regiões Administrativas utilizada pela Secretaria de Estado de Saúde-DF. 
DISTRIB UIÇAO ESPACIAL DAS TAXAS DE MORTALIDADE POR DAC - 2004

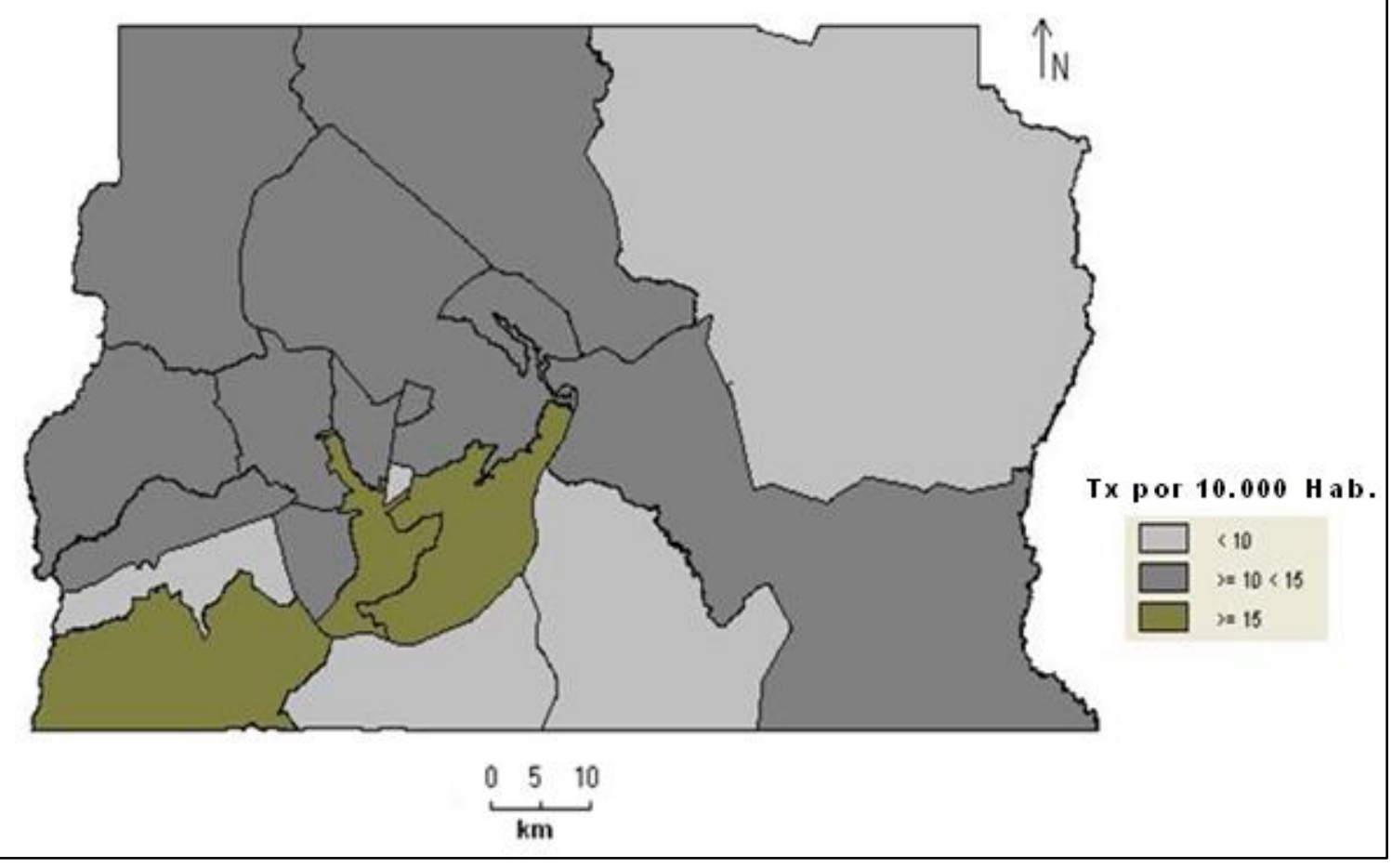

Figura 11 - Taxa média anual de óbitos por doenças do aparelho circulatório no Distrito Federal (grupo de 10.000 hab.), ano de 2004, distribuídos por Região Administrativa. Fonte de dados: SES/DF, CODEPLAN, MS/SVS/CGIAE/SIM, IBGE. Elaboração: NATAL, 2015.

Em 2004, ocorreram 2.799 óbitos por doenças do aparelho circulatório. Analisando a Figura 11, o ano de 2004 teve mudanças na taxa média anual dos óbitos por doenças do aparelho circulatório por grupo de 10.000 habitantes. Neste período analisado, o Lago Sul teve um aumento na taxa média em relação ao ano de 2003, de 19,3 para 21,8 casos por grupo de 10.000 habitantes, já o Núcleo Bandeirante teve uma queda acentuada de 18,2 para 16, 8 casos por grupo de 10.000 habitantes. O Gama que apresentou taxa alta no ano de 2003, teve um leve aumento no ano de 2004, de 14,6 para 15,2 casos por grupo de 10.000 habitantes. Neste período, ainda vem destacar com taxa média anual as Regiões administrativas de Taguatinga (14,1\%), Sobradinho (13,8\%) e Guara $(13,4 \%)$ em relação as demais Regiões Administrativas. (Tabela 08).

Na Figura 12, apresentamos a distribuição espacial dos óbitos por doenças do aparelho circulatório por Região Administrativa do Distrito Federal, no ano de 2005, adotando a divisão política antiga das 19 (dezenove) Regiões Administrativas utilizada pela Secretaria de Estado de Saúde-DF. 
DISTRIB UIÇAO ESPACIAL DAS TAXAS DE MORTALIDADE POR DAC - 2005

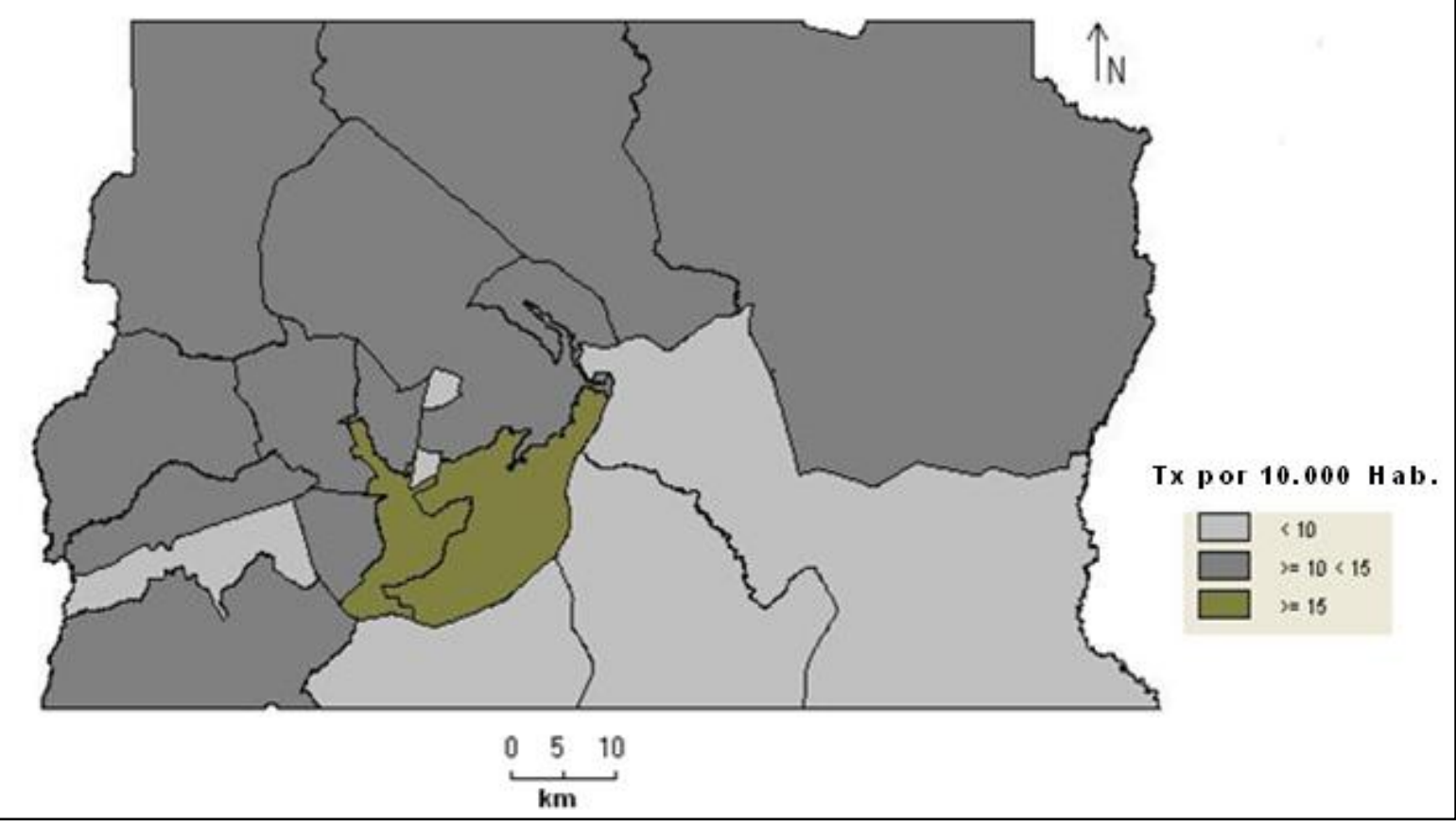

Figura 12 - Taxa média anual de óbitos por doenças do aparelho circulatório no Distrito Federal (grupo de 10.000 hab.), ano de 2005, distribuídos por Região Administrativa. Fonte de dados: SES/DF, CODEPLAN, MS/SVS/CGIAE/SIM, IBGE. Elaboração: NATAL, 2015.

Em 2005, ocorreram 2.700 óbitos por doenças do aparelho circulatório, analisando a Figura 12, o ano de 2005 teve uma distribuição homogênea na taxa média anual dos óbitos por doenças do aparelho circulatório por grupo de 10.000 habitantes. Neste período analisado o Lago Sul e o Núcleo Bandeirante tiveram uma queda acentuada na taxa média em relação ao ano de 2004, Lago Sul de 21,8 para 20,9 casos por grupo de 10.000 habitantes, Núcleo Bandeirante 16,8 para 15,1 casos por grupo de 10.000 habitantes. O Gama, que apresentou taxa alta no ano de 2004, teve uma queda acentuada no ano de 2005, de 15,2 para 13,3 casos por grupo de 10.000 habitantes. Neste período, ainda cabe destacar com taxas médias anual as Regiões administrativas de Taguatinga (12,8\%), Sobradinho (11,8\%) e Guara (13,) todas com queda acentuada nas taxas médias anuais (Tabela 08).

$\mathrm{Na}$ Figura 13, apresentamos a distribuição espacial dos óbitos por doenças do aparelho circulatório por Região Administrativa do Distrito Federal, no ano de 2006, adotando a divisão política antiga das 19 (dezenove) Regiões Administrativas utilizada pela Secretaria de Estado de Saúde-DF. 


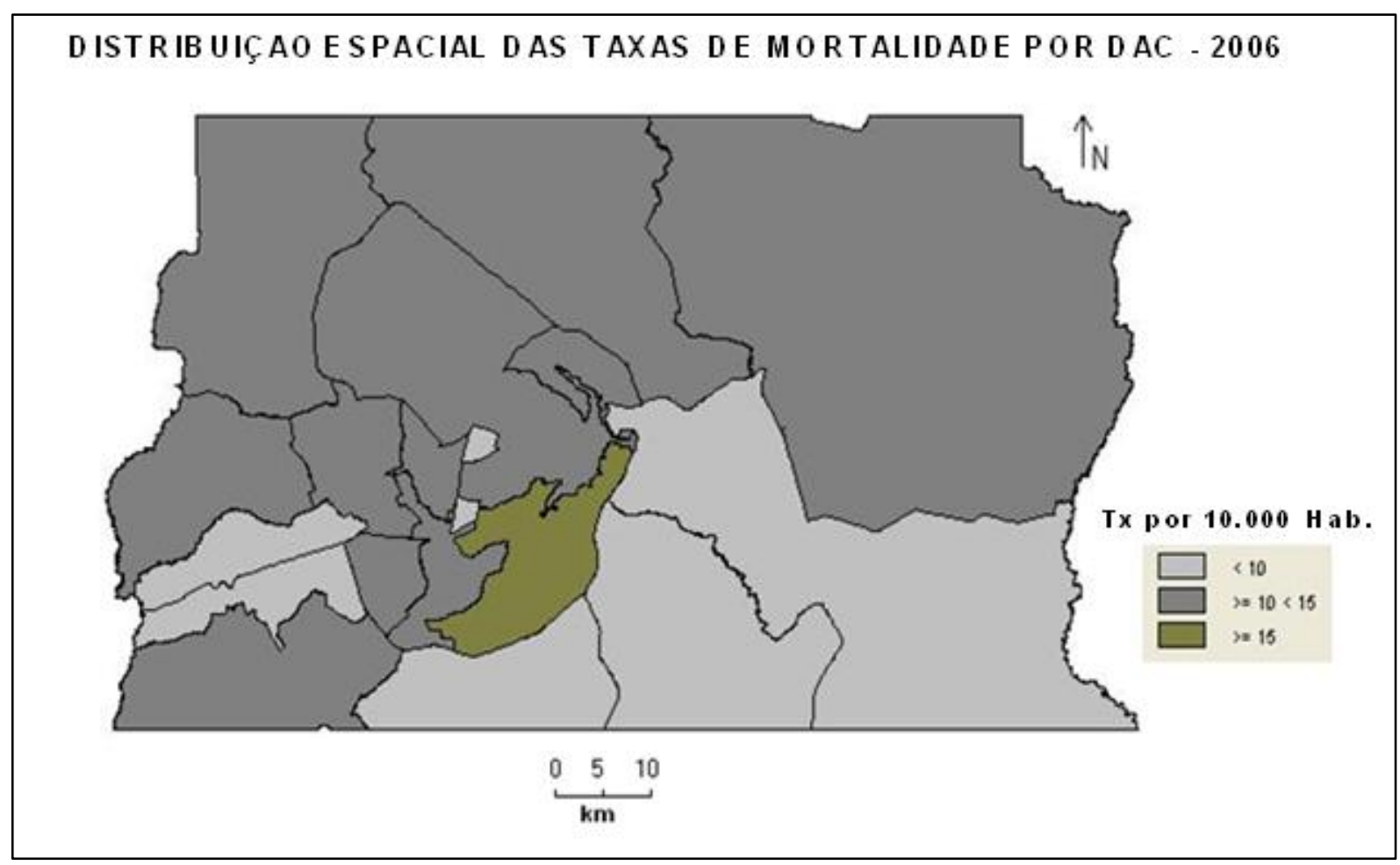

Figura 13 - Taxa média anual de óbitos por doenças do aparelho circulatório no Distrito Federal (grupo de 10.000 hab.), ano de 2006, distribuídos por Região Administrativa. Fonte de dados: SES/DF, CODEPLAN, MS/SVS/CGIAE/SIM, IBGE. Elaboração: NATAL, 2015.

Em 2006, ocorreram 2.678 óbitos por doenças do aparelho circulatório, analisando a Figura 13, o ano de 2006 teve uma queda na taxa média anual dos óbitos por doenças do aparelho circulatório por grupo de 10.000 habitantes. Neste período analisado o Lago Sul teve uma queda acentuada na taxa média em relação ao ano de 2005, e o Núcleo Bandeirante não figura entre as regiões administrativas com a taxa média anual alta. O Lago Sul apresenta taxa média anual alta em relação às demais regiões administrativas. Porém, o Lago Sul apresentou queda brusca de 2005 para 2006, de 20,6 para 15,6 casos por grupo de 10.000 habitantes. Brazlândia vem apresentando leve alta na taxa media anual por grupo de 10.000 habitantes nos anos pesquisados, 2003 (11,6\%), 2004 (12,7\%), (12,8\%) e 2006 (13,3\%). Neste período analisado, Gama, Sobradinho e Guará tiveram uma queda acentuada na taxa media anual de óbitos por doenças do aparelho circulatório por grupo de 10.000 habitantes (Tabela 08).

Na Figura 14, apresentamos a distribuição espacial dos óbitos por doenças do aparelho circulatório por Região Administrativa do Distrito Federal, no ano de 
2007, adotando a divisão política antiga das 19 (dezenove) Regiões Administrativas utilizada pela Secretaria de Estado de Saúde-DF.

DISTRIB UIÇAO ESPACIAL DAS TAXAS DE MORTALIDADE POR DAC - 2007

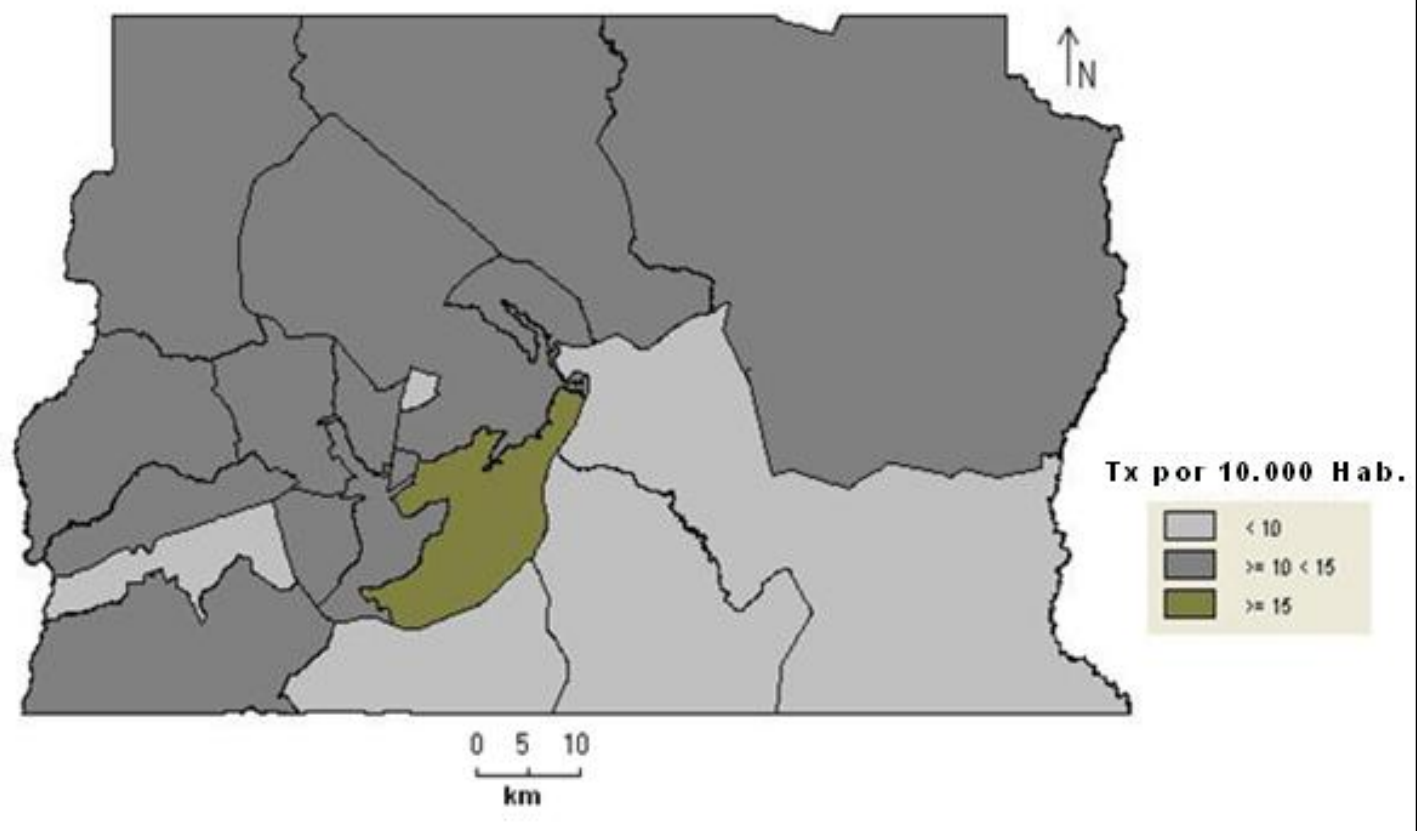

Figura 14 - Taxa média anual de óbitos por doenças do aparelho circulatório no Distrito Federal (grupo de 10.000 hab.), ano de 2007, distribuídos por Região Administrativa. Fonte de dados: SES/DF, CODEPLAN, MS/SVS/CGIAE/SIM, IBGE. Elaboração: NATAL, 2015.

Em 2007, ocorreram 2.776 óbitos por doenças do aparelho circulatório, analisando a Figura 14, o ano de 2007, manteve o Lago Sul em destaque em relação as demais regiões administrativas na taxa média anual dos óbitos por doenças do aparelho circulatório por grupo de 10.000 habitantes, porém, manteve estável em relação ao ano anterior com a taxa média anual de 15,5 casos por grupo de 10.000 habitantes. Neste período analisado, Gama e Taguatinga tem suas taxas um aumento em relação ao ano anterior (2006). O Gama teve sua taxa média anual de 12,9 para 14,9 casos por grupo de 10.000 habitantes e Taguatinga de 12,8 para 13,2 casos por grupo de 10.000 habitantes. Neste período analisado, as demais regiões administrativas apresentaram um leve crescimento na taxa media anual de óbitos por doenças do aparelho circulatório por grupo de 10.000 habitantes (Tabela 08). 
Na Figura 15, apresentamos a distribuição espacial dos óbitos por doenças do aparelho circulatório por Região Administrativa do Distrito Federal, no ano de 2008, adotando a divisão política antiga das 19 (dezenove) Regiões Administrativas utilizada pela Secretaria de Estado de Saúde-DF.

DISTRIB UIÇAO ESPACIAL DAS TAXAS DE MORTALIDADE POR DAC - 2008

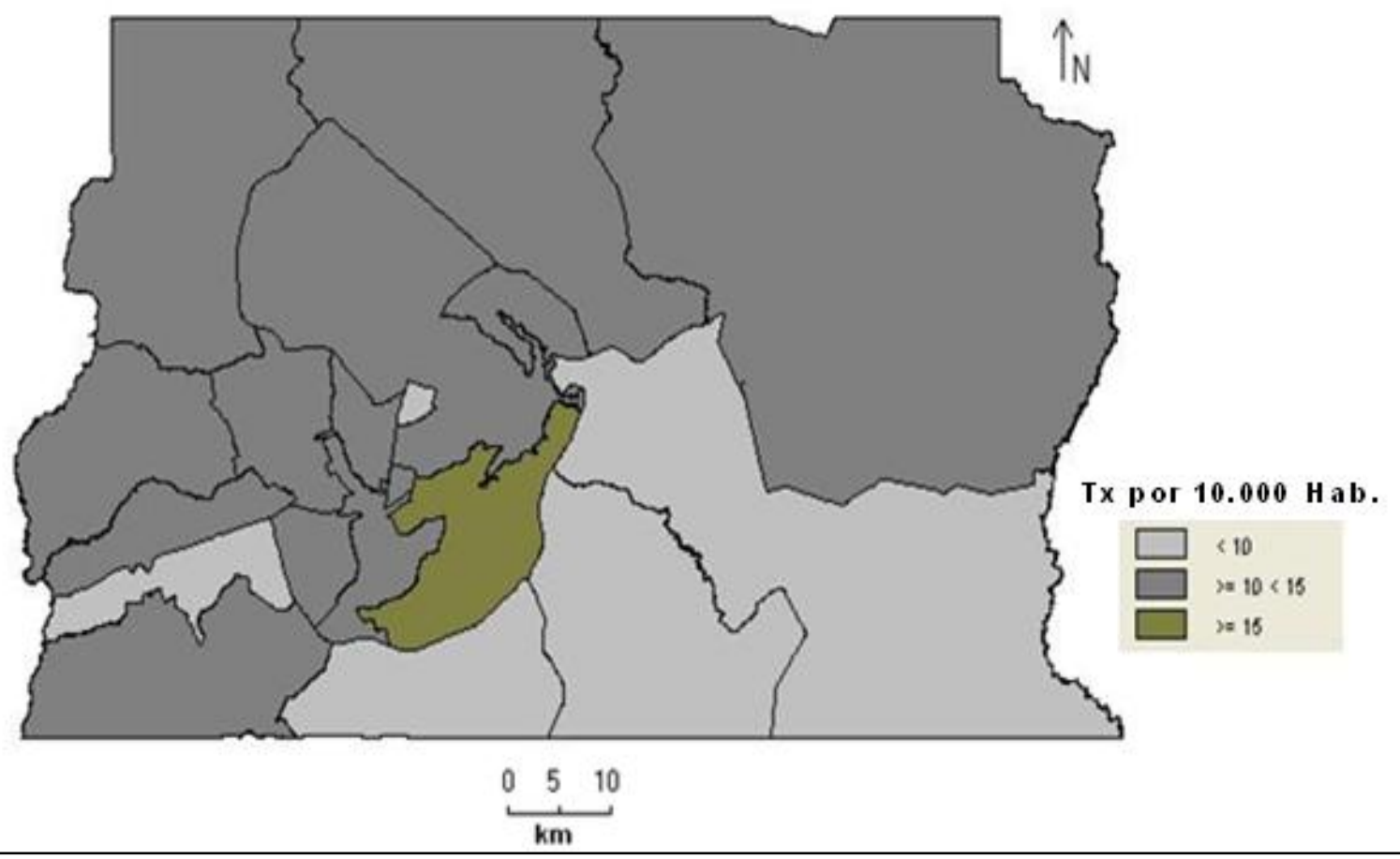

Figura 15 - Taxa média anual de óbitos por doenças do aparelho circulatório no Distrito Federal (grupo de 10.000 hab.), ano de 2008, distribuídos por Região Administrativa. Fonte de dados: SES/DF, CODEPLAN, MS/SVS/CGIAE/SIM, IBGE. Elaboração: NATAL, 2015.

Em 2008, ocorreram 2.837 óbitos por doenças do aparelho circulatório, analisando a Figura 15, o Lago Sul teve um aumento acentuado na taxa média anual dos óbitos por doenças do aparelho circulatório por grupo de 10.000 habitantes em relação ao ano de 2007, de 15,5 para 16,1 casos por grupo de 10.000 habitantes. Neste período analisado, Gama e Taguatinga mantiveram suas taxas estáveis em relação ao ano anterior (2007). No período analisado Candangolândia apresentou aumento na taxa média anual em relação aos anos anteriores pesquisados (2004, 2005, 2006 e 2007), com a taxa média anual em 2008 de 13,8 casos por grupo de 10.000 habitantes. Neste período analisado Gama manteve a taxa média estável, já Taguatinga teve uma queda acentuada na taxa média anual 
em relação ao ano anterior, de 13,6 para 11,6 casos por grupo de 10.000 habitantes de óbitos por doenças do aparelho circulatório (Tabela 08).

Na Figura 16, apresentamos a distribuição espacial dos óbitos por doenças do aparelho circulatório por Região Administrativa do Distrito Federal, no ano de 2009, adotando a divisão política antiga das 19 (dezenove) Regiões Administrativas utilizada pela Secretaria de Estado de Saúde-DF.

DISTRIB UIÇAO ESPACIAL D AS TAXAS DE MORTALIDADE POR DAC - 2009

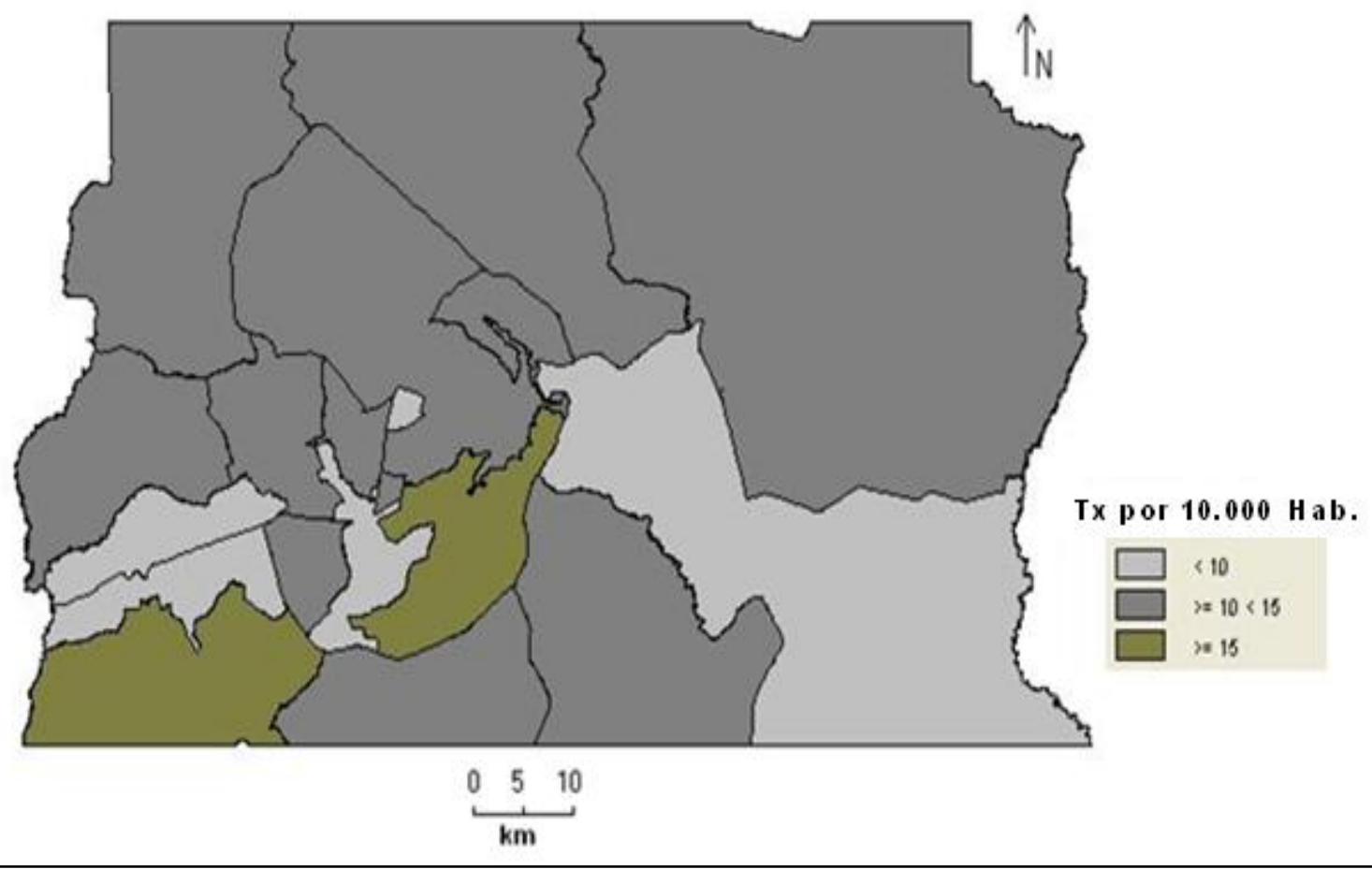

Figura 16 - Taxa média anual de óbitos por doenças do aparelho circulatório no Distrito Federal (grupo de 10.000 hab.), ano de 2009, distribuídos por Região Administrativa. Fonte de dados: SES/DF, CODEPLAN, MS/SVS/CGIAE/SIM, IBGE. Elaboração: NATAL, 2015.

Em 2009, ocorreram 2.890 óbitos por doenças do aparelho circulatório, analisando a Figura 16, verifica-se que Lago Sul e Gama são as Regiões Administrativas que apresentaram maiores taxas de óbitos por doenças do aparelho circulatório em pacientes de todas as idades, no ano de 2009. O Lago Sul apresentou uma taxa média anual de 16,8 casos por grupo de 10.000 habitantes e o Gama de 15,5 casos por grupo de 10.000 habitantes. No período analisado, Taguatinga apresentou aumento moderado na taxa média anual em relação ao ano anterior de 11,6 para 12,8 casos por grupo de 10.000 habitantes, já Candangolândia 
fez o inverso com queda moderada na taxa média anual em relação ao ano anterior de 13,8 para 10,1 casos por grupo de 10.000 habitantes. Neste período ,Riacho Fundo apresentou taxa média anual de 13,9 casos por grupo de 10.000 habitantes, tendo sua taxa elevada em relação aos anos anteriores pesquisados (Tabela 08).

Na Figura 17, apresentamos a distribuição espacial dos óbitos por doenças do aparelho circulatório por Região Administrativa do Distrito Federal, no ano de 2010, adotando a divisão política antiga das 19 (dezenove) Regiões Administrativas utilizadas pela Secretaria de Estado de Saúde-DF.

DISTRIB UIÇAO ESPACIAL DAS TAXAS DE MORTALIDADE POR DAC - 2010

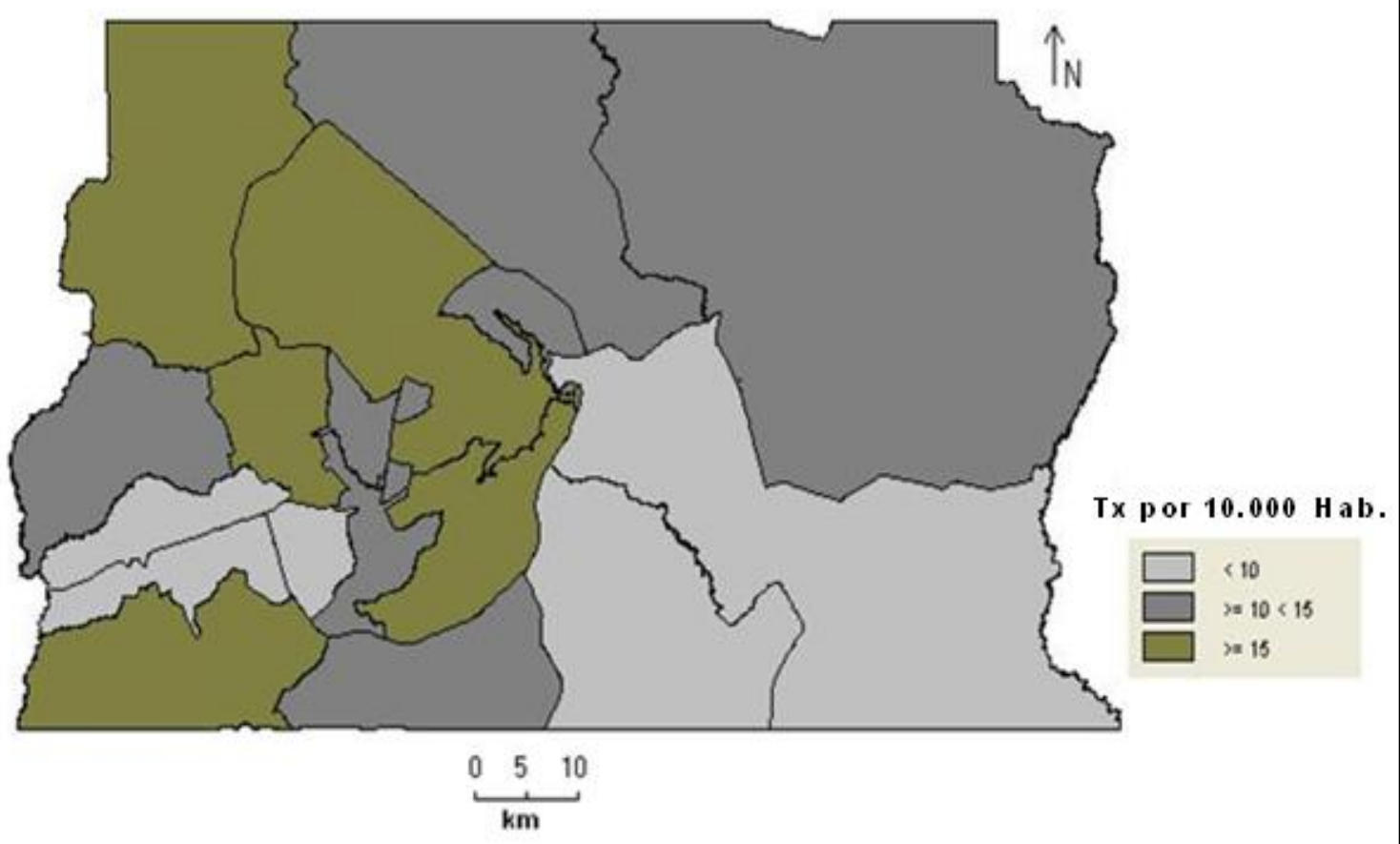

Figura 17 - Taxa média anual de óbitos por doenças do aparelho circulatório no Distrito Federal (grupo de 10.000 hab.), ano de 2010, distribuídos por Região Administrativa. Fonte de dados: SES/DF, CODEPLAN, MS/SVS/CGIAE/SIM, IBGE.

Elaboração: NATAL, 2015.

Em 2010, ocorreram 2.890 óbitos por doenças do aparelho circulatório. Analisando a Figura 17, verifica-se que Lago Sul, Gama, Brasilia, Taguatinga e Brazlândia são as Regiões Administrativas que apresentaram maiores taxas de óbitos por doenças do aparelho circulatório em pacientes de todas as idades, no ano de 2010. O Lago Sul apresentou uma taxa média anual de 17,0 casos por grupo de 10.000 habitantes, seguido do Gama com 16,1 casos por grupo de 10.000 
habitantes, Taguatinga com 16,1 casos por grupo de 10.000 habitantes, Brasilia com 15,1 casos por grupo de 10.000 habitantes e Brazlândia com 15,1 casos por grupo de 10.000 habitantes. No período analisado, Cruzeiro, Núcleo Bandeirante, Candangolandia e Lago Norte apresentaram aumento moderado na taxa média anual em relação ao ano anterior pesquisado e Riacho Fundo fez o inverso, com queda moderada na taxa média anual em relação ao ano anterior de 13,9 para 8,6 casos por grupo de 10.000 habitantes (Tabela 08).

$\mathrm{Na}$ Figura 18, apresentamos a distribuição espacial dos óbitos por doenças do aparelho circulatório por Região Administrativa do Distrito Federal, no ano de 2011, adotando a divisão política antiga das 19 (dezenove) Regiões Administrativas utilizadas pela Secretaria de Estado de Saúde-DF.

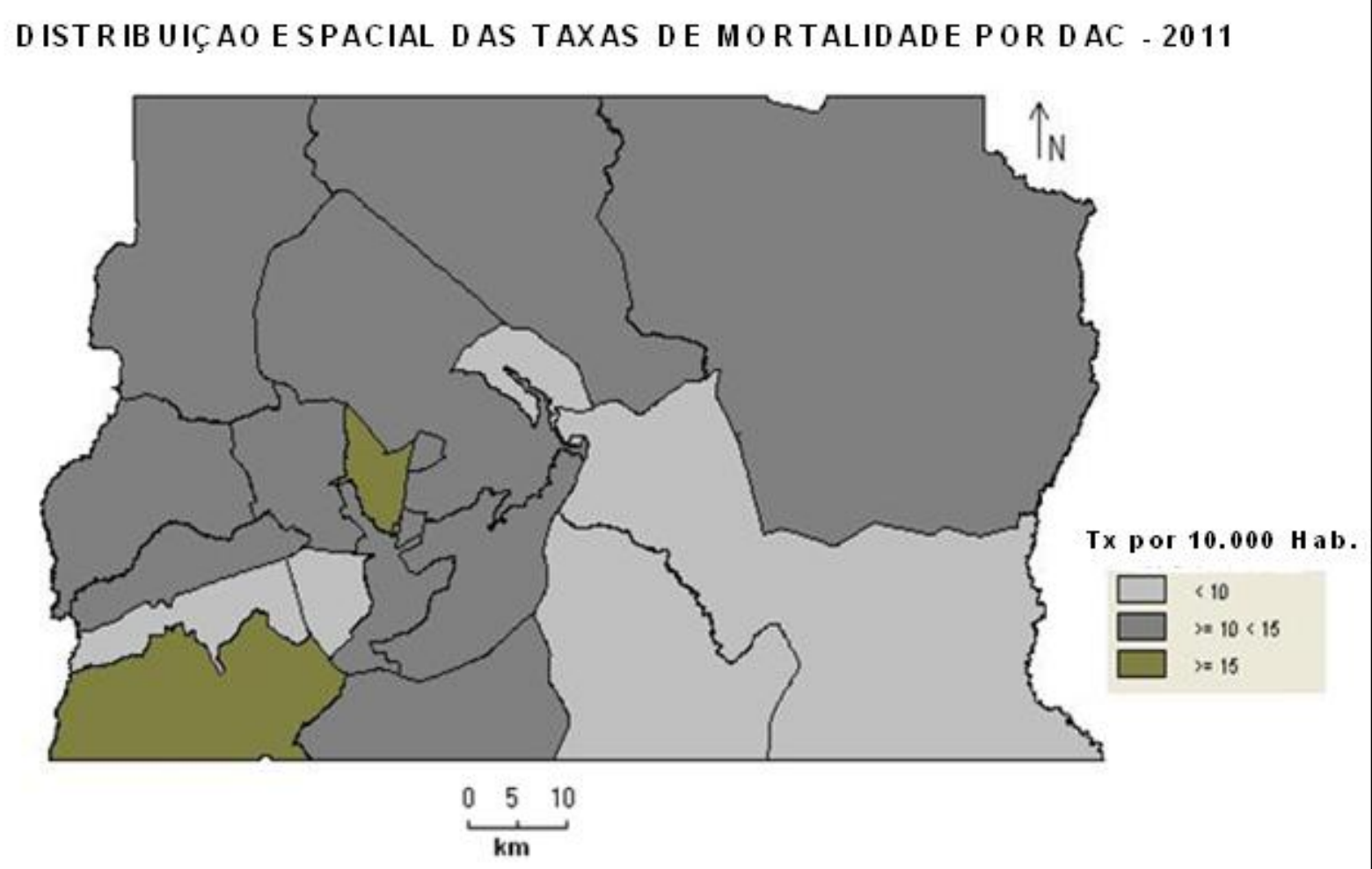

Figura 18 - Taxa média anual de óbitos por doenças do aparelho respiratório no Distrito Federal (grupo de 10.000 hab.), ano de 2011, distribuídos por Região Administrativa. Fonte de dados: SES/DF, CODEPLAN, MS/SVS/CGIAE/SIM, IBGE. Elaboração: NATAL, 2015.

Em 2011, ocorreram 2.997 óbitos por doenças do aparelho circulatório. Analisando a Figura 18, verifica-se que Gama e Guara, são as Regiões Administrativas que apresentaram maiores taxas de óbitos por doenças do aparelho circulatório em pacientes de todas as idades, no ano de 2011. O Gama apresentou 
uma taxa média anual de 15,1 casos por grupo de 10.000 habitantes, Guara de 15,1 casos por grupo de 10.000 habitantes. Neste período analisado, o Lago Sul, O Lago Norte, Brasília, Taguatinga e Brazlândia apresentaram queda moderada na taxa média anual em relação aos anos anteriores pesquisados, Lago Sul de 17 para 14,7 casos por grupo de 10.000 habitantes, Lago Norte de 13,3 para 8,8 casos por grupo de 10.000 habitantes, Brasilia de 15,1 para 13,4 casos por grupo de 10.000 habitantes, Taguatinga de 16,1 para 14,2 casos por grupo de 10.000 habitantes e Brazlândia de 15,1 para 13,3 casos por grupo de 10.000 habitantes (Tabela 08).

$\mathrm{Na}$ Figura 19, apresentamos a distribuição espacial dos óbitos por doenças do aparelho circulatório por Região Administrativa do Distrito Federal, no ano de 2012, adotando a divisão política antiga das 19 (dezenove) Regiões Administrativas utilizadas pela Secretaria de Estado de Saúde-DF.

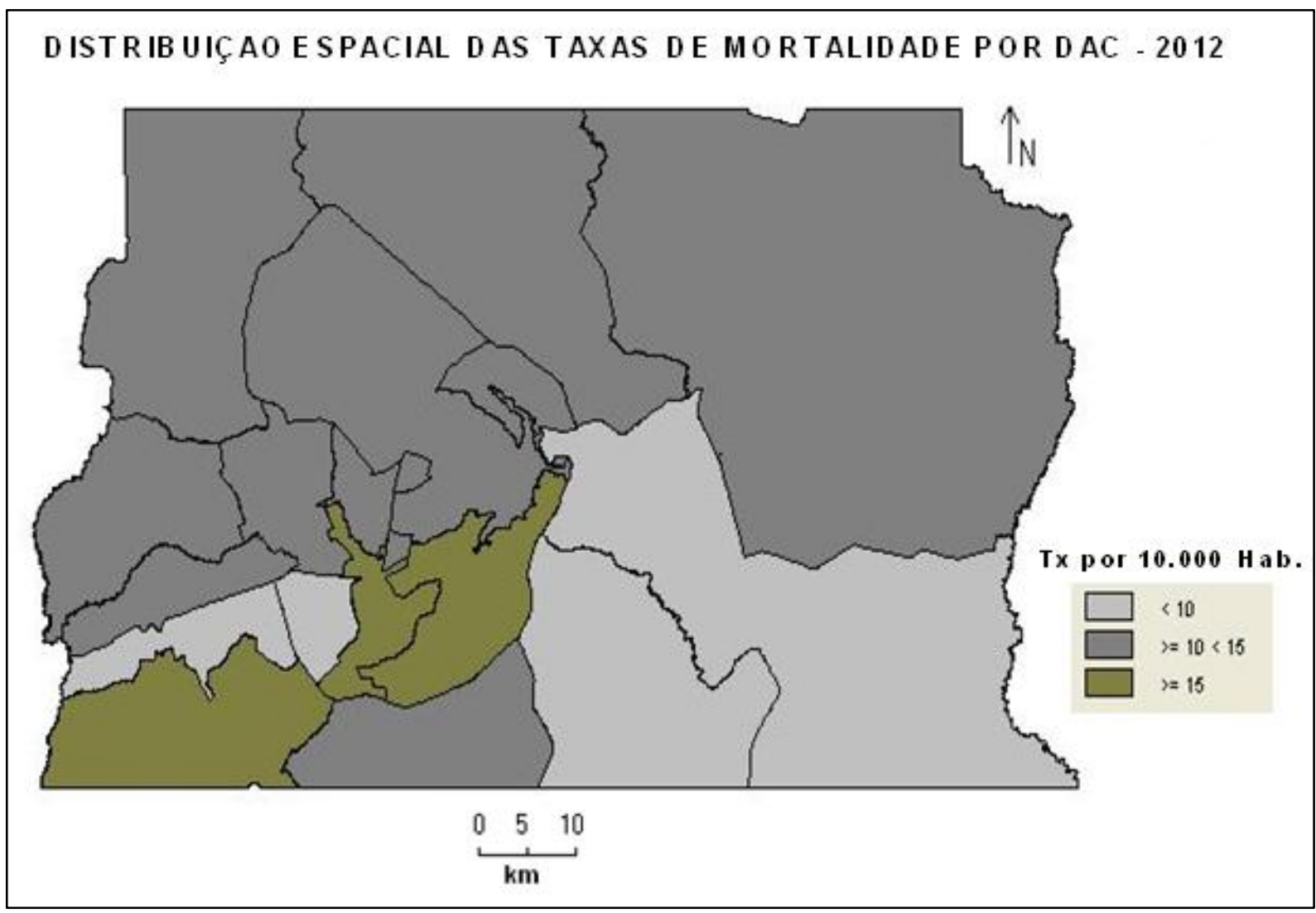

Figura 19 - Taxa média anual de óbitos por doenças do aparelho circulatório no Distrito Federal (grupo de 10.000 hab.), ano de 2012, distribuídos por Região Administrativa. Fonte de dados: SES/DF, CODEPLAN, MS/SVS/CGIAE/SIM, IBGE. Elaboração: NATAL, 2015. 
Em 2012, ocorreram 3.042 óbitos por doenças do aparelho circulatório. Analisando a Figura 19, verifica-se que Lago Sul, Núcleo Bandeirante e Gama são as Regiões Administrativas que apresentaram maiores taxas de óbitos por doenças do aparelho circulatório em pacientes de todas as idades, no ano de 2012. O Lago Sul apresentou uma taxa média anual de 20,8 casos por grupo de 10.000 habitantes, seguido do Núcleo Bandeirante com 17,0 casos por grupo de 10.000 habitantes e Gama com 15,6 casos por grupo de 10.000 habitantes. No período mostra que o Lago Sul teve um alto crescimento na taxa média anual em relação ao ano anterior, de 14,7 para 20,8 casos por grupo de 10.000 habitantes (Tabela 08).

$\mathrm{Na}$ Figura 20 e Tabela 08, apresentamos a taxa média anual da distribuição espacial dos óbitos por doenças do aparelho circulatório por Região Administrativa do Distrito Federal, de 2003 a 2012, adotando a divisão política antiga das 19 (dezenove) Regiões Administrativas utilizadas pela Secretaria de Estado de SaúdeDistrito Federal.

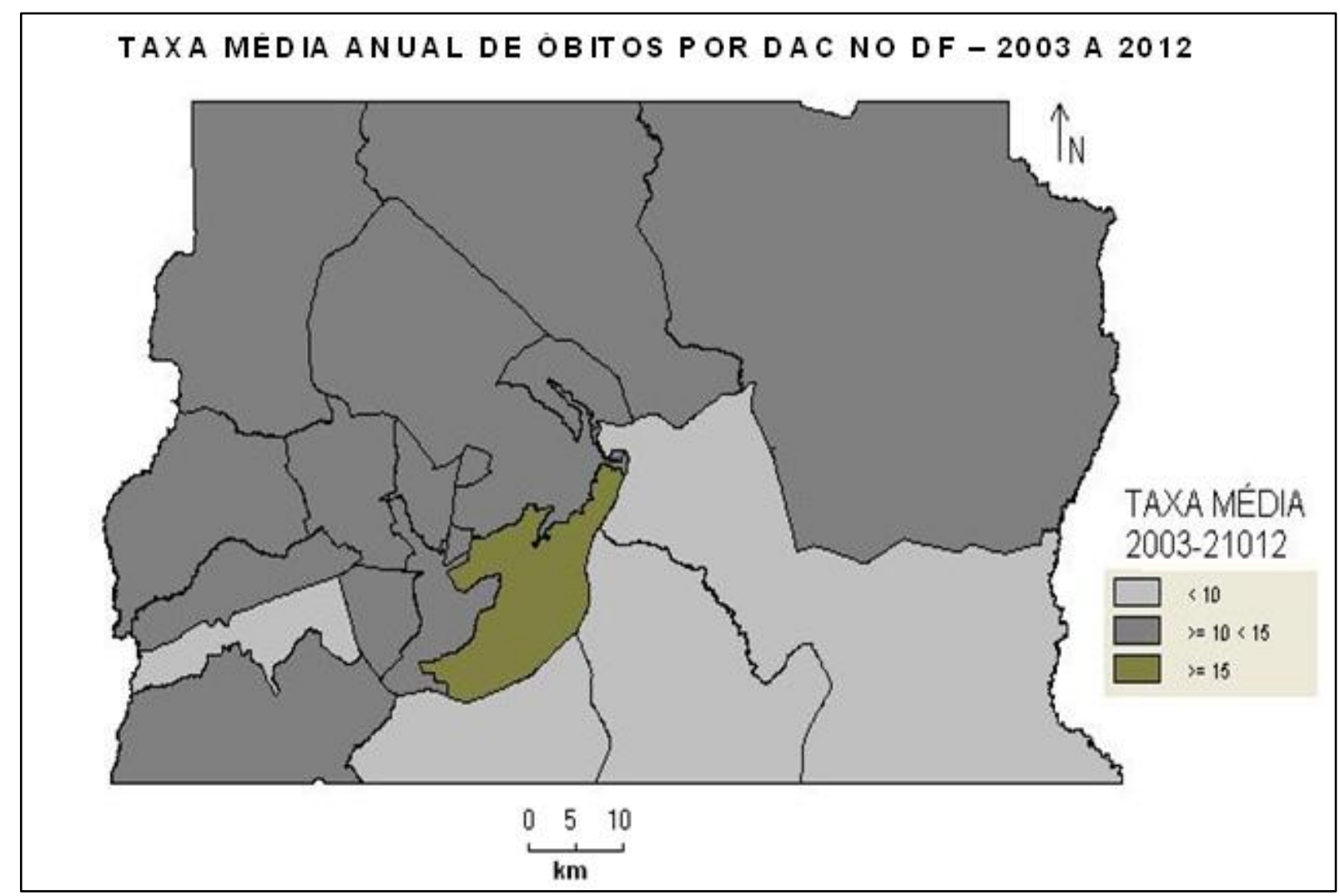

Figura 20 - Taxa média de óbitos por doenças do aparelho circulatório no Distrito Federal (grupo de 10.000 hab.), nos anos pesquisados (2003 a 2012), distribuídos por Região Administrativa Fonte de dados: SES/DF, CODEPLAN, MS/SVS/CGIAE/SIM, IBGE. Elaboração: NATAL, 2015. 
No período analisado, de 2003 a 2012 tivemos 28.247 óbitos por Doenças do aparelho circulatório no Distrito Federal, distribuídos nas 19 regiões administrativas reconhecidas pelo IBGE. O Lago Sul foi a Região Administrativa que apresentou a maior taxa média de anual nos anos pesquisados com 17,9 casos por grupo de 10.000 habitantes, seguido em segundo lugar do Gama com 14,8 casos por grupo de 10.000 habitantes, terceiro lugar Núcleo Bandeirante com 13,8 casos por grupo de 10.000 habitantes, quarto lugar Brazlândia com 13,4 casos por grupo de 10.000 habitantes, quinto lugar Taguatinga com 13,3 casos por grupo de 10.000 habitantes e sexto lugar Brasília com 12,5 casos por grupo de 10.000 habitantes (Tabela 08).

Segundo a CODEPLAN (2012) Lago Sul, Lago Norte e Brasília são as regiões administrativas com maior população idosa relativa. Cerca de $20 \%$ dos habitantes do Lago Sul são idosos, no Lago Norte, 15,28\% é composta por pessoas acima de 60 anos e, em Brasilia, 13,93\% da população encontra-se nessa faixa etária. A Tabela 06 mostra que acima de 40 anos a população pesquisada entra no grupo de risco de ser acometido por alguma doença do aparelho circulatório. E na faixa etária maior que 60 anos de idade chega a mais de $65 \%$ do total anual. 
Tabela 08 - Taxa média anual de óbitos por doenças do aparelho circulatório no Distrito Federal (grupo de 10.000 hab.), 2003 a 2012, distribuídos por Região Administrativa.

\begin{tabular}{|c|c|c|c|c|c|c|c|c|c|c|c|}
\hline Regiões Administrativas & 2003 & 2004 & 2005 & 2006 & 2007 & 2008 & 2009 & 2010 & 2011 & 2012 & Média \\
\hline Brasilia & $12,6 \%$ & $12,5 \%$ & $11,8 \%$ & $11,6 \%$ & $12,3 \%$ & $11,4 \%$ & $10,8 \%$ & $15,1 \%$ & $13,4 \%$ & $13,2 \%$ & $12,5 \%$ \\
\hline & $14,6 \%$ & $15,2 \%$ & $13,3 \%$ & $12,9 \%$ & $14,9 \%$ & $14,7 \%$ & $15,5 \%$ & $16,1 \%$ & $15,1 \%$ & $15,6 \%$ & $14,8 \%$ \\
\hline Taguatinga & $11,9 \%$ & $14,1 \%$ & $12,8 \%$ & $12,8 \%$ & $13,2 \%$ & $11,6 \%$ & $12,8 \%$ & $16,1 \%$ & $14,2 \%$ & $13,9 \%$ & $13,3 \%$ \\
\hline Sobradinho & $11,2 \%$ & $13,8 \%$ & $11,8 \%$ & $10,2 \%$ & $11,8 \%$ & $11,6 \%$ & $12,9 \%$ & $12,6 \%$ & $11,4 \%$ & $12,0 \%$ & $11,9 \%$ \\
\hline Planaltina & $9,6 \%$ & $9,9 \%$ & $10,0 \%$ & $11,1 \%$ & $11,1 \%$ & $12,1 \%$ & $10,3 \%$ & $11,1 \%$ & $11,4 \%$ & $12,2 \%$ & $10,9 \%$ \\
\hline Paranoá & $6,1 \%$ & $10,3 \%$ & $8,4 \%$ & $7,5 \%$ & $6,0 \%$ & $6,9 \%$ & $6,3 \%$ & $6,4 \%$ & $7,3 \%$ & $7,3 \%$ & $7,3 \%$ \\
\hline Ceilândia & $11,6 \%$ & $11,6 \%$ & $11,8 \%$ & $11,7 \%$ & $12,4 \%$ & $11,7 \%$ & $12,0 \%$ & $12,5 \%$ & $13,3 \%$ & $13,0 \%$ & 12,26 \\
\hline Guara & $14,4 \%$ & $13,4 \%$ & $13,0 \%$ & $12,6 \%$ & $12,0 \%$ & $10,6 \%$ & $10,5 \%$ & $13,9 \%$ & $15,1 \%$ & $12,9 \%$ & $12,8 \%$ \\
\hline Cruzeiro & $12,9 \%$ & $11,2 \%$ & $6,8 \%$ & $9,1 \%$ & $9,45 \%$ & $9,6 \%$ & $8,4 \%$ & $14,6 \%$ & $13,2 \%$ & $11,4 \%$ & $10,7 \%$ \\
\hline Samambaia & $9,5 \%$ & $10,9 \%$ & $10,3 \%$ & $9,9 \%$ & $10,0 \%$ & $11,7 \%$ & $9,6 \%$ & $9,7 \%$ & $10,7 \%$ & $10,3 \%$ & $10,3 \%$ \\
\hline Candangolândia & $13,2 \%$ & $9,4 \%$ & $9,0 \%$ & $9,3 \%$ & $11,9 \%$ & $13,8 \%$ & $10,1 \%$ & $13,1 \%$ & $11,7 \%$ & $10,9 \%$ & $11,2 \%$ \\
\hline R. das Emas & $8,2 \%$ & $9,6 \%$ & $7,0 \%$ & $7,0 \%$ & $7,4 \%$ & $7,7 \%$ & $6,5 \%$ & $8,3 \%$ & $8,2 \%$ & $8,8 \%$ & $7,9 \%$ \\
\hline Tx Média Anual & $11,6 \%$ & $12,3 \%$ & $11,3 \%$ & $10,9 \%$ & $11,2 \%$ & $11,3 \%$ & $11,0 \%$ & $12,3 \%$ & $11,7 \%$ & $12,1 \%$ & $11,6 \%$ \\
\hline
\end{tabular}

Fonte de dados: SES/DF, CODEPLAN, MS/SVS/CGIAE/SIM, IBGE.

Elaboração: NATAL, 2015. 


\section{3 - Correlações Mensais das Variáveis Climáticas com os óbitos por doenças do aparelho circulatório no Distrito Federal de 2003 a 2012.}

A seguir apresentam-se anualmente as análises realizadas das correlações entre as variáveis climáticas (precipitação pluviométrica; pressão atmosférica; umidade relativa do ar e temperaturas máxima, mínima e média) com os dados de registros de óbitos por doenças do aparelho circulatório notificados pela Secretaria de Estado de Saúde do Distrito Federal de 2003 a 2012.

Para o ano de 2003, analisando a Figura 21 das variáveis climatológicas e os óbitos por doenças do aparelho circulatório mostram uma relação inversa com a temperatura máxima, mínima, média, precipitação e umidade relativa do ar, exceto, para a pressão atmosférica que apontam uma relação direta.

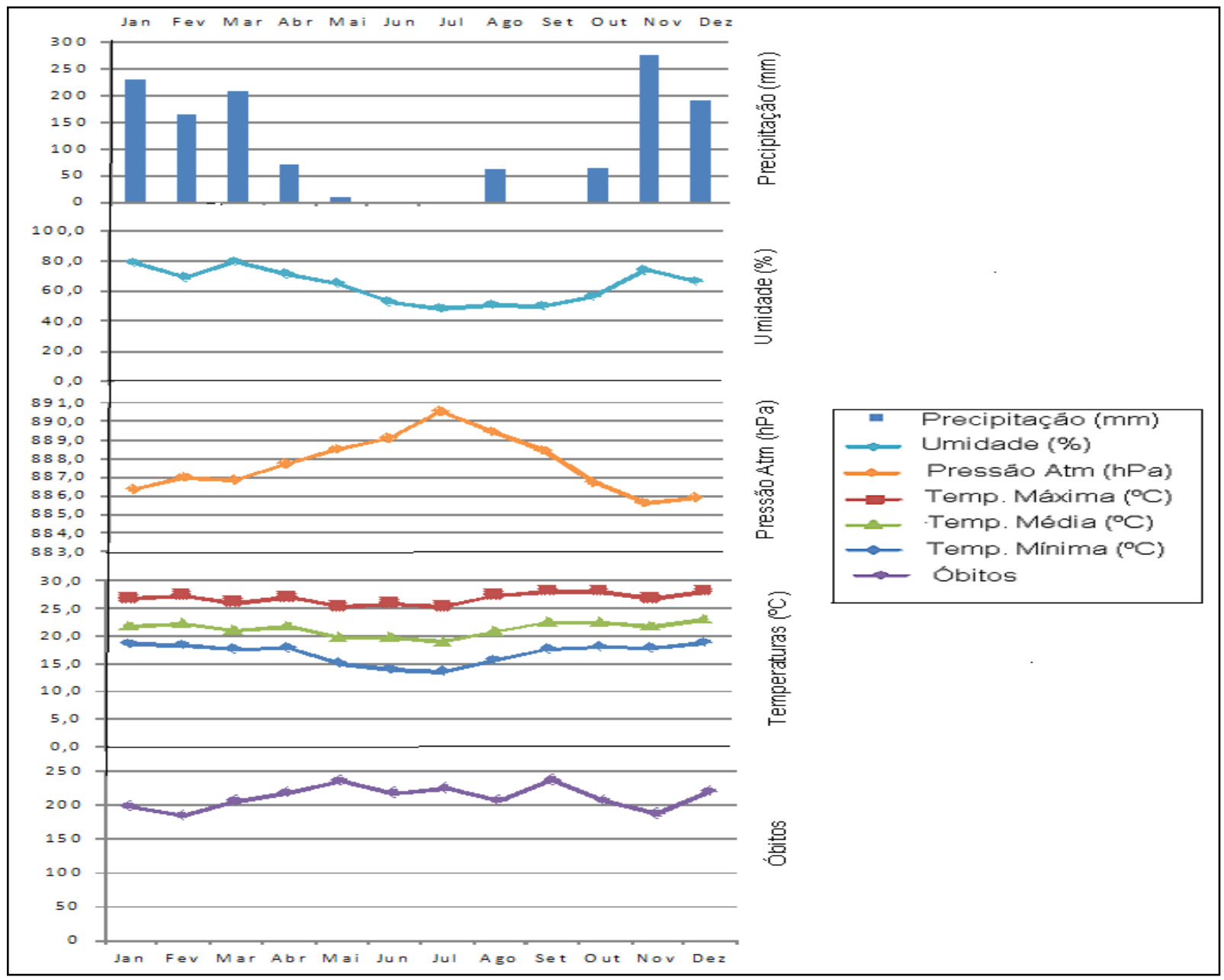

Figura 21 - Relações entre as variáveis climatológicas e os óbitos por doenças do aparelho circulatório mensais em 2003, no Distrito Federal. Fonte dos dados: INMET, SES/DF, CODEPLAN, MS/SVS/CGIAE/SIM, IBGE. Elaboração: NATAL, 2015. 
Ao analisarmos a Tabela 09 os coeficientes de correlação e determinação mostram na classificação que o ano de 2003, os óbitos por doenças do aparelho circulatório tiveram maior correlação direta com a pressão atmosférica confirmada pelo valor positivo do coeficiente de correlação $(R=50)$, e o coeficiente de determinação $\left(R^{2}=0,30\right)$ indicou que $30 \%$ dos casos de óbitos por doenças do aparelho circulatório tiveram correlação com os altos valores da pressão atmosférica, classificada como uma correlação de classificação "Média". Já a umidade relativa do ar teve a maior correlação inversa confirmada pelo valor negativo do coeficiente de correlação $(R=-49)$, onde o coeficiente de determinação $\left(R^{2}=0,24\right)$ indicou que $24 \%$ dos casos de óbitos por doenças do aparelho circulatório tiveram correlação inversa com os valores baixos da temperatura. Nesta análise a temperatura média e a mínima tiveram classificação no coeficiente de determinação uma correlação de classificação "Média" e na temperatura máxima e precipitação, a classificação do coeficiente de determinação foi "Fraca", Figura 21 e Tabela 09.

Tabela 09: Valores dos coeficientes de correlação $(R)$, de determinação $\left(R^{2}\right)$ e classificação $(C)$ encontrados entre as variáveis climatológicas e os números de óbitos mensais por doenças circulatórias ocorridas no Distrito Federal, 2003.

\begin{tabular}{cccc} 
Variáveis Climáticas & \multicolumn{3}{c}{ Obitos em Geral } \\
& $\mathbf{R}$ & $\mathbf{R}^{\mathbf{2}}$ & $\mathbf{C}$ \\
\hline Precipitação $(\mathrm{mm})$ & $-0,70$ & 0,04 & Forte \\
\hline Pressão Atm $(\mathrm{hPa})$ & 0,54 & 0,30 & Média \\
\hline Temp. Máxima $\left({ }^{\circ} \mathrm{C}\right)$ & $-0,17$ & 0,03 & Fraca \\
\hline Temp. Mínima $\left({ }^{\circ} \mathrm{C}\right)$ & $-0,44$ & 0,19 & Média \\
\hline Temp. Média $\left({ }^{\circ} \mathrm{C}\right)$ & $-0,31$ & 0,10 & Média \\
\hline Umidade rel. do ar $(\%)$ & $-0,49$ & 0,24 & Média
\end{tabular}

Fonte dos dados: INMET, SES/DF, CODEPLAN, MS/SVS/CGIAE/SIM, IBGE. Elaboração: NATAL, 2015.

Na Figura 22 observa-se que o gráfico de regressão no ano de 2003, a pressão atmosférica foi a variável que mais influenciou nos casos de óbitos por doenças do aparelho circulatório. Podemos verificar nesta variável que a linha de tendência inclinada para cima confirma que a relação é direta, ou seja, a pressão atmosférica teve influência direta sobre os casos de óbitos neste ano pesquisado. 
Nesta mesma figura, podemos observar que na temperatura mínima, média e na umidade relativa do ar a reta está ligeiramente inclinada para baixo confirmando a relação inversa dessas variáveis com os casos de óbitos. Na precipitação e temperatura máxima a reta mantem sua posição horizontal indicando "Fraca" relação com as duas variáveis.
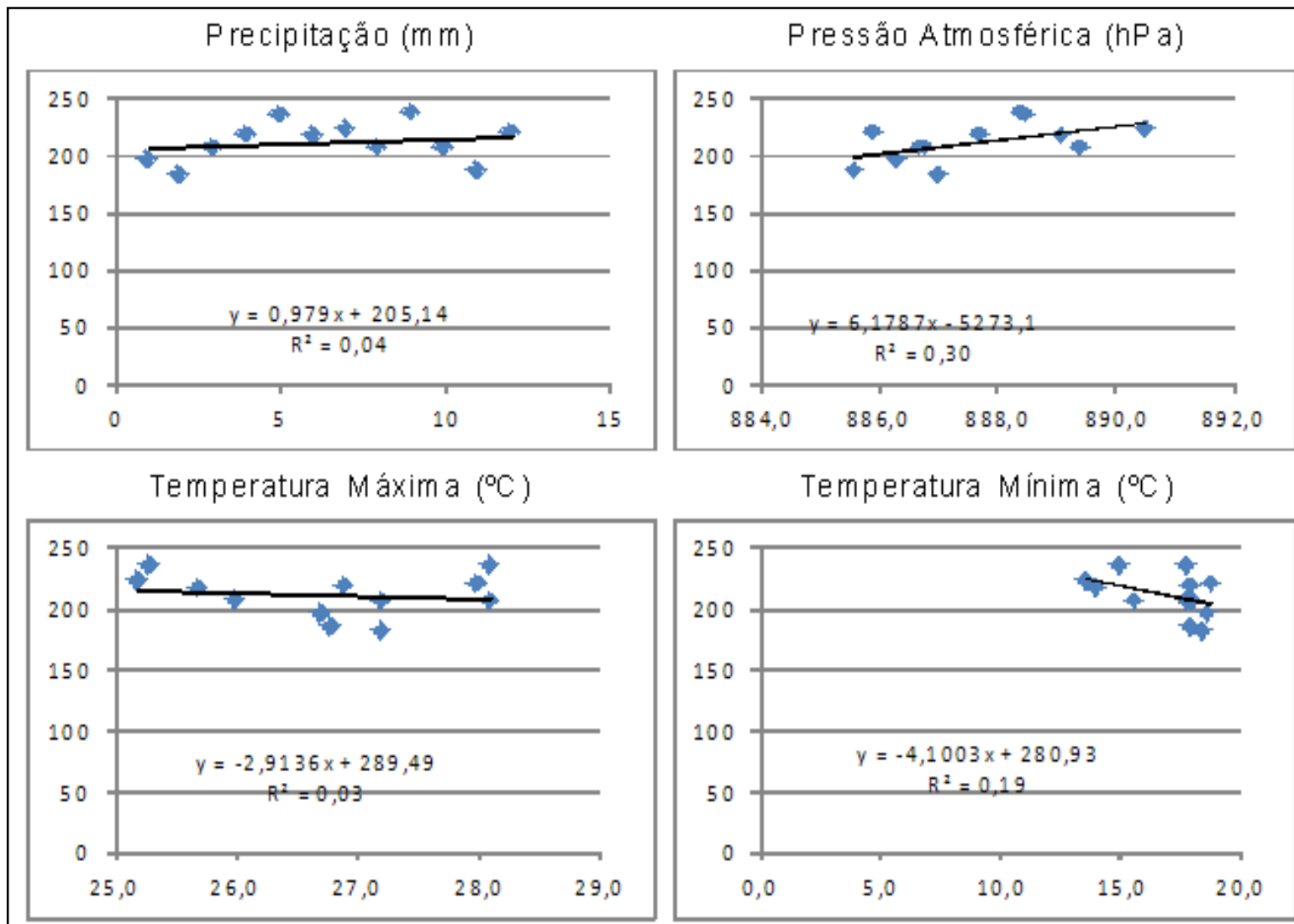

Temperatura Mínima $\left({ }^{\circ} \mathrm{C}\right)$

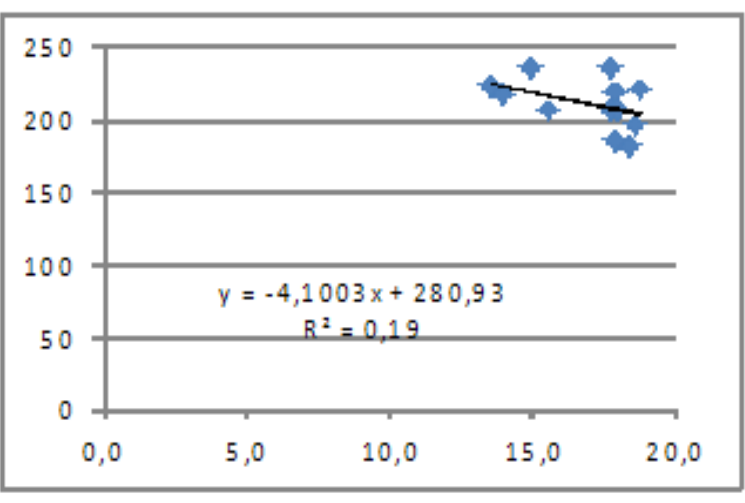

Temperatura Média $\left({ }^{\circ} \mathrm{C}\right)$

Umidade Relativa do Ar (\%)
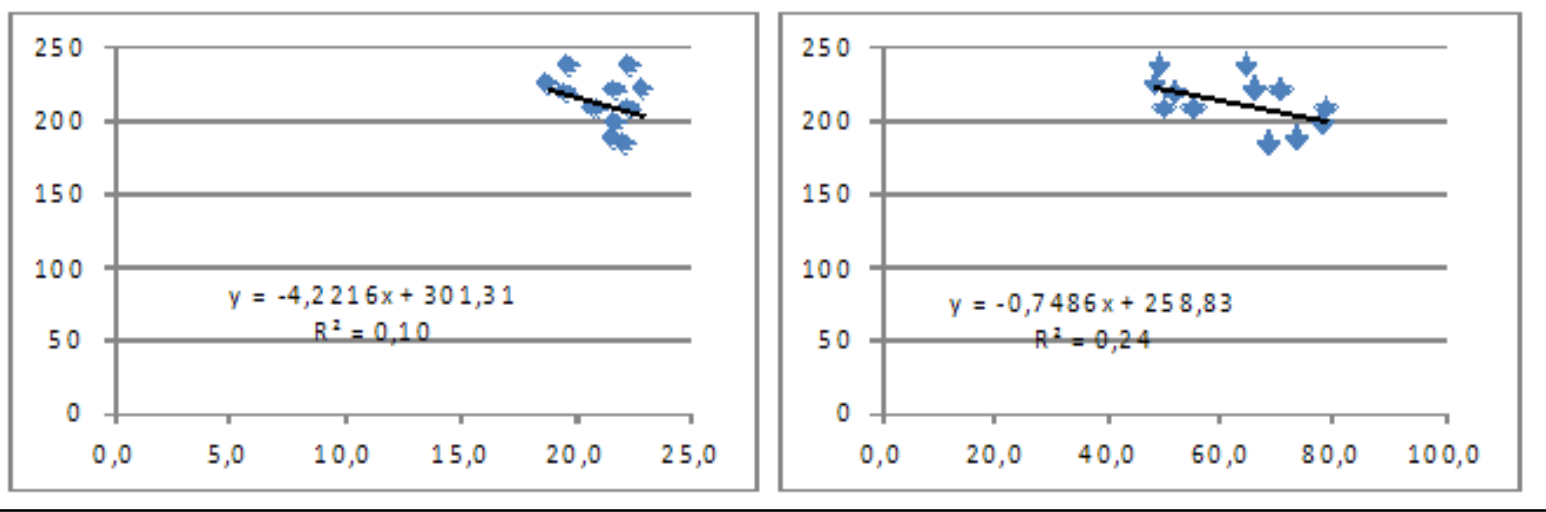

Figura 22 - Regressão entre as variáveis climatológicas e os casos de óbitos por doenças do aparelho circulatório na população humana de todas as idades e sexo, em 2003, no Distrito Federal. Fonte dos dados: INMET, SES/DF, CODEPLAN, MS/SVS/CGIAE/SIM, IBGE. Elaboração: NATAL, 2015. 
Para o ano de 2004, analisando a Figura 23 das variáveis climatológicas e os óbitos por doenças do aparelho circulatório há uma relação inversa com a temperatura máxima, mínima, média, precipitação, exceto, para a pressão atmosférica que aponta uma relação direta.

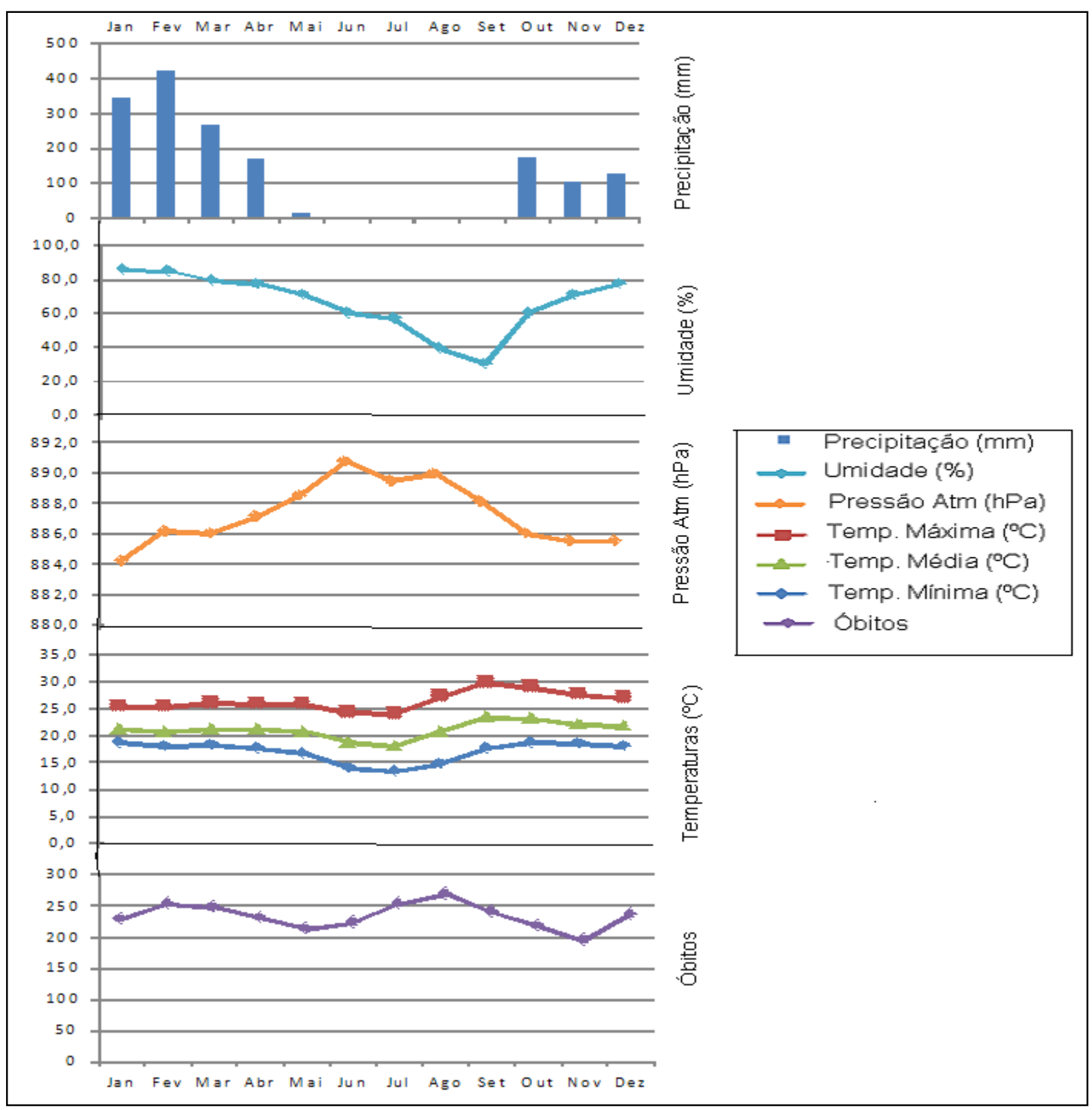

Figura 23 - Relações entre as variáveis climatológicas e os óbitos por doenças do aparelho circulatório mensais em 2004, no Distrito Federal. Fonte dos dados: INMET, SES/DF, CODEPLAN, MS/SVS/CGIAE/SIM, IBGE. Elaboração: NATAL, 2015.

Ao analisarmos a Tabela 10 os coeficientes de correlação e determinação mostram, na classificação que o ano de 2004, que os óbitos por doenças do 
aparelho circulatório tiveram maior correlação inversa com a temperatura mínima, confirmada negativa no coeficiente de correlação $(R=-39)$, e o coeficiente de determinação $\left(R^{2}=15\right)$ indicando que $15 \%$ dos casos de óbitos por doenças do aparelho circulatório tiveram correlação com os baixos valores da temperatura, classificada como "Média". Já a pressão atmosférica teve uma correlação direta, confirmada pelo valor positivo do coeficiente de correlação $(R=30)$, e o coeficiente de determinação $\left(R^{2}=0,09\right)$ indicou que $9 \%$ dos casos de óbitos por doenças do aparelho circulatório tiveram correlação direta com os valores altos da pressão atmosférica. Nesta análise a temperatura máxima, média, precipitação e a umidade relativa do ar tiveram classificação no coeficiente de determinação "Fraca", Tabela 10.

Tabela 10: Valores dos coeficientes de correlação $(R)$, de determinação $\left(R^{2}\right)$ e classificação $(C)$, encontrados entre as variáveis climatológicas e os números de óbitos mensais por doenças circulatórias ocorridas no Distrito Federal, ano de 2004.

\begin{tabular}{cccc} 
Variáveis Climáticas & \multicolumn{3}{c}{ Obitos em Geral } \\
& $\mathbf{R}$ & $\mathbf{R}^{\mathbf{2}}$ & $\mathbf{C}$ \\
\hline Precipitação $(\mathrm{mm})$ & 0,07 & 0,01 & Fraca \\
\hline Pressão Atm $(\mathrm{hPa})$ & 0,30 & 0,09 & Média \\
\hline Temp. Máxima $\left({ }^{\circ} \mathrm{C}\right)$ & $-0,15$ & 0,02 & Fraca \\
\hline Temp. Mínima $\left({ }^{\circ} \mathrm{C}\right)$ & $-0,39$ & 0,15 & Média \\
\hline Temp. Média $\left({ }^{\circ} \mathrm{C}\right)$ & $-0,28$ & 0,08 & Fraca \\
\hline Umidade rel. do ar $(\%)$ & $-0,27$ & 0,07 & Fraca
\end{tabular}

Fonte dos dados: INMET, SES/DF, CODEPLAN, MS/SVS/CGIAE/SIM, IBGE. Elaboração: NATAL, 2015.

Na Figura 24 observa-se que o gráfico de regressão no ano de 2004, a temperatura mínima foi a variável que mais influenciou nos casos de óbitos por doenças do aparelho circulatório. Podemos verificar nesta variável que a reta inclinada para baixo confirma que a relação é inversa já que a temperatura mínima teve influência inversa sobre os casos de óbitos neste ano pesquisado. Nesta mesma figura, podemos observar que na temperatura máxima, média e na umidade relativa do ar a reta está ligeiramente inclinada para baixo, confirmando a relação 
inversa "Fraca" dessas variáveis com os casos de óbitos. Na precipitação a reta mantem sua posição horizontal indicando "Fraca" ou "Nula" relação com essa variável.

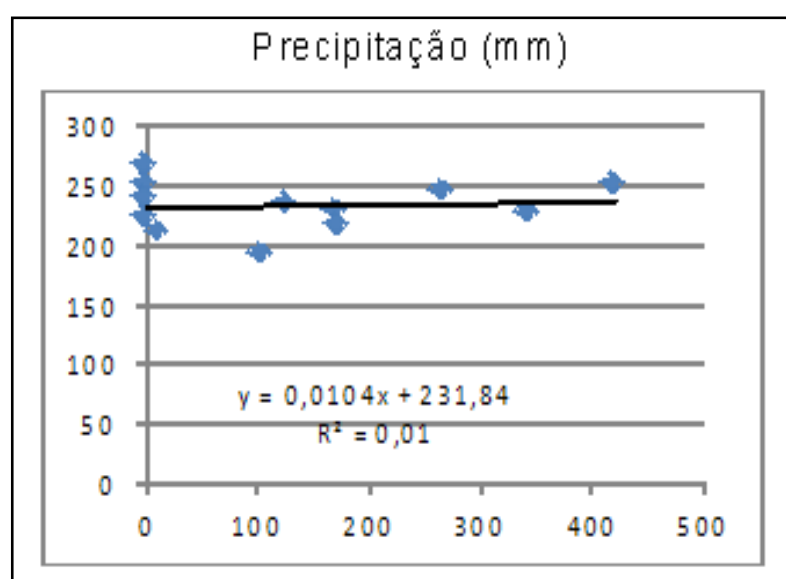

Temperatura Máxima $\left({ }^{\circ} \mathrm{C}\right)$

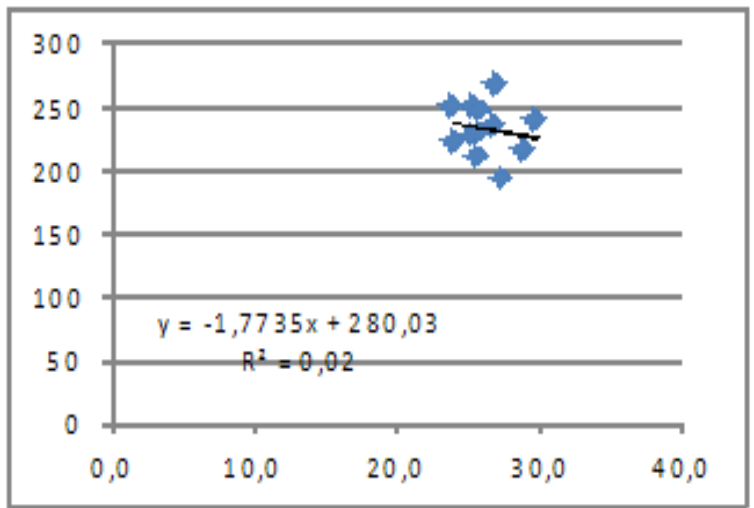

Temperatura Média $\left({ }^{\circ} \mathrm{C}\right)$

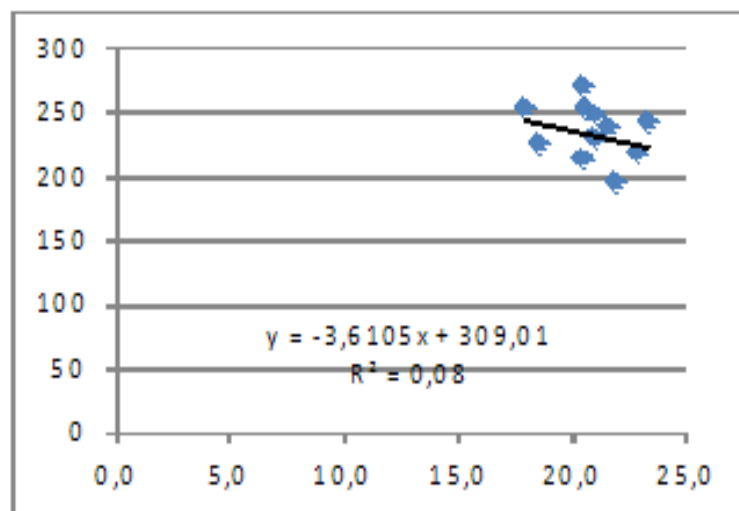

Pressẵo A tmostérica ( $\mathrm{hPa}$ )

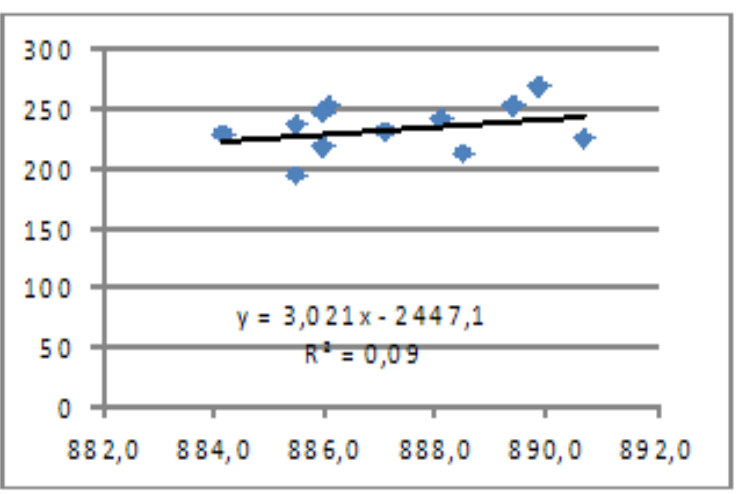

Temperatura Mínima $\left({ }^{\circ} \mathrm{C}\right)$

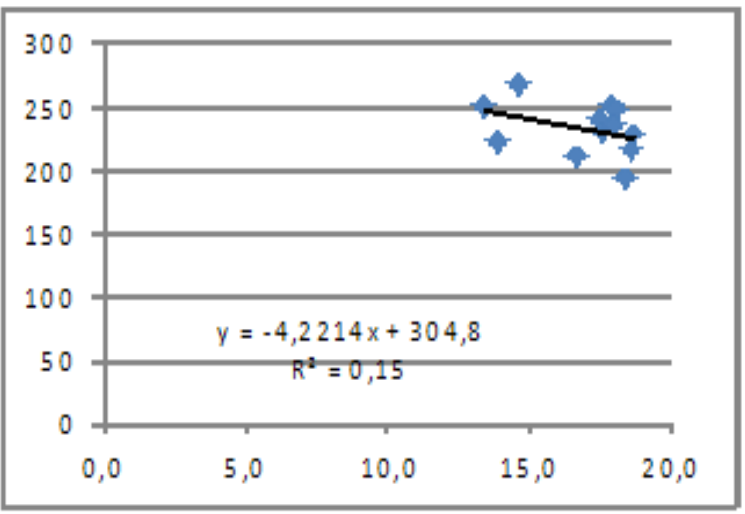

Umidade Relativa do Ar (\%)

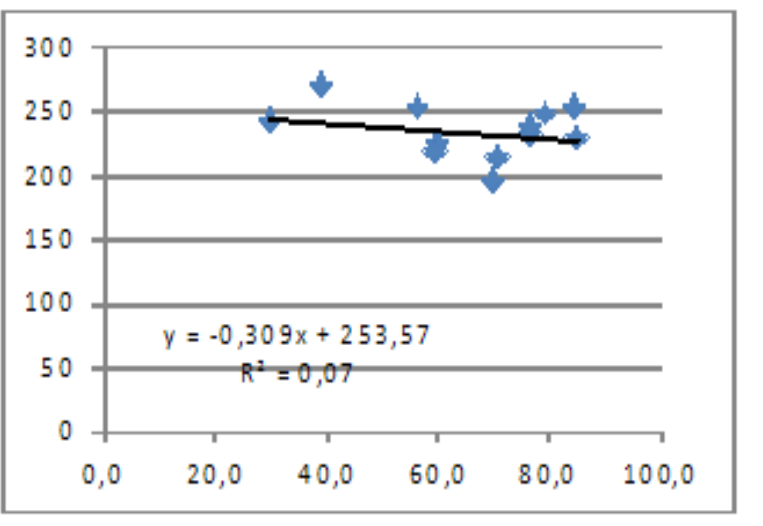

Figura 24 - Regressão entre as variáveis climatológicas e os casos de óbitos por doenças do aparelho circulatório na população humana de todas as idades e sexo, em 2004, no Distrito Federal. Fonte dos dados: INMET, SES/DF, CODEPLAN, MS/SVS/CGIAE/SIM, IBGE. Elaboração: NATAL, 2015. 
Para o ano de 2005, analisando a Figura $\mathbf{2 5}$ as variáveis climatológicas e os óbitos por doenças do aparelho circulatório mostram uma relação inversa com as temperaturas máxima, mínima, média, e fraca ou nula para precipitação e umidade relativa do ar, exceto para a pressão atmosférica que aponta uma relação direta forte.

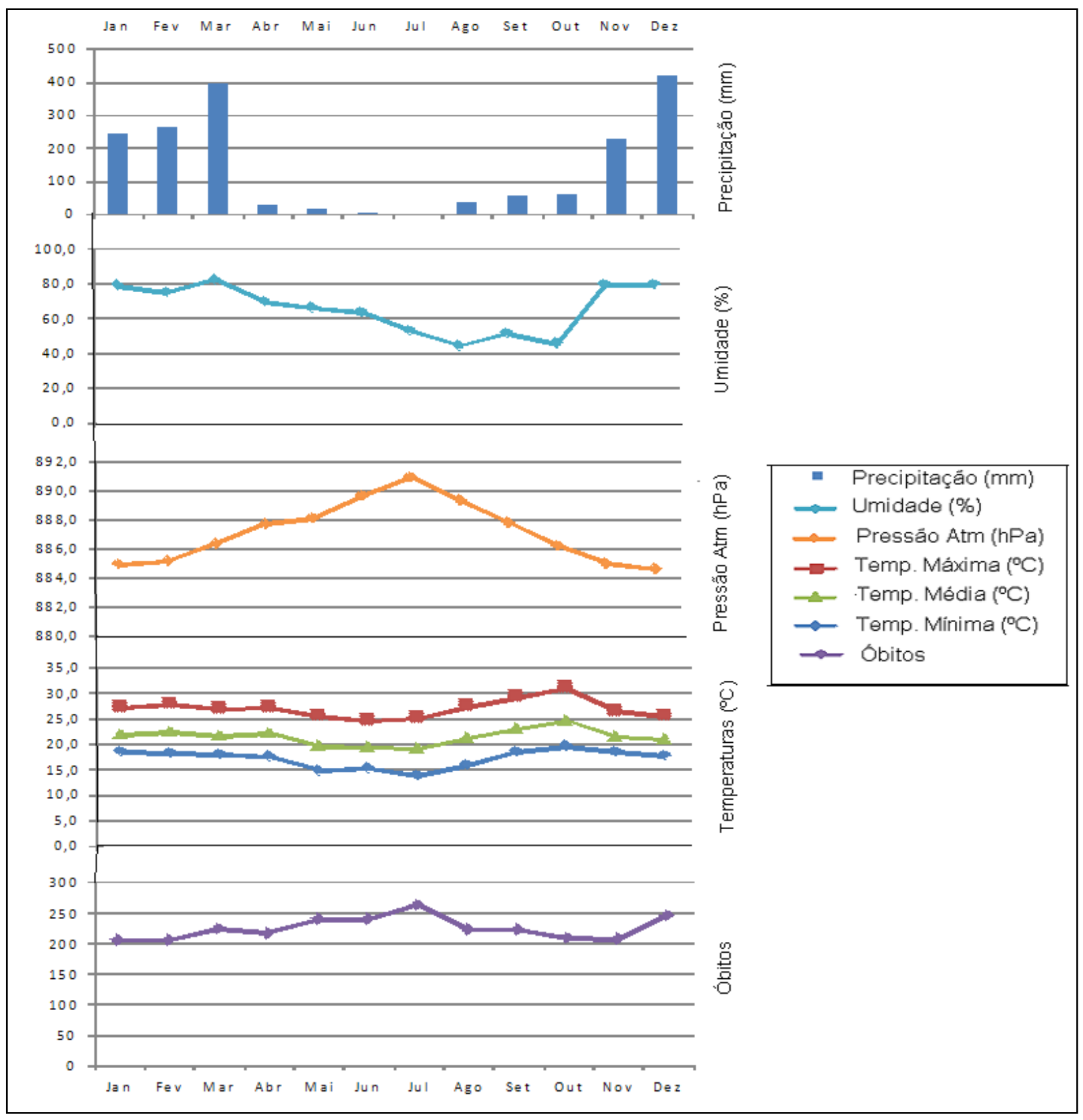

Figura 25 - Relações entre as variáveis climatológicas e os óbitos por doenças do aparelho circulatório mensais em 2005, no Distrito Federal. Fonte dos dados: INMET, SES/DF, CODEPLAN, MS/SVS/CGIAE/SIM, IBGE. Elaboração: NATAL, 2015.

Ao analisarmos a Tabela 11 os coeficientes de correlação e determinação mostram na classificação que o ano de 2005, os óbitos por doenças do aparelho 
circulatório tiveram maior correlação inversa com as temperaturas mínima, média e máxima, sendo que a temperatura mínima foi a variável que apresentou a maior correlação inversa, confirmada pelo valor negativo do coeficiente de correlação $(R=-$ $78)$, e o coeficiente de determinação $\left(R^{2}=62\right)$ indicou que $62 \%$ dos casos de óbitos por doenças do aparelho circulatório tiveram correlação com os baixos valores da temperatura, classificada como "Forte". Já a pressão atmosférica teve a correlação direta, confirmada positiva no coeficiente de correlação $(R=61)$, e o coeficiente de determinação $\left(R^{2}=0,38\right)$ que indicou $38 \%$ dos casos de óbitos por doenças do aparelho circulatório tiveram correlação direta com os valores altos da pressão atmosférica. Nesta análise a precipitação e a umidade relativa do ar tiveram a classificação no coeficiente de determinação "Fraca", Tabela 11.

Tabela 11: Valores dos coeficientes de correlação $(R)$, de determinação $\left(R^{2}\right)$ e classificação $(C)$, encontrados entre as variáveis climatológicas e os números de óbitos mensais por doenças circulatórias ocorridas no Distrito Federal, ano de 2005.

\begin{tabular}{cccc} 
Variáveis Climáticas & \multicolumn{3}{c}{ Obitos em Geral } \\
Precipitação $(\mathrm{mm})$ & $-0,19$ & $\mathbf{R}^{\mathbf{2}}$ & $\mathbf{C}$ \\
\hline Pressão Atm $(\mathrm{hPa})$ & 0,61 & 0,04 & Fraca \\
\hline Temp. Máxima $\left({ }^{\circ} \mathrm{C}\right)$ & $-0,67$ & 0,38 & Forte \\
\hline Temp. Mínima $\left({ }^{\circ} \mathrm{C}\right)$ & $-0,78$ & 0,45 & Forte \\
\hline Temp. Média $\left({ }^{\circ} \mathrm{C}\right)$ & $-0,75$ & 0,62 & Forte \\
\hline Umidade rel. do ar $(\%)$ & $-0,18$ & 0,56 & Forte \\
\hline
\end{tabular}

Fonte dos dados: INMET, SES/DF, CODEPLAN, MS/SVS/CGIAE/SIM, IBGE. Elaboração: NATAL, 2015.

Na Figura 26 observa-se que o gráfico de regressão no ano de 2005, as temperaturas mínima, média e máxima foram as variáveis que mais influenciaram nos casos de óbitos por doenças do aparelho circulatório. Podemos verificar que nestas variáveis que a reta inclinada para baixo, confirma que a relação é inversa, já que as temperaturas mínima, média e máxima tiveram influência inversa sobre os casos de óbitos neste ano pesquisado. Na pressão atmosférica a relação com os óbitos por doenças do aparelho circulatório foi de relação direta, verificado nesta variável que a reta inclinada para cima confirma que a relação é direta, ou seja, a 
pressão atmosférica teve influência direta sobre os casos de óbitos neste ano pesquisado. Ainda, nesta figura, podemos observar que na precipitação e umidade relativa do ar a reta mantém sua posição horizontal, indicando "Fraca" ou "Nula" relação com essas duas variáveis.

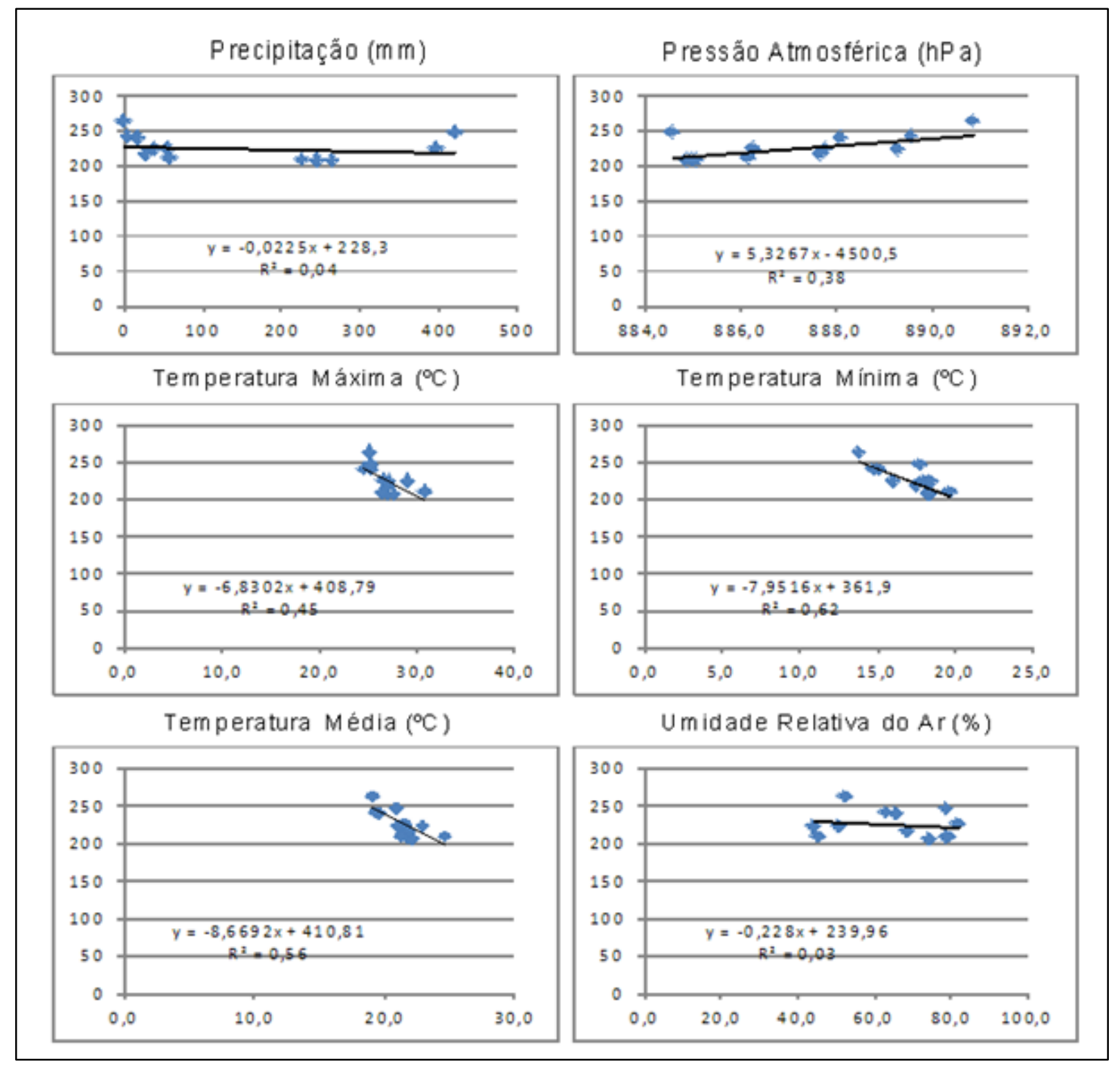

Figura 26 - Regressão entre as variáveis climatológicas e os casos de óbitos por doenças do aparelho circulatório na população humana de todas as idades e sexo, em 2005, no Distrito Federal. Fonte dos dados: INMET, SES/DF, CODEPLAN, MS/SVS/CGIAE/SIM, IBGE. Elaboração: NATAL, 2015.

Para o ano de 2006, analisando a Figura 27 das variáveis climatológicas e os óbitos por doenças do aparelho circulatório mostraram uma relação inversa forte com as temperaturas máxima, mínima e média e relação fraca ou nula para precipitação e umidade relativa do ar, exceto para a pressão atmosférica que aponta uma relação direta e tendo correlação de classificação média. 


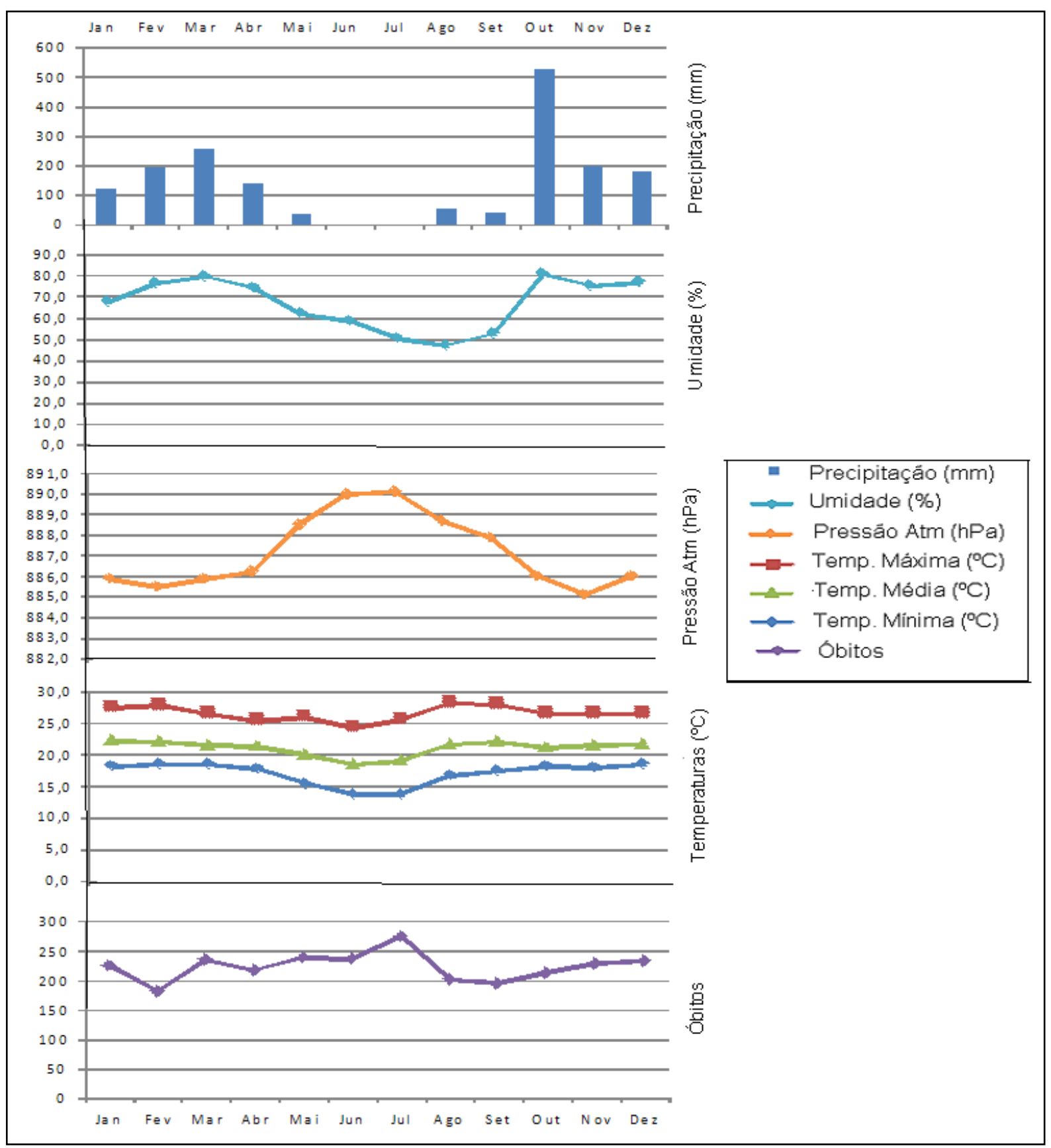

Figura 27 - Relações entre as variáveis climatológicas e os óbitos por doenças do aparelho circulatório mensais em 2006, no Distrito Federal. Fonte dos dados: INMET, SES/DF, CODEPLAN, MS/SVS/CGIAE/SIM, IBGE. Elaboração: NATAL, 2015.

Ao analisarmos a Tabela 12, os coeficientes de correlação e determinação mostraram na classificação que o ano de 2006, os óbitos por doenças do aparelho circulatório tiveram maior correlação inversa com as temperaturas máxima, média e mínima, sendo que a temperatura máxima foi a variável que apresentou a maior correlação inversa, confirmada pelo valor negativo do coeficiente de correlação ( $R=$ $68)$, e o coeficiente de determinação $\left(R^{2}=47\right)$ indicou que $47 \%$ dos casos de óbitos 
por doenças do aparelho circulatório tiveram correlação com os altos valores da temperatura, classificada como "Forte". Já a pressão atmosférica teve a correlação direta, confirmada positiva no coeficiente de correlação $(R=43)$, e o coeficiente de determinação $\left(R^{2}=0,18\right)$ o qual indicou que $18 \%$ dos casos de óbitos por doenças do aparelho circulatório tiveram correlação direta com os valores altos da pressão atmosférica. Nesta análise a precipitação e a umidade relativa do ar tiveram a classificação no coeficiente de determinação "Fraca", Tabela 12.

Tabela 12: Valores dos coeficientes de correlação $(R)$, de determinação $\left(R^{2}\right)$ e classificação (C), encontrados entre as variáveis climatológicas e os números de óbitos mensais por doenças circulatórias ocorridas no Distrito Federal, ano de 2006.

\begin{tabular}{cccc}
\hline Variáveis Climáticas & $\mathbf{R}$ & Obitos em Geral & \\
& $-0,26$ & $\mathbf{R}^{\mathbf{2}}$ & $\mathbf{C}$ \\
\hline Precipitação $(\mathrm{mm})$ & 0,07 & Fraca \\
\hline Pressão Atm $(\mathrm{hPa})$ & 0,43 & 0,18 & Média \\
\hline Temp. Máxima $\left({ }^{\circ} \mathrm{C}\right)$ & $-0,68$ & 0,47 & Forte \\
\hline Temp. Mínima $\left({ }^{\circ} \mathrm{C}\right)$ & $-0,59$ & 0,34 & Forte \\
\hline Temp. Média $\left({ }^{\circ} \mathrm{C}\right)$ & $-0,67$ & 0,46 & Forte \\
\hline Umidade rel. do ar $(\%)$ & $-0,16$ & 0,03 & Fraca
\end{tabular}

Fonte dos dados: INMET, SES/DF, CODEPLAN, MS/SVS/CGIAE/SIM, IBGE. Elaboração: NATAL, 2015.

Na Figura 27 observa-se que o gráfico de regressão no ano de 2006, as temperaturas máxima, média e mínima foram as variáveis que mais influenciaram nos casos de óbitos por doenças do aparelho circulatório. Podemos verificar que nestas variáveis que a reta inclinada para baixo, confirma que a relação é inversa, ou seja, as temperaturas máxima, média e mínima tiveram influência inversa sobre os casos de óbitos neste ano pesquisado. Na pressão atmosférica a relação com os óbitos por doenças do aparelho circulatório foi de relação direta, verificado nesta variável que a reta inclinada para cima confirma que a relação é direta, ou seja, a pressão atmosférica teve influência direta sobre os casos de óbitos neste ano pesquisado. Ainda, nesta figura, podemos observar que na precipitação e umidade relativa do ar a reta mantem sua posição horizontal, indicando "Fraca" ou "Nula" relação com essas duas variáveis. 


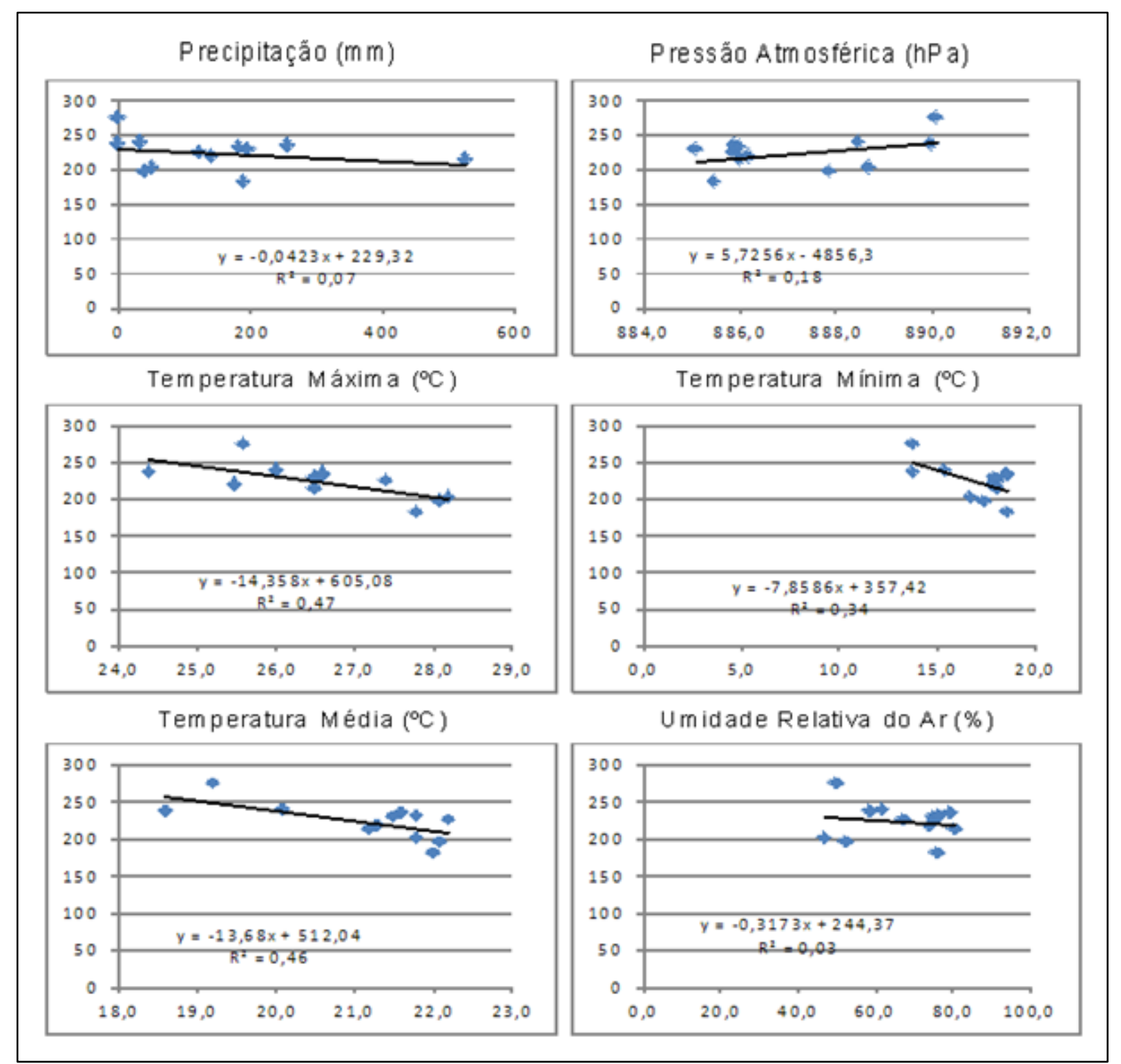

Figura 28 - Regressão entre as variáveis climatológicas e os casos de óbitos por doenças do aparelho circulatório na população humana de todas as idades e sexo, em 2006, no Distrito Federal. Fonte dos dados: INMET, SES/DF, CODEPLAN, MS/SVS/CGIAE/SIM, IBGE. Elaboração: NATAL, 2015.

Para o ano de 2007, analisando a Figura 29 das variáveis climatológicas e os óbitos por doenças do aparelho circulatório, mostram que este ano as temperaturas tiveram uma fraca relação com os óbitos por doenças do aparelho circulatório, numa relação inversa fraca com as temperaturas máxima, e média e relação inversa média com a temperatura mínima, precipitação e umidade relativa do ar, exceto para a pressão atmosférica que aponta uma relação direta média. 


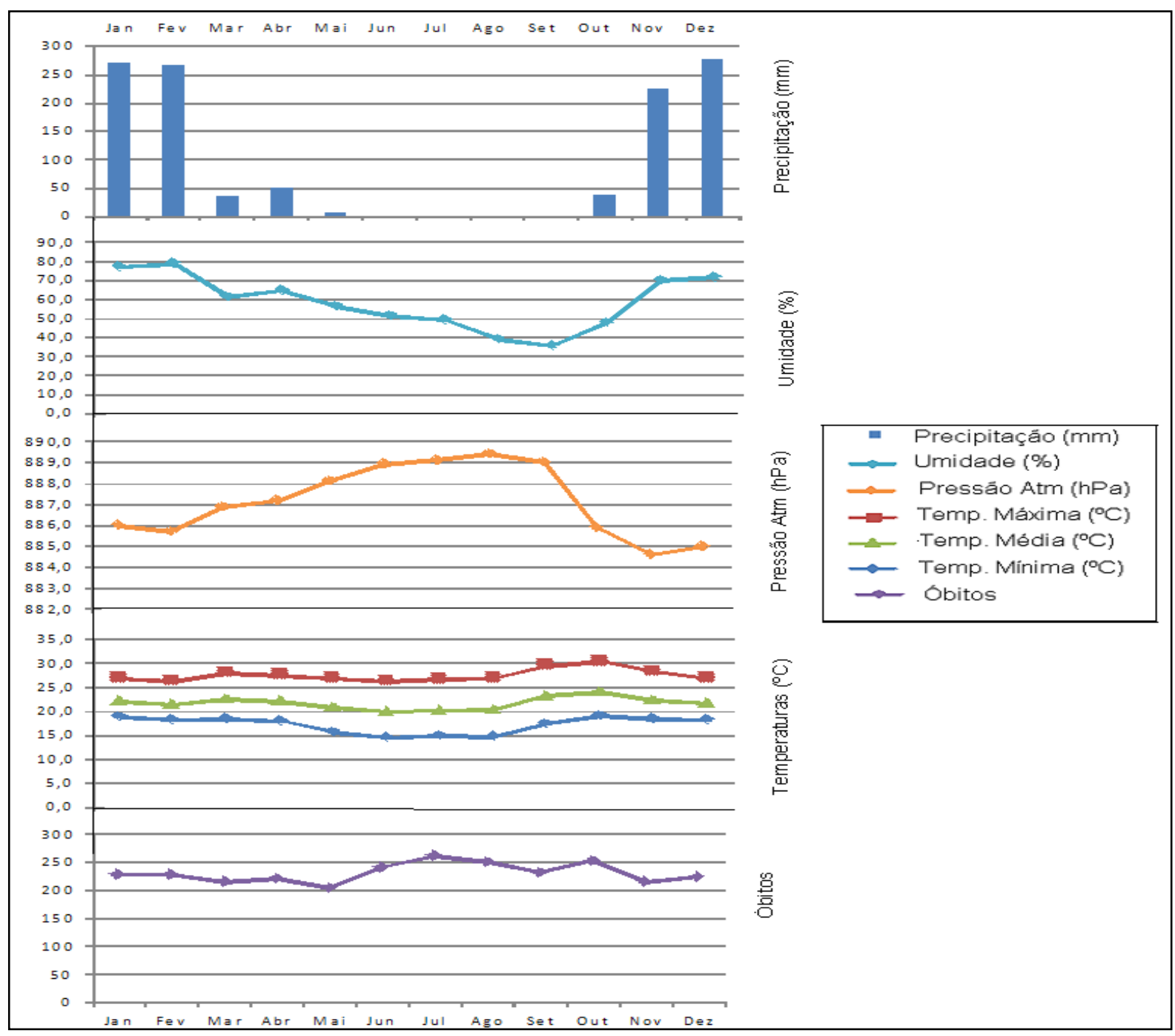

Figura 29 - Relações entre as variáveis climatológicas e os óbitos por doenças do aparelho circulatório mensais em 2007, no Distrito Federal. Fonte dos dados: INMET, SES/DF, CODEPLAN, MS/SVS/CGIAE/SIM, IBGE. Elaboração: NATAL, 2015.

Ao analisarmos a Tabela 12, os coeficientes de correlação e determinação mostram na classificação que o ano de 2007, os óbitos por doenças do aparelho circulatório tiveram fraca correlação com as temperaturas máxima, média e que a umidade relativa do ar apresentou a maior correlação inversa, confirmada pelo valor negativo do coeficiente de correlação $(R=-51)$, e o coeficiente de determinação $\left(R^{2}=\right.$ 26) indicando que $26 \%$ dos casos de óbitos por doenças do aparelho circulatório tiveram correlação com os baixos valores da umidade relativa do ar classificada como "Média". Já a pressão atmosférica teve a maior correlação direta, confirmada positiva no coeficiente de correlação $(R=41)$, e o coeficiente de determinação $\left(R^{2}=\right.$ $0,16)$ indicou que $16 \%$ dos casos de óbitos por doenças do aparelho circulatório tiveram correlação direta com os valores altos da pressão atmosférica. Ainda, nesta 
análise a temperatura mínima teve a maior correlação inversa da temperatura, confirmada negativa no coeficiente de correlação $(R=-37)$, e o coeficiente de determinação $\left(R^{2}=14\right)$ que indicou $14 \%$ dos casos de óbitos por doenças do aparelho circulatório tiveram correlação com os baixos valores da temperatura, classificada como "Média", Tabela 13.

Tabela 13: Valores dos coeficientes de correlação $(R)$, de determinação $\left(R^{2}\right)$ e classificação (C), encontrados entre as variáveis climatológicas e os números de óbitos mensais por doenças circulatórias ocorridas no Distrito Federal, ano de 2007.

\begin{tabular}{cccc}
\hline Variáveis Climáticas & \multicolumn{3}{c}{ Óbitos em Geral } \\
& $\mathbf{R}$ & $\mathbf{R}^{\mathbf{2}}$ & $\mathbf{C}$ \\
\hline Precipitação $(\mathrm{mm})$ & $-0,31$ & 0,10 & Média \\
\hline Pressão Atm $(\mathrm{hPa})$ & 0,41 & 0,16 & Média \\
\hline Temp. Máxima $\left({ }^{\circ} \mathrm{C}\right)$ & 0,09 & 0,01 & Fraca \\
\hline Temp. Mínima $\left(^{\circ} \mathrm{C}\right)$ & $-0,37$ & 0,14 & Média \\
\hline Temp. Média $\left({ }^{\circ} \mathrm{C}\right)$ & $-0,18$ & 0,03 & Fraca \\
\hline Umidade rel. do ar $(\%)$ & $-0,51$ & 0,26 & Média
\end{tabular}

Fonte dos dados: INMET, SES/DF, CODEPLAN, MS/SVS/CGIAE/SIM, IBGE. Elaboração: NATAL, 2015.

Na Figura 30 observa-se que o gráfico de regressão no ano de 2007, a umidade relativa do ar foi a variável que mais influenciou nos casos de óbitos por doenças do aparelho circulatório. Podemos verificar que nesta variável a reta inclinada para baixo confirma que a relação é inversa, ou seja, a umidade relativa do ar teve influência inversa sobre os casos de óbitos neste ano pesquisado. $\mathrm{Na}$ pressão atmosférica a relação com os óbitos por doenças do aparelho circulatório foi de relação direta, verificado nesta variável que a reta está levemente inclinada para cima, confirmando que a relação é direta, pois a pressão atmosférica teve influência direta sobre os casos de óbitos neste ano pesquisado. Ainda, nesta figura, podemos observar que na precipitação, temperatura máxima e média a reta mantém sua posição horizontal, indicando "Fraca" ou "Nula" relação com essas três variáveis e que a temperatura mínima a reta está levemente inclinada para baixo, confirmando que a relação é inversa, indicando "Média" influência sobre os casos de óbitos neste ano pesquisado. 


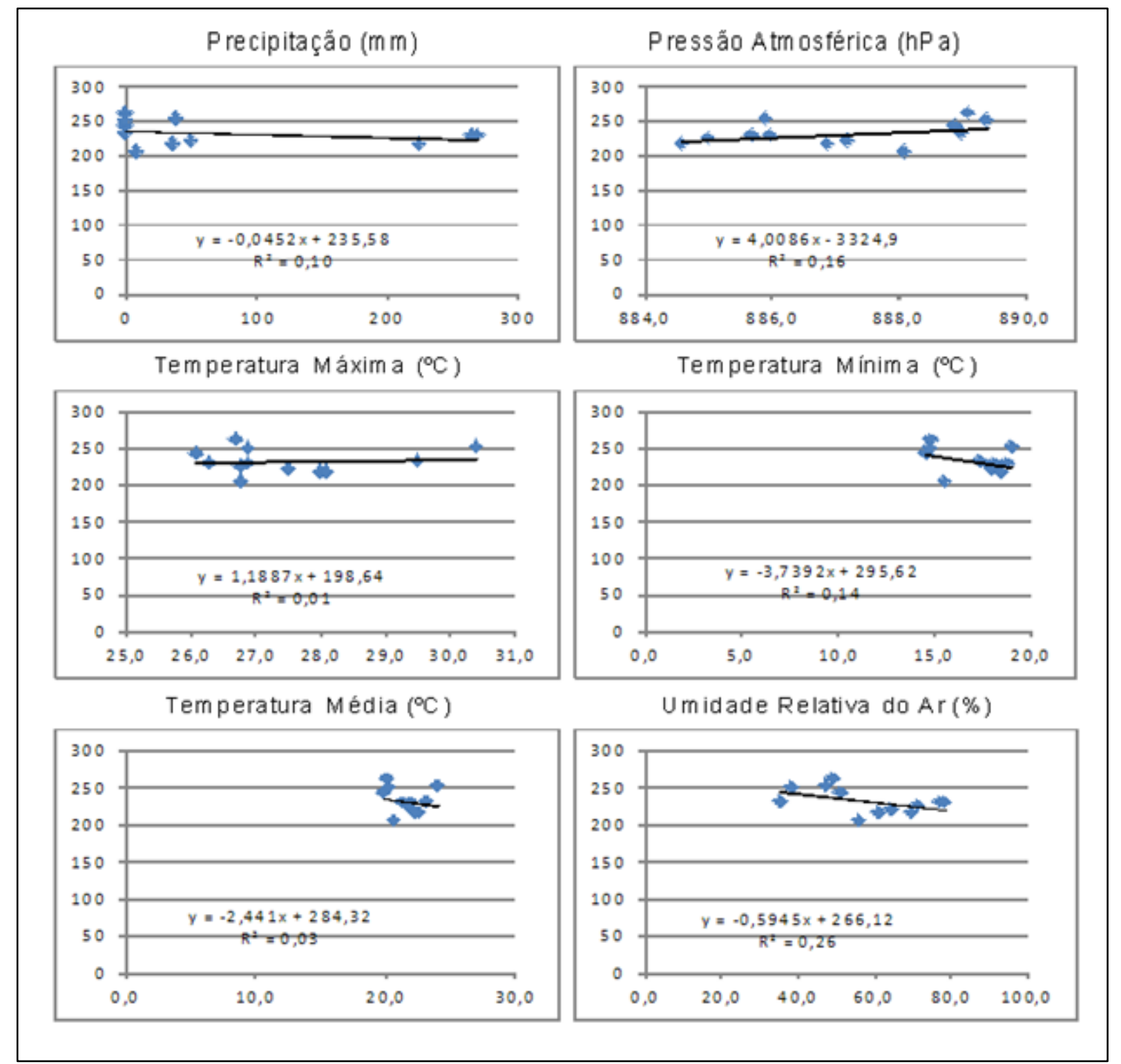

Figura 30 - Regressão entre as variáveis climatológicas e os casos de óbitos por doenças do aparelho circulatório na população humana de todas as idades e sexo, em 2007, no Distrito Federal. Fonte dos dados: INMET, SES/DF, CODEPLAN, MS/SVS/CGIAE/SIM, IBGE. Elaboração: NATAL, 2015.

Para o ano de 2008, analisando a Figura 31 das variáveis climatológicas e os óbitos por doenças do aparelho circulatório, há uma relação inversa com as temperaturas máxima, média e mínima e com a precipitação e umidade relativa do ar, exceto para a pressão atmosférica que aponta uma relação direta média. 


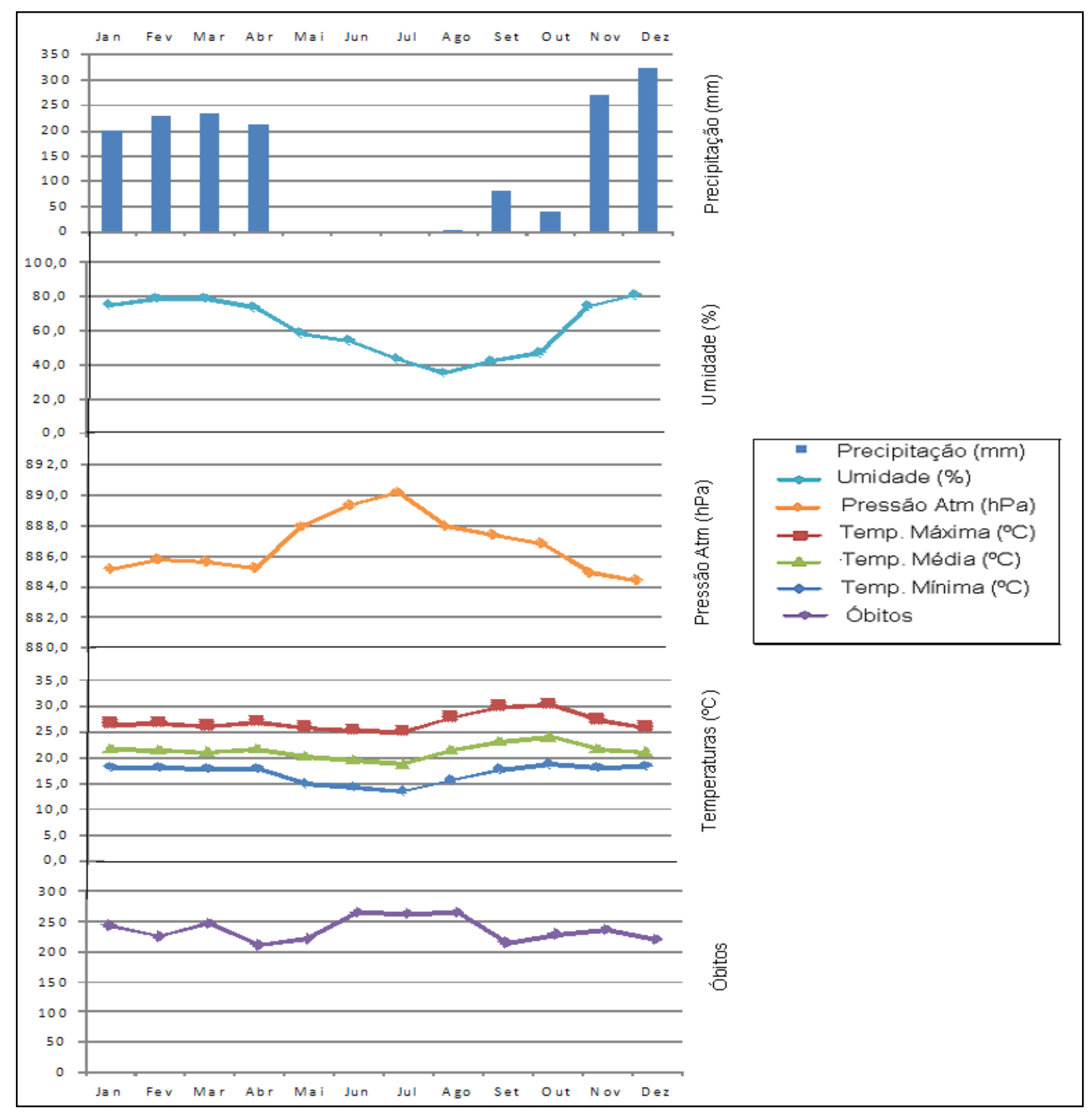

Figura 31 - Relações entre as variáveis climatológicas e os óbitos por doenças do aparelho circulatório mensais em 2008, no Distrito Federal. Fonte dos dados: INMET, SES/DF, CODEPLAN, MS/SVS/CGIAE/SIM, IBGE. Elaboração: NATAL, 2015.

Ao analisarmos a Tabela 14, os coeficientes de correlação e determinação mostraram na classificação que o ano de 2008 que os óbitos por doenças do aparelho circulatório tiveram maior correlação inversa, com precipitação, umidade relativa do ar e com as temperaturas máxima, média e mínima, sendo que a temperatura mínima foi a variável que apresentou a maior correlação inversa, confirmada pelo valor negativo do coeficiente de correlação $(R=-65)$, e o coeficiente de determinação $\left(R^{2}=42\right)$ que indicou $42 \%$ dos casos de óbitos por doenças do 
aparelho circulatório tiveram correlação com os baixos valores da temperatura, classificada como "Forte". Já a pressão atmosférica teve a correlação direta, confirmada positiva no coeficiente de correlação $(R=59)$, e o coeficiente de determinação $\left(R^{2}=0,35\right)$ indicou que $35 \%$ dos casos de óbitos por doenças do aparelho circulatório tiveram correlação direta com os valores altos da pressão atmosférica, Tabela 14.

Tabela 14: Valores dos coeficientes de correlação $(R)$, de determinação $\left(R^{2}\right)$ e classificação $(\mathrm{C})$, encontrados entre as variáveis climatológicas e os números de óbitos mensais por doenças circulatórias ocorridas no Distrito Federal, ano de 2008.

\begin{tabular}{cccc}
\hline Variáveis Climáticas & \multicolumn{3}{c}{ Obitos em Geral } \\
Precipitação $(\mathrm{mm})$ & $-0,45$ & $\mathbf{R}^{\mathbf{2}}$ & $\mathbf{C}$ \\
\hline Pressão Atm $(\mathrm{hPa})$ & 0,59 & 0,21 & Média \\
\hline Temp. Máxima $\left({ }^{\circ} \mathrm{C}\right)$ & $-0,41$ & 0,35 & Média \\
\hline Temp. Mínima $\left({ }^{\circ} \mathrm{C}\right)$ & $-0,65$ & 0,17 & Média \\
\hline Temp. Média $\left({ }^{\circ} \mathrm{C}\right)$ & $-0,53$ & 0,42 & Forte \\
\hline Umidade rel. do ar $(\%)$ & $-0,39$ & 0,28 & Média \\
\hline
\end{tabular}

Fonte dos dados: INMET, SES/DF, CODEPLAN, MS/SVS/CGIAE/SIM, IBGE. Elaboração: NATAL, 2015.

Na Figura 32 observa-se que o gráfico de regressão no ano de 2008, as temperaturas máxima, média e mínima foram as variáveis que mais influenciaram nos casos de óbitos por doenças do aparelho circulatório. Podemos verificar que nestas variáveis que a reta inclinada para baixo confirma que a relação é inversa, ou seja, as temperaturas máxima, média e mínima tiveram influência inversa sobre os casos de óbitos neste ano pesquisado. Na pressão atmosférica a relação com os óbitos por doenças do aparelho circulatório foi de relação direta, verificando nesta variável que a reta inclinada para cima confirma que a relação é direta, pois a pressão atmosférica teve influência direta sobre os casos de óbitos neste ano pesquisado. Ainda, nesta figura, podemos observar que na precipitação e umidade relativa do ar, a reta esta levemente inclinada para baixo, confirma que a relação é 
inversa, indicando "Média" influência sobre os casos de óbitos neste ano pesquisado.

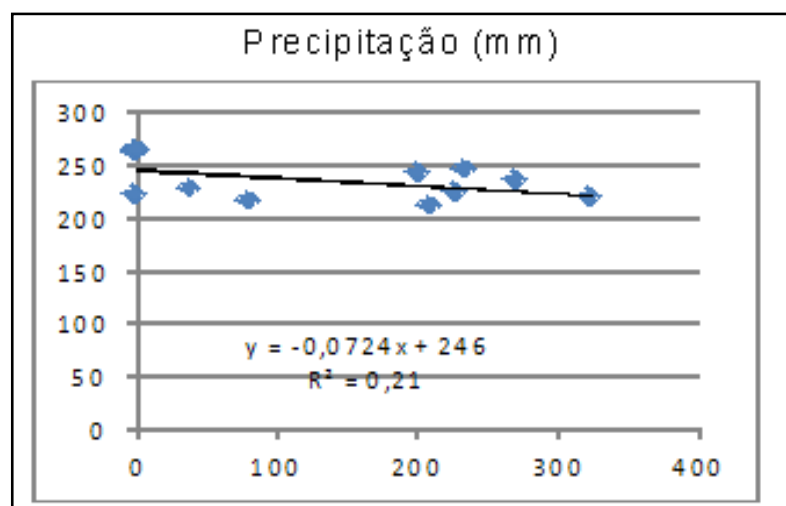

Temperatura Máxima $\left({ }^{\circ} \mathrm{C}\right)$

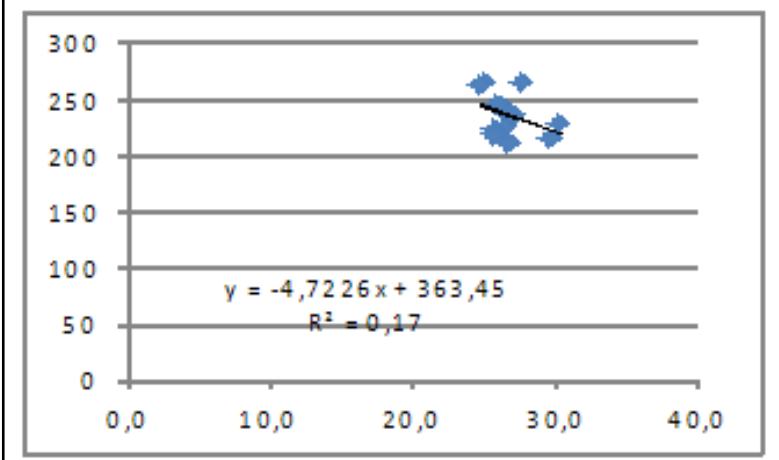

Temperatura Média $\left({ }^{\circ} \mathrm{C}\right)$

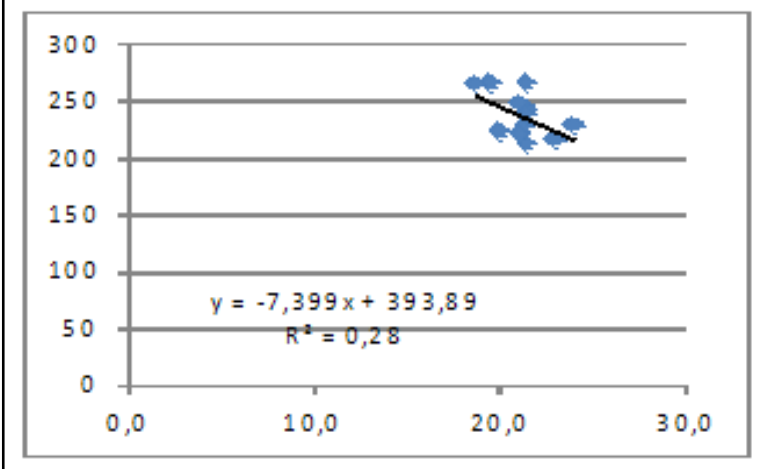

Pressäo Atmosférica ( $\mathrm{hPa}$ )

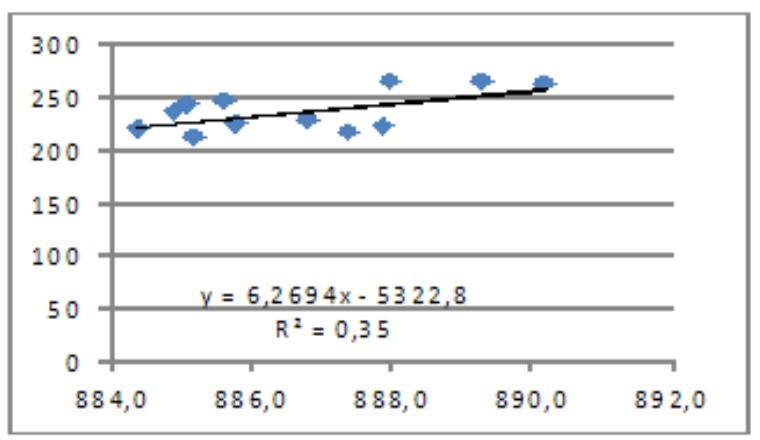

Temperatura Mínima $\left({ }^{\circ} \mathrm{C}\right)$

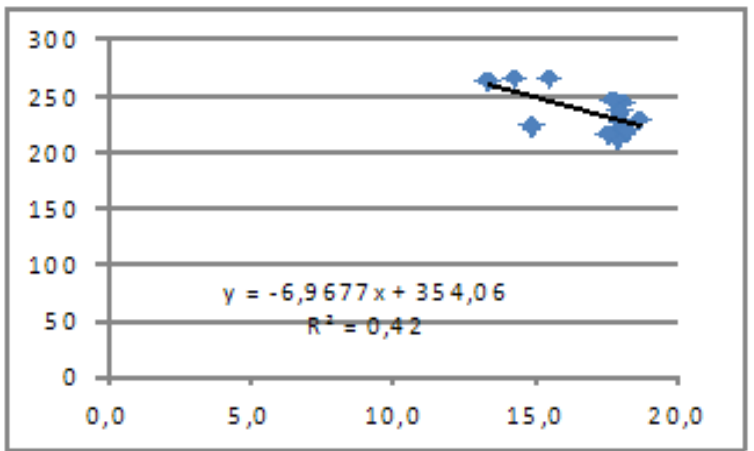

U midade Relativa do Ar (\%)

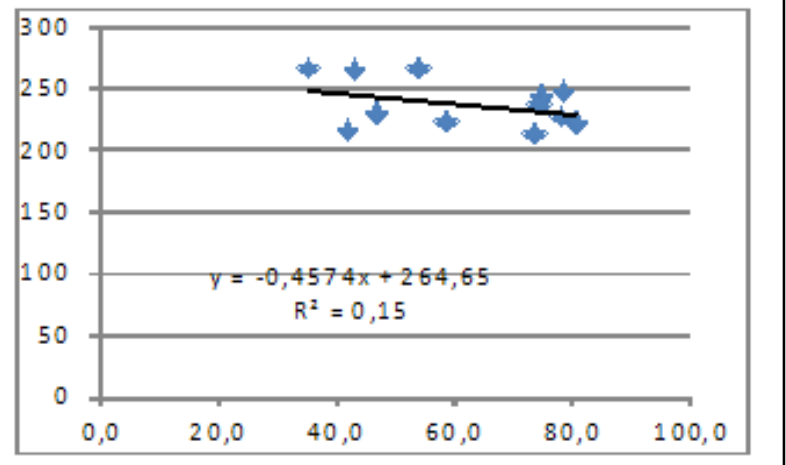

Figura 32 - Regressão entre as variáveis climatológicas e os casos de óbitos por doenças do aparelho circulatório na população humana de todas as idades e sexo, em 2008, no Distrito Federal. Fonte dos dados: INMET, SES/DF, CODEPLAN, MS/SVS/CGIAE/SIM, IBGE. Elaboração: NATAL, 2015.

Para o ano de 2009, analisando a Figura 33 das variáveis climatológicas e os óbitos por doenças do aparelho circulatório, há uma relação inversa com a precipitação, umidade relativa do ar e com as temperaturas máxima, média e mínima, exceto para a pressão atmosférica que aponta uma relação direta. 


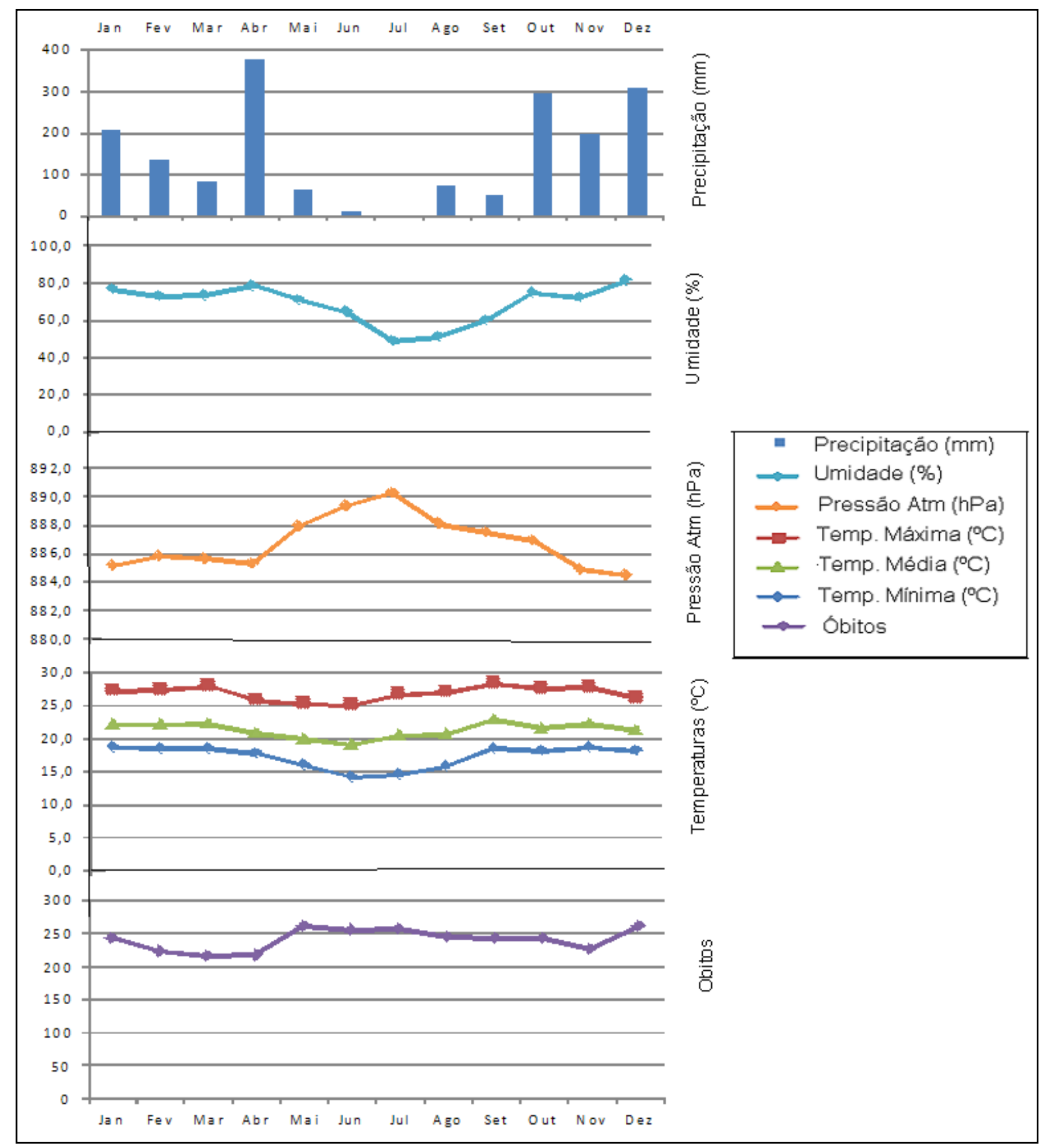

Figura 33 - Relações entre as variáveis climatológicas e os óbitos por doenças do aparelho circulatório mensais em 2009, no Distrito Federal. Fonte dos dados: INMET, SES/DF, CODEPLAN, MS/SVS/CGIAE/SIM, IBGE. Elaboração: NATAL, 2015.

Ao analisarmos a Tabela 14, os coeficientes de correlação e determinação mostram na classificação que o ano de 2009, os óbitos por doenças do aparelho circulatório tiveram maior correlação inversa, com precipitação, umidade relativa do ar e com as temperaturas máxima, média e mínima, sendo que a temperatura mínima foi a variável que apresentou a maior correlação inversa, confirmada pelo 
valor negativo do coeficiente de correlação $(R=-59)$, e o coeficiente de determinação $\left(R^{2}=34\right)$ indicou que $34 \%$ dos casos de óbitos por doenças do aparelho circulatório tiveram correlação com os baixos valores da temperatura, classificada como "Média". Já a pressão atmosférica teve a correlação direta, confirmada positiva no coeficiente de correlação $(R=54)$, e o coeficiente de determinação $\left(R^{2}=0,30\right)$ indicou que $30 \%$ dos casos de óbitos por doenças do aparelho circulatório tiveram correlação direta "Média" com os valores altos da pressão atmosférica, Tabela 15.

Tabela 15: Valores dos coeficientes de correlação $(R)$, de determinação $\left(R^{2}\right)$ e classificação $(\mathrm{C})$, encontrados entre as variáveis climatológicas e os números de óbitos mensais por doenças circulatórias ocorridas no Distrito Federal, ano de 2009.

\begin{tabular}{cccc}
\hline Variáveis Climáticas & \multicolumn{3}{c}{ Obitos em Geral } \\
Precipitação $(\mathrm{mm})$ & $-0,33$ & $\mathbf{R}^{\mathbf{2}}$ & $\mathbf{C}$ \\
\hline Pressão Atm $(\mathrm{hPa})$ & 0,54 & 0,11 & Média \\
\hline Temp. Máxima $\left({ }^{\circ} \mathrm{C}\right)$ & $-0,49$ & 0,30 & Média \\
\hline Temp. Mínima $\left({ }^{\circ} \mathrm{C}\right)$ & $-0,59$ & 0,24 & Média \\
\hline Temp. Média $\left({ }^{\circ} \mathrm{C}\right)$ & $-0,57$ & 0,34 & Média \\
\hline Umidade rel. do ar $(\%)$ & $-0,33$ & 0,33 & Média \\
\hline
\end{tabular}

Fonte dos dados: INMET, SES/DF, CODEPLAN, MS/SVS/CGIAE/SIM, IBGE. Elaboração: NATAL, 2015.

Na Figura 34 observa-se que o gráfico de regressão no ano de 2009, as temperaturas máxima, média e mínima foram as variáveis que mais influenciaram nos casos de óbitos por doenças do aparelho circulatório. Podemos verificar que nestas variáveis que a reta inclinada para baixo confirma que a relação é inversa, que a temperaturas máxima, média e mínima tiveram influência inversa sobre os casos de óbitos neste ano pesquisado. Na pressão atmosférica a relação com os óbitos por doenças do aparelho circulatório foi de relação direta, verificando nesta variável que a reta inclinada para cima confirma que a relação é direta, pois a pressão atmosférica teve influência direta sobre os casos de óbitos neste ano pesquisado. Ainda, nesta figura, podemos observar que na precipitação e umidade relativa do ar, a reta está levemente inclinada para baixo, confirmando que a relação 
é inversa, indicando "Média" influência sobre os casos de óbitos neste ano pesquisado.

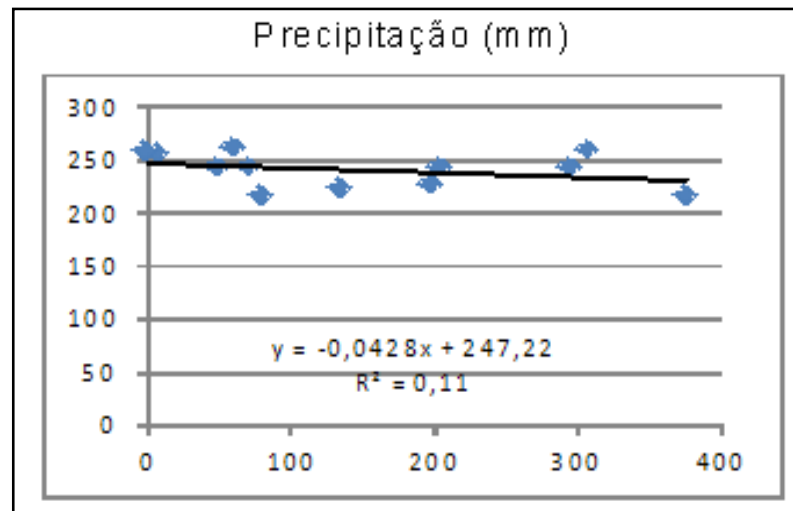

Temperatura Máxima $\left({ }^{\circ} \mathrm{C}\right)$

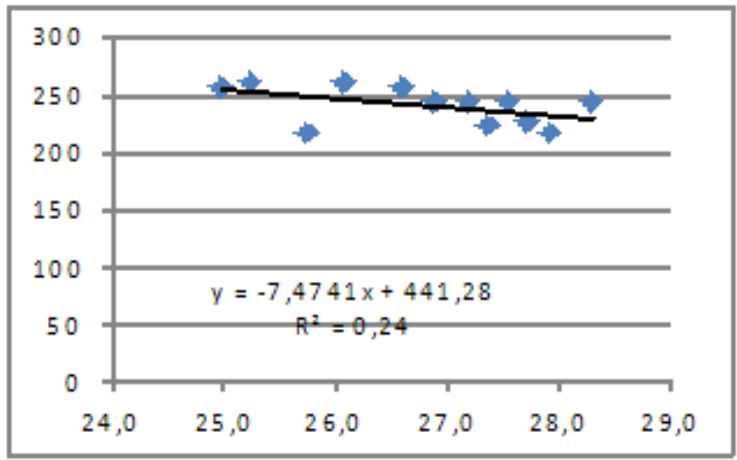

Temperatura Média $\left({ }^{\circ} \mathrm{C}\right)$

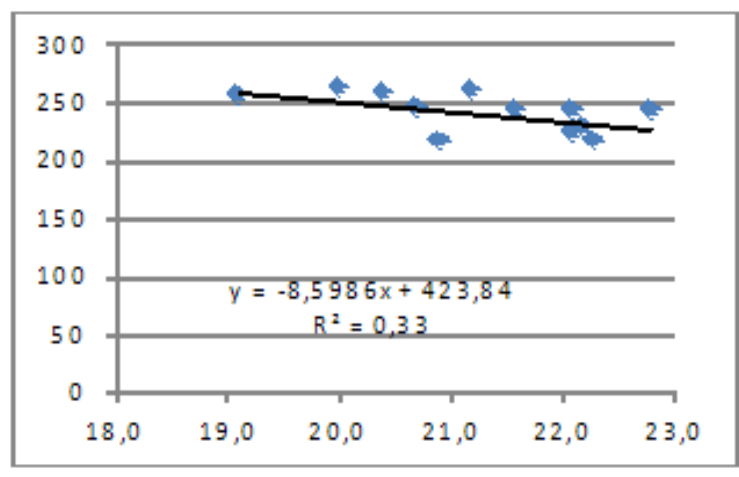

Pressẵo Atmosférica ( $\mathrm{hPa}$ )

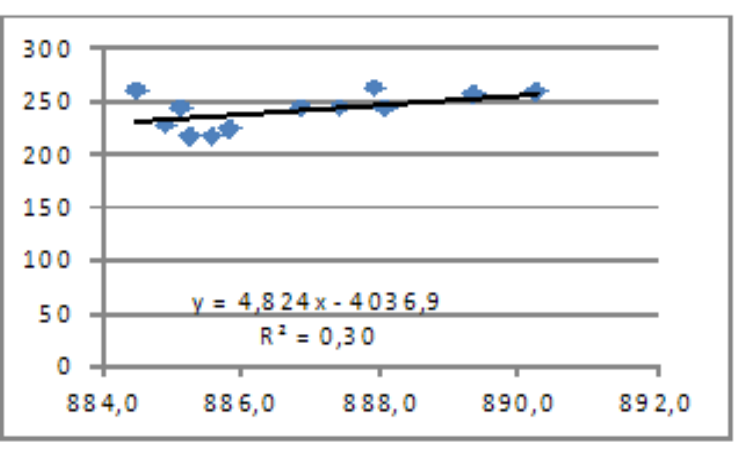

Temperatura Mínima $\left({ }^{\circ} \mathrm{C}\right)$

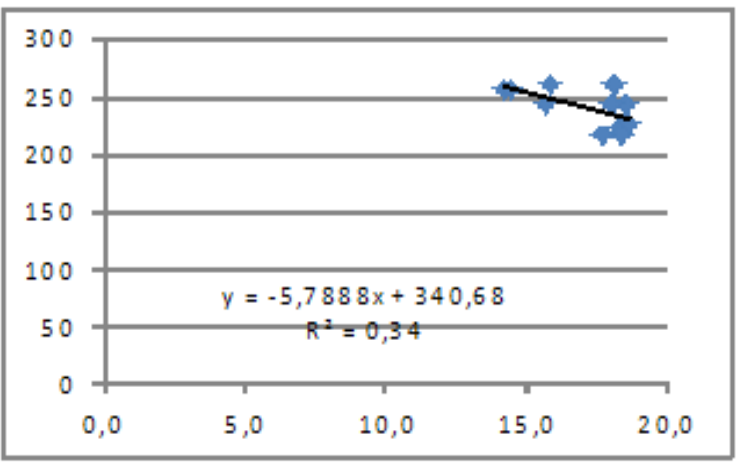

U midade Relativa do Ar (\%)

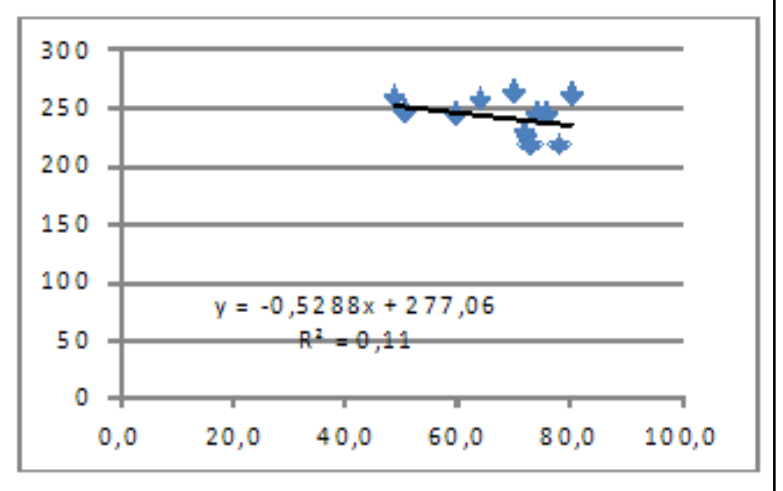

Figura 34 - Regressão entre as variáveis climatológicas e os casos de óbitos por doenças do aparelho circulatório na população humana de todas as idades e sexo, em 2009, no Distrito Federal. Fonte dos dados: INMET, SES/DF, CODEPLAN, MS/SVS/CGIAE/SIM, IBGE. Elaboração: NATAL, 2015.

Para o ano de 2010, analisando a Figura 35 das variáveis climatológicas e os óbitos por doenças do aparelho circulatório, há uma relação inversa com a com as temperaturas máxima, média e mínima, exceto para máxima a pressão atmosférica que aponta uma relação direta. 


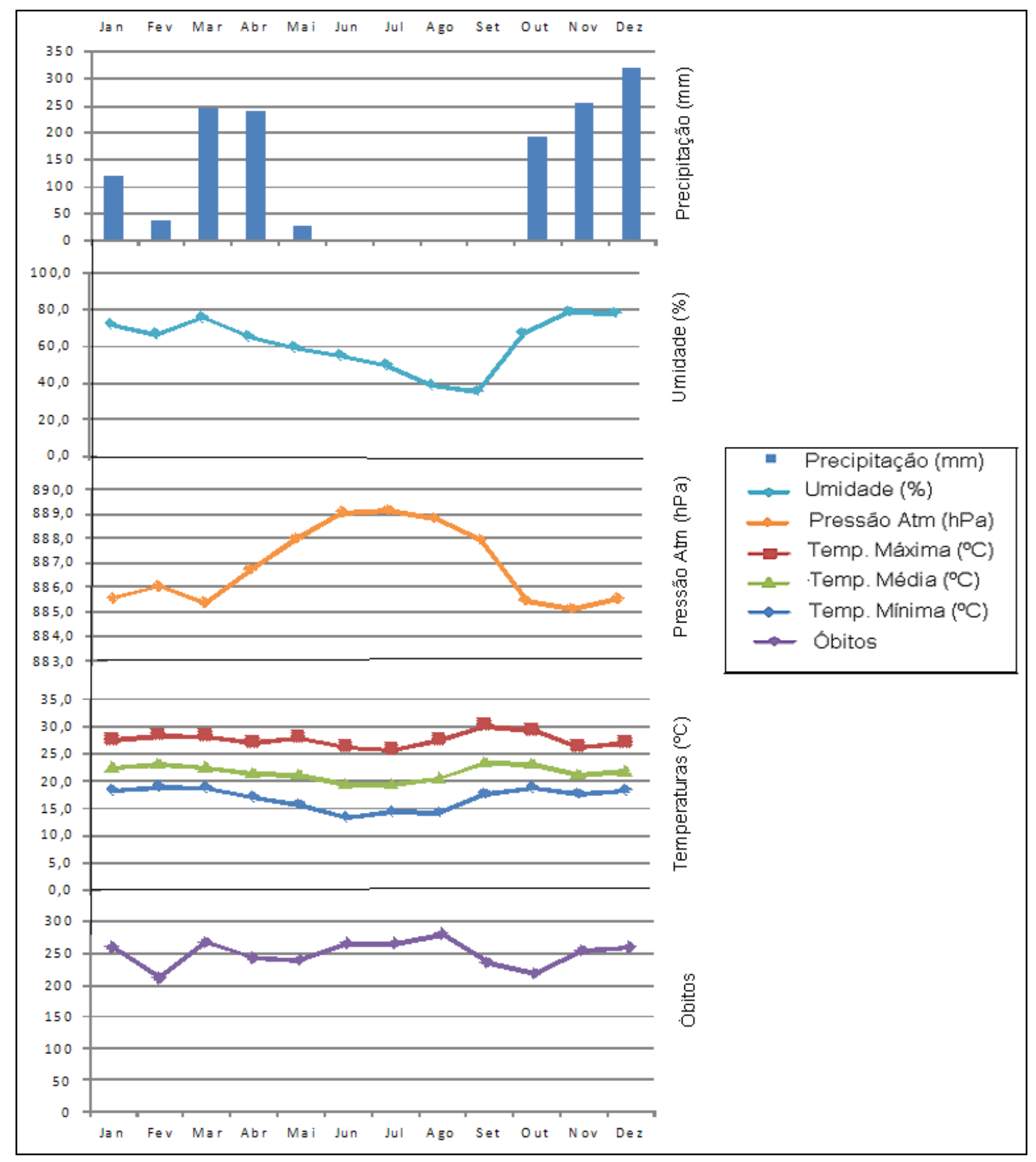

Figura 35 - Relações entre as variáveis climatológicas e os óbitos por doenças do aparelho circulatório mensais em 2010, no Distrito Federal. Fonte dos dados: INMET, SES/DF, CODEPLAN, MS/SVS/CGIAE/SIM, IBGE. Elaboração: NATAL, 2015.

Ao analisarmos a Tabela 16, os coeficientes de correlação e determinação mostraram na classificação que o ano de 2010, os óbitos por doenças do aparelho circulatório tiveram maior correlação inversa, com as temperaturas máxima, média e mínima, sendo que a temperatura média foi a variável que apresentou a maior correlação inversa, confirmada pelo valor negativo do coeficiente de correlação $(R=-$ 
65), e o coeficiente de determinação $\left(R^{2}=42\right)$ indicou que $42 \%$ dos casos de óbitos por doenças do aparelho circulatório tiveram correlação com os médios valores da temperatura, classificada como "Forte". Já a pressão atmosférica teve a correlação direta, confirmada positiva no coeficiente de correlação $(R=32)$, e o coeficiente de determinação $\left(R^{2}=0,10\right)$ que indicou $10 \%$ dos casos de óbitos por doenças do aparelho circulatório tiveram correlação direta "Média" com os valores altos da pressão atmosférica. Ainda, nesta análise a precipitação e a umidade relativa do ar tiveram correlação "Nula" e "Fraca" ,respectivamente, Tabela 16.

Tabela 16: Valores dos coeficientes de correlação $(R)$, de determinação $\left(R^{2}\right)$ e classificação $(\mathrm{C})$, encontrados entre as variáveis climatológicas e os números de óbitos mensais por doenças circulatórias ocorridas no Distrito Federal, ano de 2010.

\begin{tabular}{cccc} 
Variáveis Climáticas & \multicolumn{3}{c}{ Obitos em Geral } \\
Precipitação $(\mathrm{mm})$ & 0,02 & $\mathbf{R}^{\mathbf{2}}$ & $\mathbf{C}$ \\
\hline Pressão Atm $(\mathrm{hPa})$ & 0,32 & 0,00 & Nula \\
\hline Temp. Máxima $\left({ }^{\circ} \mathrm{C}\right)$ & $-0,61$ & 0,10 & Média \\
\hline Temp. Mínima $\left({ }^{\circ} \mathrm{C}\right)$ & $-0,53$ & 0,37 & Forte \\
\hline Temp. Média $\left({ }^{\circ} \mathrm{C}\right)$ & $-0,65$ & 0,28 & Média \\
\hline Umidade rel. do ar $(\%)$ & $-0,12$ & 0,42 & Forte \\
\hline
\end{tabular}

Fonte dos dados: INMET, SES/DF, CODEPLAN, MS/SVS/CGIAE/SIM, IBGE. Elaboração: NATAL, 2015.

Na Figura 36 observa-se que o gráfico de regressão no ano de 2010, as temperaturas máxima, média e mínima foram as variáveis que mais influenciaram nos casos de óbitos por doenças do aparelho circulatório. Podemos verificar que nestas variáveis que a reta inclinada para baixo confirma que a relação é inversa, ou seja, as temperaturas máxima, média e mínima tiveram influência inversa sobre os casos de óbitos neste ano pesquisado. Na pressão atmosférica a relação com os óbitos por doenças do aparelho circulatório foi de relação direta, verificando nesta variável que a reta inclinada para cima confirma que a relação é direta, pois a pressão atmosférica teve influência direta sobre os casos de óbitos neste ano pesquisado. Ainda, nesta figura, podemos observar que na precipitação e umidade relativa do ar a reta mantém sua posição horizontal, indicando "Fraca" ou "Nula" 
relação com essas duas variáveis nos casos de óbitos por doenças do aparelho circulatório, neste ano pesquisado.

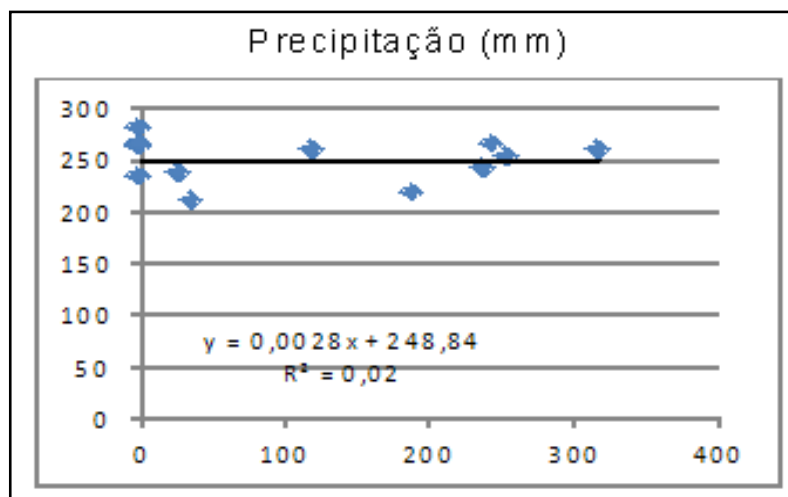

Temperatura Máxima $\left({ }^{\circ} \mathrm{C}\right)$

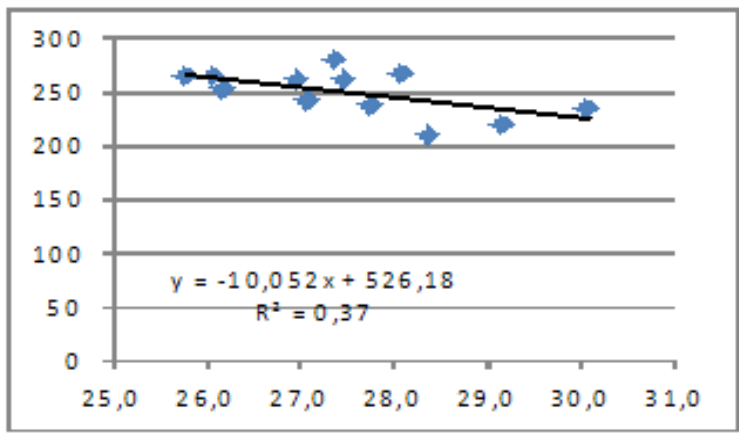

Temperatura Média $\left({ }^{\circ} \mathrm{C}\right)$

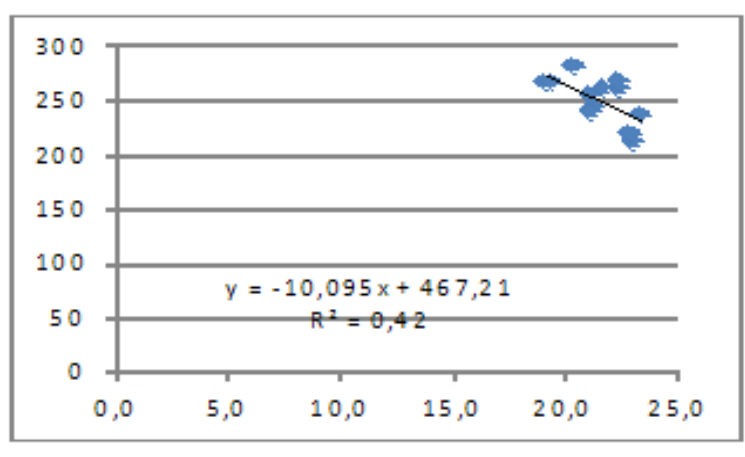

Pressão Atmosférica (hP a)

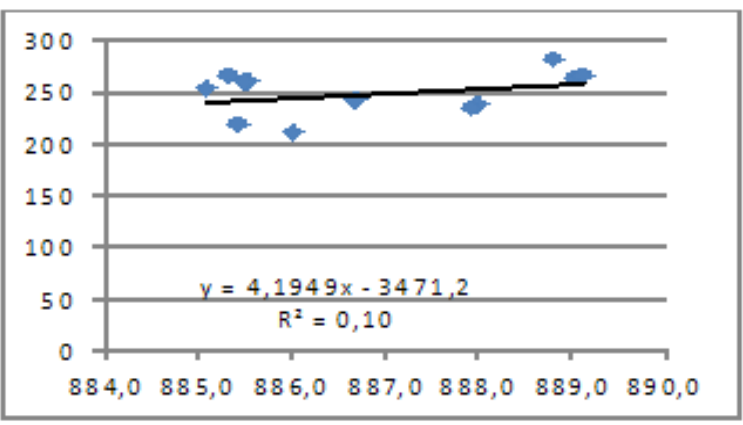

Temperatura Mínima $\left({ }^{\circ} \mathrm{C}\right)$

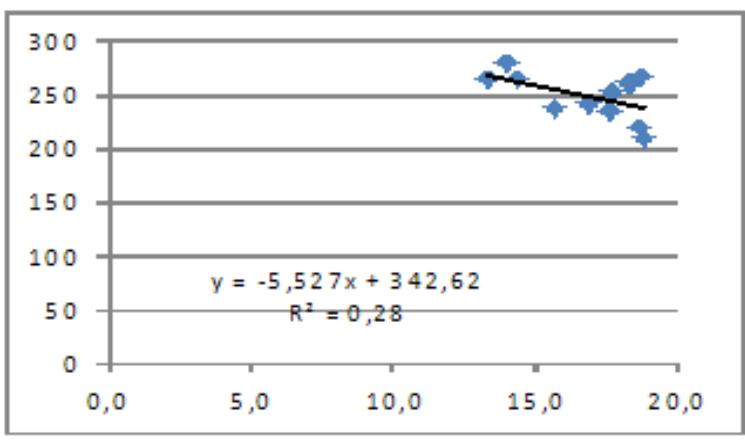

Umidade Relativa do Ar (\%)

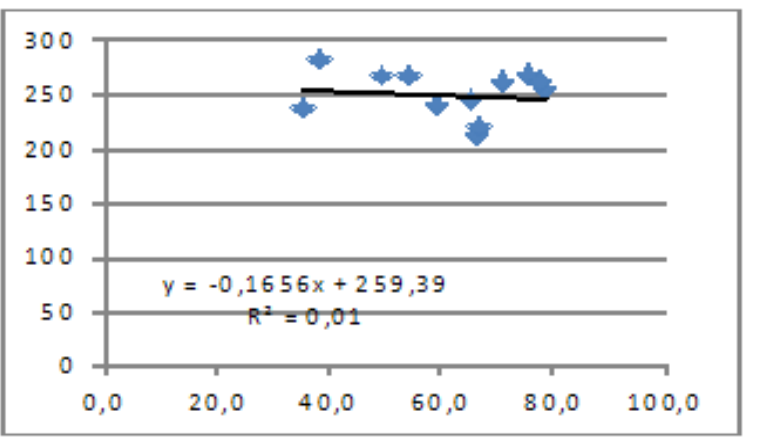

Figura 36 - Regressão entre as variáveis climatológicas e os casos de óbitos por doenças do aparelho circulatório na população humana de todas as idades e sexo, em 2010, no Distrito Federal. Fonte dos dados: INMET, SES/DF, CODEPLAN, MS/SVS/CGIAE/SIM, IBGE. Elaboração: NATAL, 2015.

Para o ano de 2011, analisando a Figura 37 das variáveis climatológicas e os óbitos por doenças do aparelho circulatório, há uma relação inversa com a precipitação, temperatura mínima e umidade relativa do ar, e para a pressão atmosférica aponta uma relação direta. 


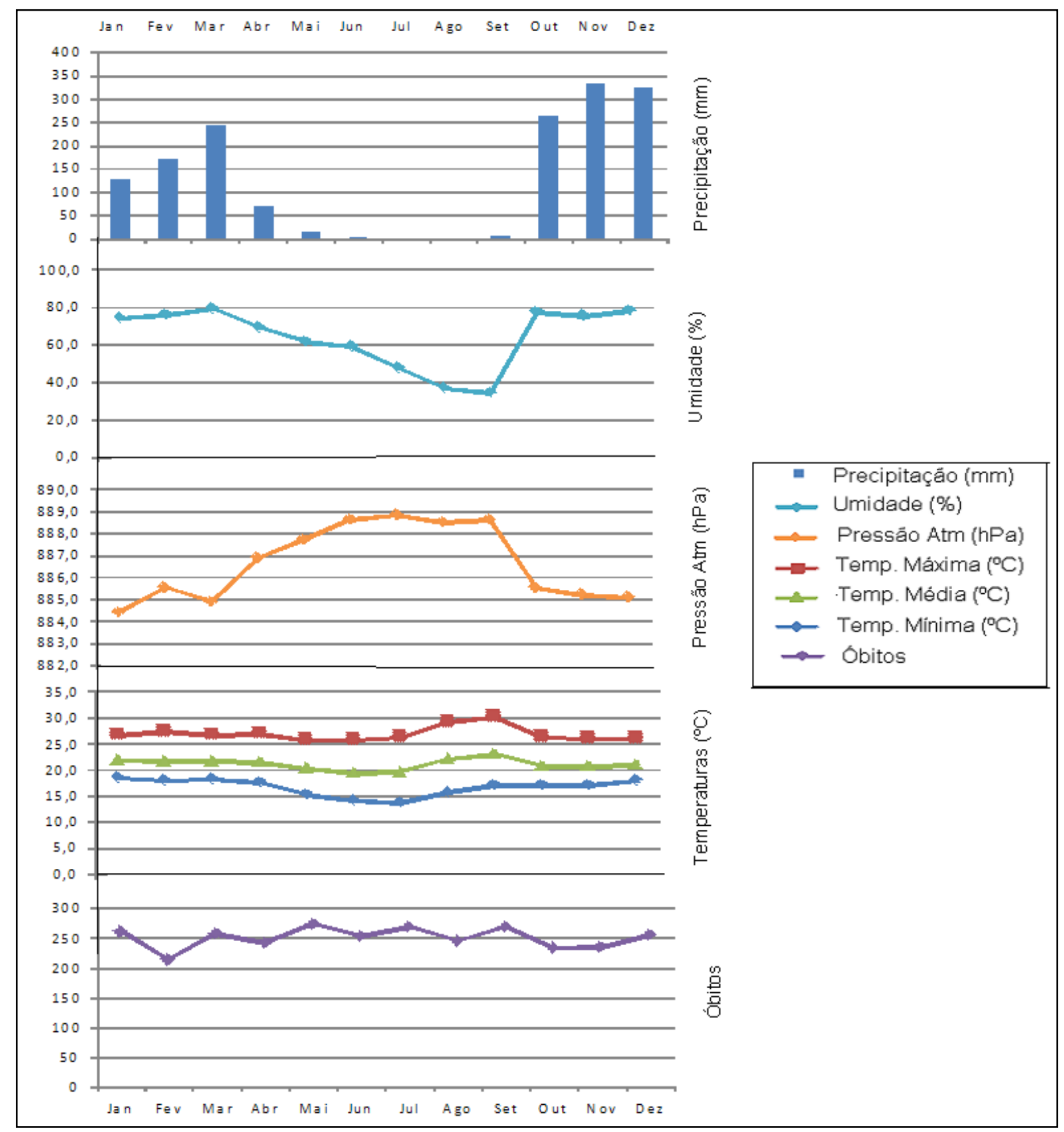

Figura 37 - Relações entre as variáveis climatológicas e os óbitos por doenças do aparelho circulatório mensais em 2011, no Distrito Federal. Fonte dos dados: INMET, SES/DF, CODEPLAN, MS/SVS/CGIAE/SIM, IBGE. Elaboração: NATAL, 2015.

Ao analisarmos a Tabela 17, os coeficientes de correlação e determinação mostraram na classificação que o ano de 2011, os óbitos por doenças do aparelho circulatório tiveram maior correlação inversa com a precipitação, temperatura mínima e umidade relativa do ar, sendo que a precipitação foi a variável que apresentou a maior correlação inversa, confirmada pelo valor negativo do coeficiente de correlação $(R=-46)$, e o coeficiente de determinação $\left(R^{2}=22\right)$ indicou que $22 \%$ dos 
casos de óbitos por doenças do aparelho circulatório tiveram correlação com os baixos valores da precipitação, classificada como "Média". Já a pressão atmosférica teve a correlação direta, confirmada positiva no coeficiente de correlação $(R=0,40)$, e o coeficiente de determinação $\left(R^{2}=0,16\right)$ indicou que $16 \%$ dos casos de óbitos por doenças do aparelho circulatório tiveram correlação direta "Média" com os valores altos da pressão atmosférica. Ainda, nesta análise a temperatura máxima e média tiveram correlação "Nula" e "Fraca”, respectivamente, Tabela 17.

Tabela 17: Valores dos coeficientes de correlação $(R)$, de determinação $\left(R^{2}\right)$ e classificação $(C)$, encontrados entre as variáveis climatológicas e os números de óbitos mensais por doenças circulatórias ocorridas no Distrito Federal, ano de 2011.

\begin{tabular}{cccc} 
Variáveis Climáticas & \multicolumn{3}{c}{ Obitos em Geral } \\
Precipitação $(\mathrm{mm})$ & $\mathbf{R}$ & $\mathbf{R}^{\mathbf{2}}$ & $\mathbf{C}$ \\
\hline Pressão Atm $(\mathrm{hPa})$ & $-0,46$ & 0,22 & Média \\
\hline Temp. Máxima $\left({ }^{\circ} \mathrm{C}\right)$ & 0,40 & 0,16 & Média \\
\hline Temp. Mínima $\left({ }^{\circ} \mathrm{C}\right)$ & 0,04 & 0,00 & Nula \\
\hline Temp. Média $\left({ }^{\circ} \mathrm{C}\right)$ & $-0,37$ & 0,14 & Média \\
\hline Umidade rel. do ar $(\%)$ & $-0,11$ & 0,01 & Fraca \\
\hline
\end{tabular}

Fonte dos dados: INMET, SES/DF, CODEPLAN, MS/SVS/CGIAE/SIM, IBGE. Elaboração: NATAL, 2015.

Na Figura 38 observa-se que o gráfico de regressão no ano de 2011, a precipitação, temperatura mínima e umidade relativa do foram as variáveis que mais influenciaram nos casos de óbitos por doenças do aparelho circulatório. Podemos verificar que nestas variáveis que a reta inclinada para baixo confirma que a relação é inversa já que a precipitação, temperatura mínima e umidade relativa do ar tiveram influência inversa sobre os casos de óbitos neste ano pesquisado. Na pressão atmosférica a relação com os óbitos por doenças do aparelho circulatório foi de relação direta, verificando nesta variável que a reta inclinada para cima confirma que a relação é direta, ou seja, a pressão atmosférica teve influência direta sobre os casos de óbitos neste ano pesquisado. Ainda, nesta figura, podemos observar que na temperatura máxima e média, a reta mantém sua posição horizontal, indicando 
"Fraca" ou "Nula" relação com essas duas variáveis nos casos de óbitos por doenças do aparelho circulatório, neste ano pesquisado.

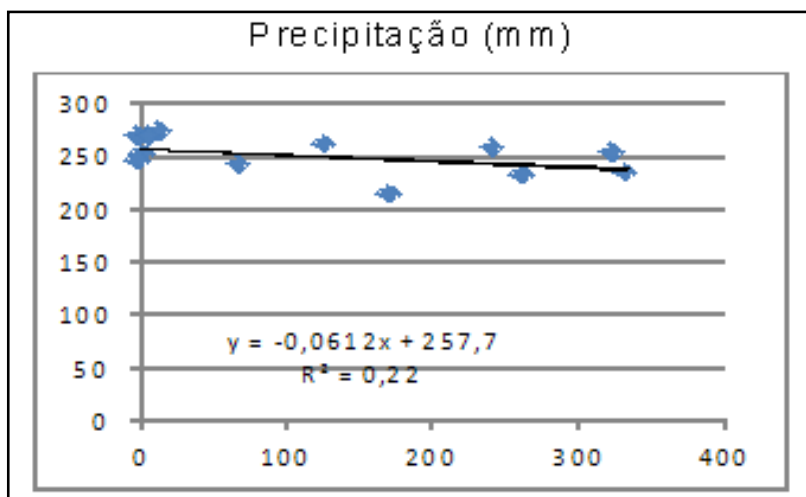

Temperatura Máxima $\left({ }^{\circ} \mathrm{C}\right)$

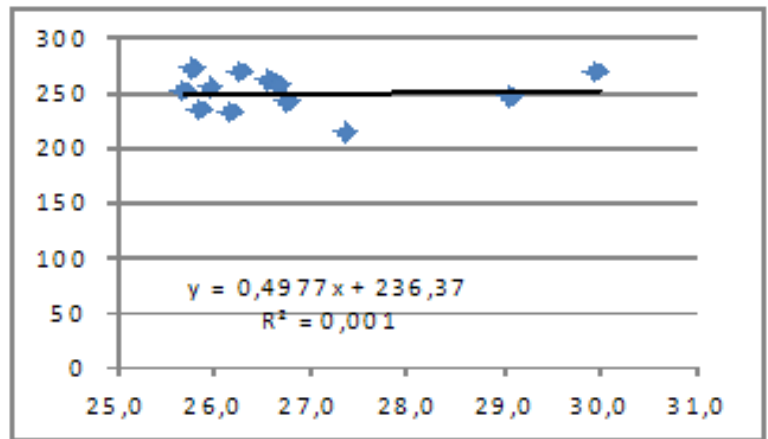

Temperatura Média $\left({ }^{\circ} \mathrm{C}\right)$

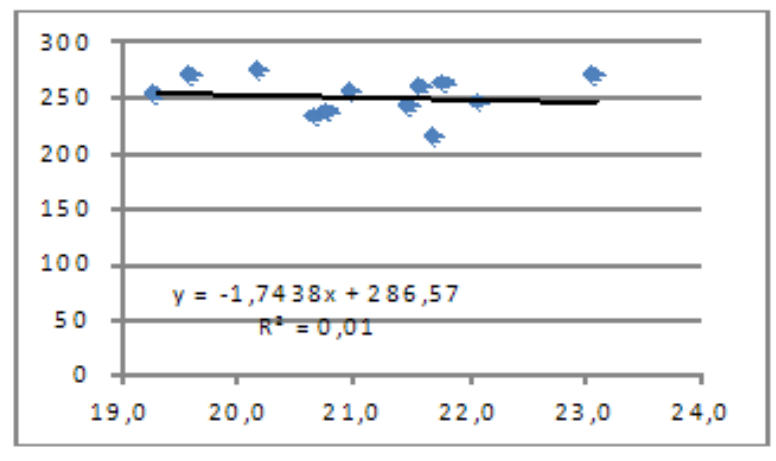

Pressẫo Atmosférica (hP a)

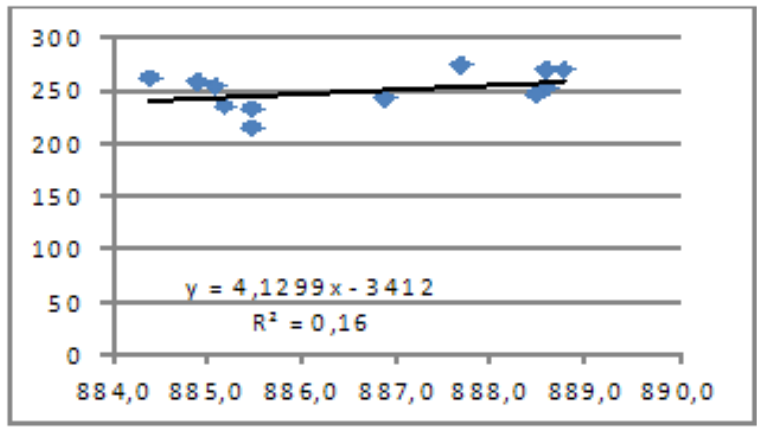

Temperatura Mínima $\left({ }^{\circ} \mathrm{C}\right)$

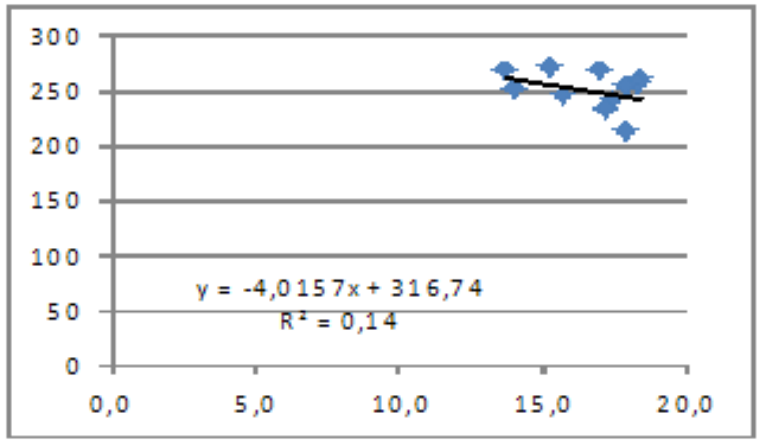

U midade Relativa do Ar (\%)

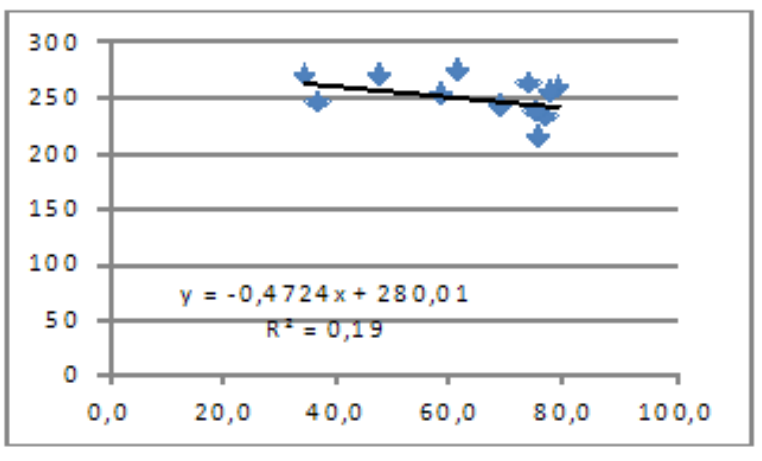

Figura 38 - Regressão entre as variáveis climatológicas e os casos de óbitos por doenças do aparelho circulatório na população humana de todas as idades e sexo, em 2011, no Distrito Federal. Fonte dos dados: INMET, SES/DF, CODEPLAN, MS/SVS/CGIAE/SIM, IBGE. Elaboração: NATAL, 2015.

Para o ano de 2012, analisando a Figura 39 das variáveis climatológicas e os óbitos por doenças do aparelho circulatório mostraram uma relação inversa com a precipitação, temperaturas máxima, média, mínima e umidade relativa do ar, e para a pressão atmosférica aponta uma relação direta. 


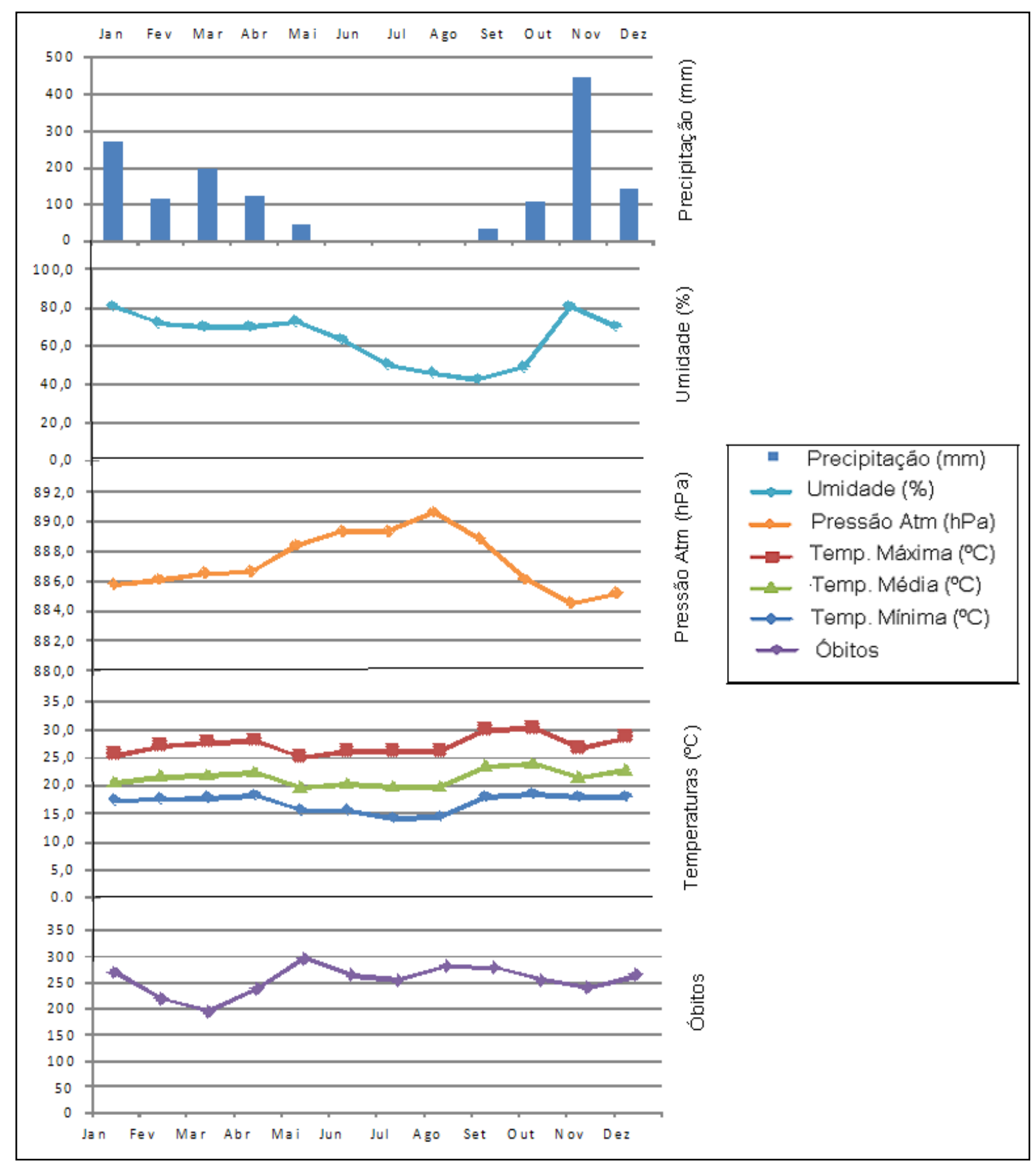

Figura 39 - Relações entre as variáveis climatológicas e os óbitos por doenças do aparelho circulatório mensais em 2012, no Distrito Federal. Fonte dos dados: INMET, SES/DF, CODEPLAN, MS/SVS/CGIAE/SIM, IBGE. Elaboração: NATAL, 2015.

Ao analisarmos, Tabela 17, os coeficientes de correlação e determinação mostraram na classificação do ano de 2012, que os óbitos por doenças do aparelho circulatório tiveram maior correlação inversa, com a precipitação, temperaturas máxima, média, mínima e umidade relativa do ar, sendo que a precipitação foi a variável que apresentou a maior correlação inversa, confirmada pelo valor negativo 
do coeficiente de correlação $(R=-40)$, e o coeficiente de determinação $\left(R^{2}=16\right)$ indicou que $16 \%$ dos casos de óbitos por doenças do aparelho circulatório tiveram correlação com os baixos valores da precipitação, classificada como "Média". Já a pressão atmosférica teve a correlação direta, confirmada pelo valor positivo do coeficiente de correlação $(R=0,48)$, e o coeficiente de determinação $\left(R^{2}=0,23\right)$ indicando que $23 \%$ dos casos de óbitos por doenças do aparelho circulatório tiveram correlação direta "Média" com os valores altos da pressão atmosférica, Tabela 18.

Tabela 18: Valores dos coeficientes de correlação $(R)$, de determinação $\left(R^{2}\right)$ e classificação $(\mathrm{C})$, encontrados entre as variáveis climatológicas e os números de óbitos mensais por doenças circulatórias ocorridas no Distrito Federal, ano de 2012.

\begin{tabular}{cccc}
\hline Variáveis Climáticas & $\mathbf{R}$ & Obitos em Geral & \\
Precipitação $(\mathrm{mm})$ & $-0,40$ & $\mathbf{R}^{\mathbf{2}}$ & $\mathbf{C}$ \\
\hline Pressão Atm $(\mathrm{hPa})$ & 0,48 & 0,16 & Média \\
\hline Temp. Máxima $\left({ }^{\circ} \mathrm{C}\right)$ & $-0,17$ & 0,23 & Média \\
\hline Temp. Mínima $\left({ }^{\circ} \mathrm{C}\right)$ & $-0,39$ & 0,03 & Fraca \\
\hline Temp. Média $\left({ }^{\circ} \mathrm{C}\right)$ & $-0,27$ & 0,16 & Média \\
\hline Umidade rel. do ar $(\%)$ & $-0,33$ & 0,07 & Fraca \\
\hline
\end{tabular}

Fonte dos dados: INMET, SES/DF, CODEPLAN, MS/SVS/CGIAE/SIM, IBGE. Elaboração: NATAL, 2015.

Na Figura 40 observa-se que o gráfico de regressão no ano de 2012, as variáveis do clima: precipitação, temperatura máxima, média, mínima e umidade relativa influenciaram nos casos de óbitos por doenças do aparelho circulatório. Podemos verificar que nestas variáveis a reta se inclina para baixo o que confirma a relação inversa já que a precipitação, temperaturas máxima, média, mínima e umidade relativa do ar tiveram influência inversa sobre os casos de óbitos neste ano pesquisado. Na pressão atmosférica a relação com os óbitos por doenças do aparelho circulatório foi de relação direta, verificando nesta variável que a reta inclinada para cima confirma que a relação é direta, ou seja, a pressão atmosférica teve influência direta sobre os casos de óbitos neste ano pesquisado. 


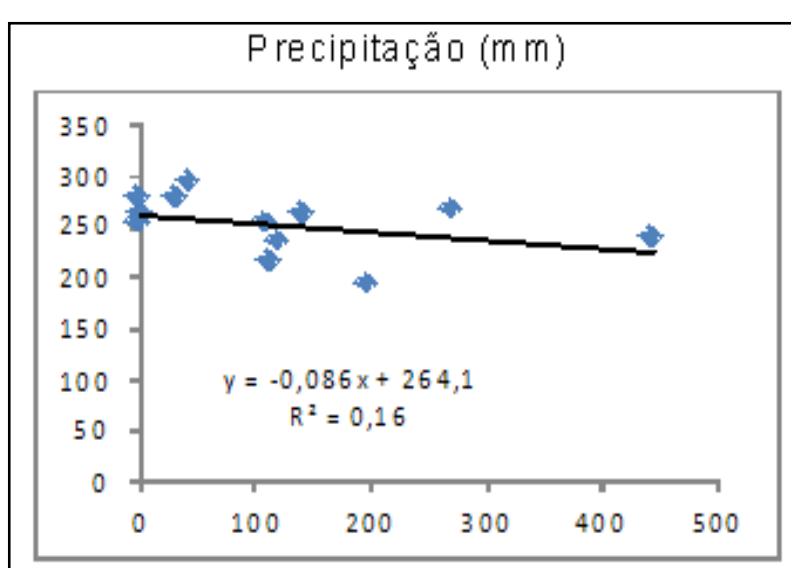

Temperatura Máxima $\left({ }^{\circ} \mathrm{C}\right)$

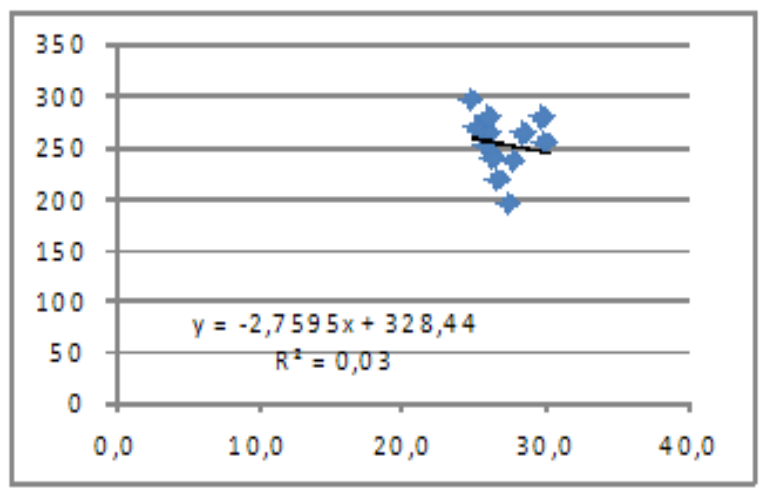

Temperatura Média $\left({ }^{\circ} \mathrm{C}\right)$

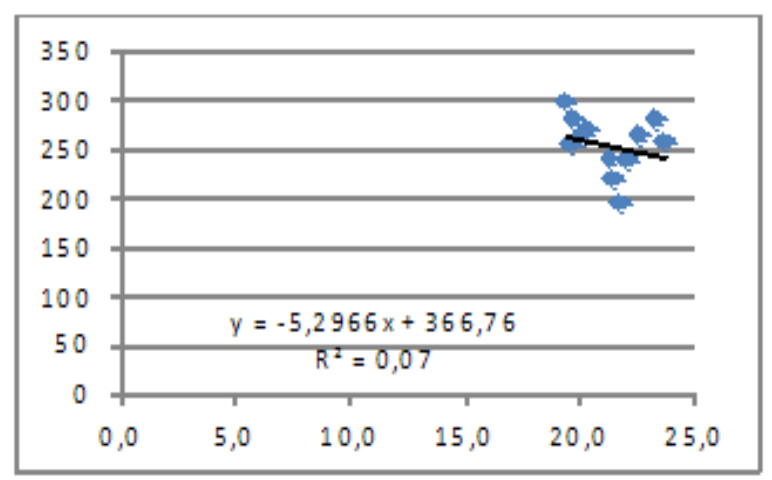

Pressẫo A tmosférica (hP a)

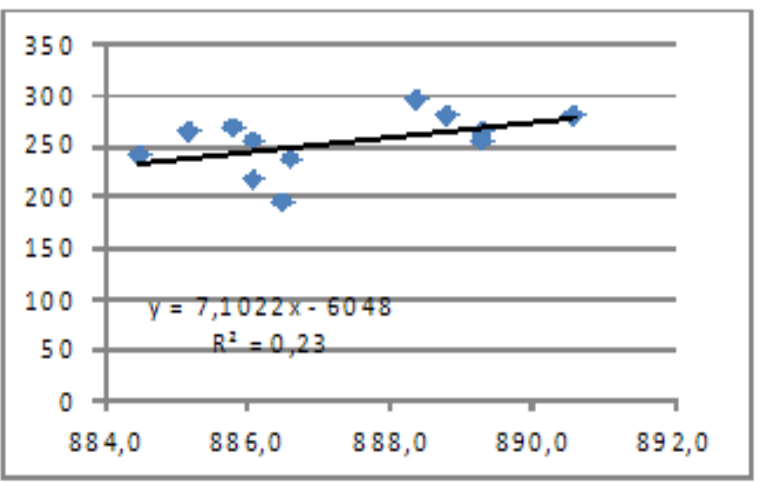

Temperatura Mínima $\left({ }^{\circ} \mathrm{C}\right)$

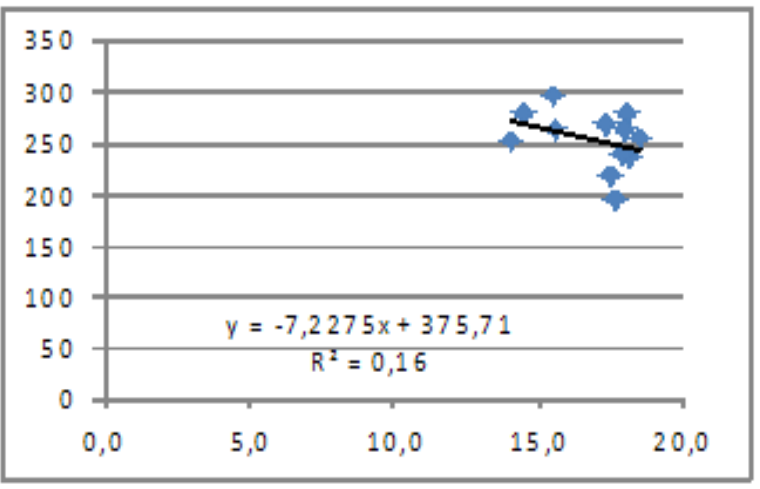

Umidade Relativa do Ar (\%)

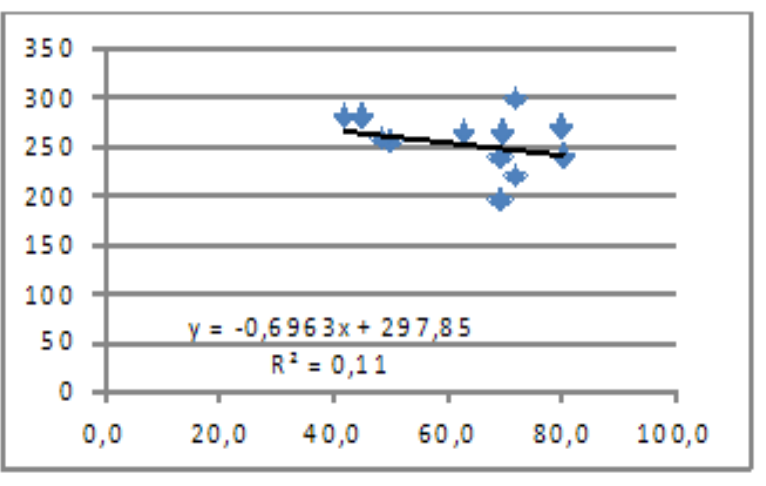

Figura 40 - Regressão entre as variáveis climatológicas e os casos de óbitos por doenças do aparelho circulatório na população humana de todas as idades e sexo, em 2012, no Distrito Federal. Fonte dos dados: INMET, SES/DF, CODEPLAN, MS/SVS/CGIAE/SIM, IBGE. Elaboração: NATAL, 2015.

Os referidos gráficos e as linhas das variáveis climáticas demonstram particularidades e similaridades entre os 10 (dez) anos analisados (2003 a 2012). Mostraram que há variação nas taxas de óbitos mensais durante o ano, verificando que o aumento ocorre em conjunto com as oscilações dos elementos climáticos. Evidenciando a variabilidade nos casos de mortalidade por doenças do aparelho circulatório no Distrito Federal devido às oscilações climáticas durante o ano. 
Nos anos pesquisados (2003 a 2012), destacaram-se os meses de maio a agosto com queda do total pluviométrico e, consequentemente, diminuição da umidade relativa do ar, aumento da pressão atmosférica mensal, com registro das menores temperaturas mínimas. Os meses de junho a setembro destacaram-se com maior amplitude térmica (valor entre a temperatura máxima e mínima) e consequentemente, um aumento nos registros de óbitos por doenças do aparelho circulatório, podendo ter relação direta com o clima já que comprovado suas relações com as alterações bruscas da temperatura e o aumento da pressão atmosférica.

Nos meses que se apresentaram aumento da pressão atmosférica e mudanças bruscas da temperatura (máxima e Mínima) e aumento da amplitude térmica, as taxas dos óbitos aumentaram, evidenciando a relação entre os óbitos e o estresse térmico.

Essas mudanças bruscas representam risco nas complicações das doenças do aparelho circulatório, pois o individuo fica vulnerável às enfermidades fora da zona de conforto térmico.

Para Castro (2000), desde as teorias de Hipócrates, eram percebidas que nas mudanças de estações, especialmente no inverno, as doenças circulatórias e respiratórias eram as mais perigosas nos idosos e nos pacientes com alguma doença no sistema circulatório (hipertensos, angina do peito, infarto do miocárdio, acidente circulatório cerebral e má circulação) o que elevava os registros de óbitos nesses 02 (dois) grupos.

Para Frota e Schiffer (2001), o ser humano é um ser homeotérmico, com temperatura corporal entre 36 e $37^{\circ} \mathrm{C}$, as temperaturas abaixo desses valores fazem com que mecanismos de controle sejam acionados, como a vasoconstrição e aumento da taxa metabólica. Como repercussão hemodinâmica há a vasoconstrição dos vasos que diminuem o calibre arterial e, consequentemente, aumentam da resistência periférica contra a qual o coração necessita bombear, elevando assim a pressão arterial. Ainda mais em indivíduos que tenham a predisposição em formar placas de ateroma que contribui sobremaneira para obstrução da luz do vaso.

Os efeitos das oscilações térmicas ambientais podem ser sentidos em pessoas predispostas, tais como as idosas, as crianças e as portadoras de doencas crônicas, os indivíduos com boa saúde suportam com facilidade estas situaçõ€ 106 
estresse térmico (PITTON e DOMINGOS, 2004).

Ainda segundo, Pitton e Domingos (2004) o sistema do corpo humano (sistema homeotérmico) que regula e mantém o equilibrio térmico quando exposto a situações extremas de calor ou frio, podem exercer impacto sobre diversas categorias de enfermidades, inclusive cardiovasculares, respiratórias e cerebrovasculares.

Nesta pesquisa, foi observado que a pressão atmosférica foi o elemento que teve maior influência direta nos registros dos óbitos por doenças do aparelho circulatório para os anos pesquisados (2003 a 2012). A pressão atmosférica é um fator externo que exerce uma força sobre os corpos na Terra. A pressão atmosférica sofre variações constantes, de acordo com o local de mensuração e das variações do clima. O aumento da pressão atmosférica pode provocar no ser humano a vasoconstrição, ou seja, uma pressão nos vasos sanguíneos.

A atmosfera terrestre contém alguns gases circulantes que exercem uma pressão sobre a superfície terrestre. Essa pressão altera-se de acordo com a altitude do local e não tem um valor constante anual pelo fato de sofrer alterações com as variáveis do clima de acordo com a época do ano, alterando a pressão exercida sobre o corpo ou objeto exposto. "Essas alterações atmosféricas implicam alterações fisiológicas para o corpo continuar a trabalhar de forma a suprir as necessidades do organismo (MAGALHAES et al., 2002)".

Portanto, com a pressão atmosférica acima dos valores normais do local mensurado provocam nos indivíduos com algum agravo fisiológico (diabetes, hipertensos, níveis de colesterol alto) e idade avançada uma série de alterações fisiológicas o que poderá levar de maneira súbita ao óbito. 


\section{OAPITULOMI}

Considerações Finais 


\section{6 - CONSIDERAÇÕES FINAIS}

Para responder à hipótese inicial da pesquisa foi utilizado o método de "correlação de Person" para correlacionar essas duas variáveis durante os anos de 2003 a 2012, no Distrito Federal, sendo confirmada que as variáveis climatológicas (precipitação, pressão atmosférica, temperaturas e umidade relativa do ar) influenciaram na mortalidade por doenças do aparelho circulatório.

Vale ressaltar que existem outras variáveis fisiológicas, comportamentais ambientais e hereditárias que influenciam nos óbitos por Doenças do Aparelho Circulatório (alimentação inadequada, obesidade, consumo de bebidas alcoólicas, sedentarismo, tabagismo, diabete, colesterol, hipertensão, idade, sexo, hereditariedade e demais outros) que contribuem com os óbitos dessa enfermidade.

Assim, não podemos concluir como única relação de causa e efeito entre as variáveis estudadas com os óbitos por Doenças do Aparelho Circulatório. Sugerimos outros estudos para que se possam considerar e correlacionar outros fatores, por exemplo, a poluição atmosférica derivada de queimadas vegetais e/ou de combustíveis fósseis.

As análises das correlações mensais dos óbitos com as variáveis climáticas mostraram que à medida que há uma alteração brusca nas variáveis climáticas, por exemplo, quando se registra temperaturas com taxas elevadas ou baixas em relação ao mês anterior, o número de registro de óbitos aumenta nesses meses. A ocorrência de infarto agudo do miocárdio foi associada com o estresse térmico, ou seja, temperaturas extremamente frias ou quentes (LEE, et. al, 2010).

As influencias do meio físico podem contribuir com diversas morbidades e óbitos, mas, vale ressaltar que outros fatores podem também contribuir com o aumento das internações é os óbitos, por exemplo, as condições socioeconômicas dos pacientes (moradia, alimentação, exposição aos poluentes atmosféricos) aliados com fatores fixos preexistentes.

No entanto, essas análises vêm reforçar a confirmação de que o homem é sensível às oscilações climáticas que podem prejudicar o comportamento de seu funcionamento fisiológico, acarretando diferentes anomalias, inclusive levar ao óbito.

.As analises nos gráficos das variáveis climáticas mostraram a prevalência da relação inversa dessas variáveis com os óbitos por doenças do aparelho circulatório, exceto, com a variável pressão atmosférica que preponderou a relação direta. 
A distribuição temporal dos óbitos por doenças do aparelho circulatório, a partir da média mensal, apontou tendência de aumento nos anos pesquisados, exceto para os anos de 2005 e 2006 quando o número total dos óbitos em todo Distrito Federal teve acentuada redução. Em 2007 retomou novamente tendência de aumento de óbitos. Nos anos pesquisados apontou-se variabilidade, ou seja, um aumento no número de óbitos nos meses de maio a agosto e diminuição nos meses de novembro a abril.

Nesta pesquisa, observa-se que o individuo do sexo masculino e as pessoas com mais de 60 anos são os mais suscetíveis aos óbitos por doenças do aparelho circulatório no Distrito Federal.

A distribuição espacial dos óbitos por doenças do aparelho circulatório no Distrito Federal é padrão em todas as regiões administrativas na idade e sexo. Dentre as Regiões Administrativas com alto índice de envelhecimento - A Região Administrativa Lago Sul - teve as maiores taxas de óbitos por doenças do aparelho circulatório em todos os anos pesquisados e a que apresentou maior taxa de envelhecimento do Distrito Federal (CODEPLAN, 2012).

Com base no exposto, acredita-se que esta pesquisa possa contribuir com os gestores no planejamento junto aos grupos que apresentam alguma enfermidade, ou outras variáveis fisiológicas, comportamentais e hereditárias que possam contribuir com o aumento dos óbitos por doenças circulatórias, enfocando com as variáveis climatológicas a fim de agir na prevenção ou mitigação de sua influência sobre os casos de morbidade e mortalidade aqui estudados.

As dificuldades encontradas na pesquisa foram: A criação de novas Regiões Administrativas sem definição das poligonais; Falta de Geo-Código das Regiões Administrativas e a alta rotatividade dos habitantes do Distrito Federal dificultando mensurar as regiões administrativas com maior crescimento nos registros de óbitos pela enfermidade pesquisada.

Recomenda-se, melhor interação entre a Companhia de Planejamento do Distrito Federal, Departamento de Trânsito do Distrito Federal, Secretaria de Estado de Meio Ambiente e Recursos Hídricos, entre outros articulados em busca de pesquisa e adoção de soluções a fim de mitigar a vulnerabilidade, tanto socioeconômica, socioambiental, proporcionando um melhor conforto à saúde. E, outros estudos que venham a ser realizados com as variáveis climatológicas e as 
internações/óbitos por diversas enfermidades possam ser realizadas em nível diário, tornando mais preciso quanto a influência do tempo sobre a saúde humana. 


\section{REFARATOLAS}

BIBLIOGRELIOEO 


\section{REFERÊNCIAS BIBLIOGRÁFICAS}

- ANDRADE, A. S. R. de; CÂMARA, J. F. A.; NETO, M. D. A.; AMORELLI, O. S. A geografia da saúde no Brasil: Análise do saneamento público nos casos de dengue. XII Colóquio Ibérico de Geografia, 2010.

- ARMSTRONG, R.W. Medical Geography. In: Advances in Medical Social Science. RUFINI, J.L. (ed.). New York: Gordon and Breach Science Publishers, n.1, 1983. p.167-183.

- AUGUSTO L. G. S. Saúde e Vigilância Ambiental: um tema em construção. Epidemiologia e Serviços de Saúde 2003; (12) 4: 177-187. Revista do Sistema Único de Saúde do Brasil. V. 12 - № 4 - out/dez - 2003.

- BARCELLOS, C.; MACHADO, J. M. H. A organização espacial condiciona as relações entre ambiente e saúde: o exemplo da exposição ao mercúrio em uma fábrica de lâmpadas fluorescentes. Ciência \& Saúde Coletiva, 3(2):103-113, 1998.

- BARCELLOS, C.; QUITÉRIO, L.A.D. Vigilância ambiental em saúde e sua implantação no Sistema Único de Saúde.Revista de Saúde Pública,, v. 40, n. 1, p. 170-77, 2006.

- BRASIL. Ministério da Saúde. Secretaria de Gestão do Trabalho e da Educação na Saúde. Departamento de Gestão da Educação na Saúde. Projeto de Profissionalização dos Trabalhadores da Área de Enfermagem. 2. ed. rev., 1.a reimpr. - Brasília: Ministério da Saúde; Rio de Janeiro: Fiocruz, 2003.

- BRASIL. Ministério da Saúde. Secretaria de Vigilância em Saúde. Departamento de Análise de Situação de Saúde. Saúde Brasil 2004 - uma análise da situação de saúde. Brasilia: Ministério da Saúde, 2004a.

- BRASIL. Ministério da Saúde. Prevenção Clínica de Doença Cardiovascular, Cerebrovascular e Renal Crônica. Cadernos de Atenção Básica - ‥ 14, Brasília DF, 2006.

- BRASIL. Ministério da Saúde. Secretaria de Vigilância em Saúde. Departamento de Análise de Situação de Saúde. Plano de ações estratégicas para o enfrentamento das doenças crônicas não transmissíveis (DCNT) no Brasil 2011-2022 / Ministério da Saúde. Secretaria de Vigilância em Saúde. Departamento de Análise de Situação de Saúde. - Brasília : Ministério da Saúde, 2011. 
- CÂmarA, G.; Casanova, M. A.; HeMerly, A. S.; MAGalhãeS, G. A.; MEDEIROS, C. M. B. Anatomia de Sistemas de Informação Geográfica. 10ª . Escola de Computação. Campinas. Instituto de Computação - UNICAMP. 1996. 197p.

- CÂMARA, G.; DAVIS, C.; MONTEIRO, A. M. V. Introdução à Ciência da Geoinformação. 2001. Disponível em: <http://www.dpi.inpe.br/gilberto/livro/introd/>. Acesso em: 10 mar. 2014.

- CASAGRANDE, A.; SILVA JUNIOR, P.; MENDONÇA, F. Mudanças Climáticas e Aquecimento Global: Controvérsias, Incertezas e a Divulgação Científica. Rev. Brasileira de Climatologia, Ano 7, volume 8, Jan-Jun/2011.

- CASTELLS, M. A Sociedade em Rede. 6. ed. São Paulo: Paz e Terra, 2002.

- CASTRO, A. W. S. Clima urbano e saúde: as patologias do aparelho circulatório associadas aos tipos de tempo no Inverno de Rio Claro - São Paulo. 2000. 202 f. Tese (Doutorado)-Instituto de Geociências e Ciências Exatas, Universidade Estadual Paulista Júlio de Mesquita Filho, São Paulo, 2000.

- CASTRO J. Geografia da fome (o dilema brasileiro: pão ou aço). 10 Janeiro: Antares Achiamé; 1980

- CHENG, X; SU, H (2010). Effects of climate Journal temperature stress on cardiovascular diseases. European Journal of Internal Medicine, n. 21, 2010.pp.164167.

- CODEPLAN. A evolução da mortalidade no Distrito Federal na Área Metropolitana de Brasília (AMIB) entre 2000 e 2010. Brasíia, 2012.

- CORRÊA, L. S. C. O Caráter Civilizatório das Práticas Higieinistas no Século XIX. Revista Geográfica de América Central Número Especial EGAL, 2011- Costa Rica ॥ Semestre 2011.

- COSTA, M.C.N e TEIXEIRA, M.G.L.C. A Concepção de "Espaço" na Investigação Epidemiológica. Cad. Saúde Publica v. 15 n.2 Rio de Janeiro abr-jun.1999.

- DILAVERIS, P; SYNETOS, A; GIANNOPOULOS, G; GIALAGOS, E; PANTAZIS, A; STEFANADIS, C. CLimate Impacts on Myocardial infarction deaths in the Athens Territory: the CLIMATE study. Heart 2006;92:1747-1751. CARDIOVASCULAR MEDICINE. 
- EDMAR, G. Palestra [ago., 2008]. Pernambuco: UFPE, 2008. Palestra proferida em Seminário organizado por estudantes do programa PET Geografia da UFPE - A Geografia da Saúde.

- FARIA, R. M; BORTOLOZZI, A. Espaço, Território e Saúde: Contribuições de Milton Santos Para o Tema da Geografia da Saúde No Brasil. Editora UFPR, R. RA'E GA, Curitiba, n. 17, p. 31-41, 2009.

- FERREIRA, M. U. Epidemiologia e geografia, o complexo patogênico de Max Sorre. Cadernos de Saúde Pública, 7:300-309, 1991.

- FONSECA, V. Clima e saúde humana. In: Anais do VI Simpósio Brasileiro de Climatologia Geográfica. Aracajú: UFA, 2004.

- FRETAS, C. M. de. Problemas ambientais, saúde coletiva e ciências sociais. Ciência \& Saúde Coletiva, 8(1):137-150, 2003.

- FROTA, A. B; SCHIFFER, S.R. Manual do Conforto Térmico. 5a Edição. São Paulo: Nobel, 2001.

- GIL, A. C. Métodos e Técnicas de Pesquisas Social. 6ํㅡㄹ Ed. Editora Atlas, São Paulo, 2008.

- GOERRE, S; EGLI, C; GERBER, S; DEFILA, C; MINDER, C; RICHNER, H; MEIER, $B$. Impact of weather and climate on the incidence of acute coronary syndromes. Elsever - International Journal of Cardiology 118 (2007) 36-40.

- GUIMARÃES, R. B. Saúde Urbana: Velho Tema, Novas Questões. Terra Livre, no 17, 2o Semestre, p. 155-170, São Paulo, 2001.

- Yi Li, T. D. et. al. The seasonality of acute coronary syndrome and its relations with climatic parameters. Elsevier - American Journal of Emergency Medicine (2011) 29, 768-774.

- JUNQUEIRA, R. D. Geografia Médica e Geografia da Saúde. Hygeia 5(8):57 - 91, Jun/2009.

- LACAZ, C. S.; BASRUZZI, R. G. \& SIQUEIRA, W. Introdução a geografia médica. São Paulo, Edgar Blücher/Edusp. 1972

- LEE, J.H. et. al. Influence of weather on daily hospital admissions for acute myocardial infarction (from the Korea Acute Myocardial Infarction Registry). International Journal of Cardiology 144 (2010) 16-21.

- LE GOFF, J. As Doenças têm História. Lisboa: Terramar. 1991.

- LEMOS, J. C.; LIMA, S. C. A Geografia Médica e as doenças infecto-parasitárias. 
Revista On LineCaminhos de Geografia, Uberlândia, v. 3, n. 6, jun. 2002.

- LIMA NETO, J. E. Geografia e Saúde. Dissertação (Mestrado em Geografia) -

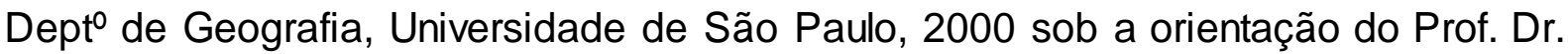
Gil Sodero de Toledo.

- Lowe, D.; Ebi, KL; Forsberg, B. Heatwave Early Warning Systems and Adaptation Advice to Reduce Human Health Consequences of Heatwaves. Int. J Environ Res Public Health 2011;8(12):4623- 4648.

- MAGALHÃES, J. et al. O desafio da altitude: uma perspectiva fisiológica. Revista portuguesa de Ciências do desporto, Porto: v. 2, n. 4, p. 81-91, 2002.

- MAGALHÃES, G. B. O Uso do Geoprocessamento e da Estatística nos Estudos Ecológicos em Epidemiologia: O Caso da Dengue na Região Metropolitana de Fortaleza. Hygeia 8(15): 63 - 77, Dez/2012.

- MYERS, S., \& BENSON, H. (1992). Psychological factors in healing: a new perspective on an old debate. Behavioral Medicine, 18, 5-11.

- MENDONÇA, F. Aspectos da Interação-Ambiente Saúde Humana: Da Relação à (In) Sustentabilidade Ambiental. Curitiba, n. 4, p. 85-99, Editora da UFPR, 2000.

- MOURA, A. A. G.; CARVALHO, E. F. S.; SILVA, N. J. C. Repercussão das doenças crônicas não-transmissíveis na concessão de benefícios pela previdência social. Ciência \& Saúde Coletiva, 12(6):1661-1672, 2007.

- MURARA, P.G; AMORIM, M.C.C.T. Clima e Saúde: variações Atmosféricas e Óbitos por Doenças circulatórias. Rev. Brasileira de Climatologia, Ano 6, volume 6, Jun/2010.

- NETTER, F. H. Atlas de Anatomia Humana. 2ed. Porto Alegre: Artmed, 2000.

- NOGUEIRA, P.; PAIXÃO, E.; RODRIGUES, E. Sazonalidade e Periodicidade do Internamento Hospitalar em Portugal Continental - 1988 a 2003. Fundacao Merck - NOSSA, P. N. Linhas de investigação contemporâneas na Geografia da saúde e a noção holística de saúde. A Geografia e o contexto dos problemas de saúde. Rio de Janeiro: ABRASCO, p.35-62, 2008.

- OLIVEIRA, J. C. F. Biometeorologia: Estudo de casos em Maceió, Alagoas. Maceió, Edufal, 2005.

- ORGANZAÇÃO PAN-AMERICANA DA SAÚDE. Estratégia mundial sobre 
alimentação saudável, atividade física e saúde. Brasilia: Organização PanAmericana da Saúde, 2003.

- PARAGUASSU-CHAVES, C, A. Geografia Medica ou Geografia da Saúde (Espaço e doença na Amazônia Ocidental). Rondonia, Edufro, 2001.

- PEIXTO. A. 1938. Clima e Saúde - Introdução Bigeográfica à Civilização Brasileira. Brasiliana Eletrônica. Acesso em: 15/02/2014. Disponível em: http://www.brasiliana.com.br/obras/clima-e-saude-introducao-biogeografica-acivilizacao-brasileira.

- PEITER, P. C. Geografia da Saúde na Faixa de Fronteira Continental do Brasil na Passagem do Milênio. Rio de Janeiro. Tese de Doutorado - Universidade Federal do Rio de Janeiro, 2005. 314p

- PESSOA, S. Ensaios Médicos Sociais. São Paulo: Hucitec, 1978.

- PITTON, S. E. e DOMINGOS, A. E. Tempos e doenças: efeitos dos parâmetros climáticos nas crises hipertensivas nos moradores de Santa Gertrudes - SP. In. Estudos Geográficos. Rio Claro, vol. 02, №. 01, p.75-86, 2004.

- PORTER, R. "Medicine, the Human Sciences, and the Environment in the Enlightment". In: DRIVER, F. \& ROSE, G. (eds.). Nature and Science: essays in the History of Geographical Knowledge, Historical Geography Research Series. n. 28, p. 27-36, 1992.

- SANTOS; M. Metamorfoses do Espaço Habitado. São Paulo: Hucitec, 1998.

- SILVA, L. J. O conceito de espaço na epidemiologia das doenças infecciosas. Cad. Saúde Públ., Rio de Janeiro, 13(4):585-593, out-dez, 1997.

- SILVA JUNIOR, J. B. da. et al. In: ROUQUAYROL, M. Z. \& ALMEIDA FILHO, N. (Orgs.) Epidemiologia e Saúde. 5.ed. Rio de Janeiro: Medsi, 2003.

- SANTA ROSA, A., AMORELli, O. S., CÂMARA, J. F. A., ARAUJO NETO, M. D. Geografia da Saúde no Brasil: Análise do Saneamento Público nos Casos de Dengue. VI Seminário Latino Americano de Geografia Física II Seminário Ibero Americano de Geografia Física Universidade de Coimbra, Maio de 2010.

- STEINKE, V. A. ; STEINKE, E. T; SAITO, C. H. . Estimativa da Temperatura de Superfície em Áreas Urbanas em Processo de Consolidação: Reflexões e Experimento em Planaltina-DF. Rev. brasileira de climatologia, v. 6, p. 37-56, 2010. 
- UJVARI, S. C. A história e suas epidemias: a convivência do homem com os microorganismos. $2^{\underline{a}}$ edição. Rio de Janeiro: Editora Senac Rio e Editora Senac São Paulo, 2003. 328p.

- VAZ, D. S. Algumas Considerações Sobre a Geografia Médica e da saúde, novas perspectivas para a Geografia brasileira. Hygeia - Volume 6, oㅜ 11. Dez, 2010.

- VASCONCELOS, J; FREIRE, E; ALMENDRA, r; SILVA, G.L; SANTANA, P. The impact of winter cold weather on acute myocardial infarctions in Portugal. Elsevier, Environmental Pollution xxx (2013) 1 e 5.

- VIETES, R. G.; FREITAS, I. A. Pavlovsky e Sorre: duas importantes contribuições à geografia médica. Ateliê Geográfico. Goiás, v. 1, n. 2, p.187-201, dez. 2007.

- WHO (2009) - Prevention of Cardiovascular Disease Pocket Guidelines for Assessment and Management of Cardiovascular Risk Predicting Heart Attack and Stroke risk. WHO, Genebra.Sharp DohmeA. 2008. 
ENA주요 


\title{
ANEXO 01
}

\section{CID 10 - CÓDIGO DAS DOENÇAS DO APARELHO CIRCULATÓRIO}

\author{
100 - Febre Reumática Sem Menção de Comprometimento do Coração \\ 101 - Febre Reumática Com Comprometimento do Coração \\ 102 - Coréia Reumática \\ 105 - Doenças Reumáticas da Valva Mitral \\ 106 - Doenças Reumáticas da Valva Aórtica \\ 107 - Doenças Reumáticas da Valva Tricúspide \\ 108 - Doenças de Múltiplas Valvas \\ 109 - Outras Doenças Reumáticas do Coração \\ 110 - Hipertensão Essencial (primária) \\ 111 - Doença Cardíaca Hipertensiva \\ 112 - Doença Renal Hipertensiva \\ 113 - Doença Cardíaca e Renal Hipertensiva \\ 115 - Hipertensão Secundária \\ 120 - Angina Pectoris \\ 121 - Infarto Agudo do Miocárdio \\ 122 - Infarto do Miocárdio Recorrente \\ 123 - Algumas Complicações Atuais Subseqüentes ao Infarto Agudo do Miocárdio \\ 124 - Outras Doenças Isquêmicas Agudas do Coração \\ 125 - Doença Isquêmica Crônica do Coração \\ I26 - Embolia Pulmonar \\ 127 - Outras Formas de Doença Cardíaca Pulmonar \\ 128 - Outras Doenças Dos Vasos Pulmonares \\ 130 - Pericardite Aguda \\ 131 - Outras Doenças do Pericárdio \\ I32 - Pericardite em Doenças Classificadas em Outra Parte \\ 133 - Endocardite Aguda e Subaguda \\ 134 - Transtornos Não-reumáticos da Valva Mitral \\ 135 - Transtornos Não-reumáticos da Valva Aórtica \\ 136 - Transtornos Não-reumáticos da Valva Tricúspide \\ 137 - Transtornos da Valva Pulmonar \\ 138 - Endocardite de Valva Não Especificada \\ 139 - Endocardite e Transtornos Valvulares Cardíacos em Doenças Classificadas em Outra Parte \\ 140 - Miocardite Aguda \\ 141 - Miocardite em Doenças Classificadas em Outra Parte \\ 142 - Cardiomiopatias \\ 143 - Cardiomiopatia em Doenças Classificadas em Outra Parte \\ 144 - Bloqueio Atrioventricular e do Ramo Esquerdo \\ 145 - Outros Transtornos de Condução \\ 146 - Parada Cardíaca \\ 147 - Taquicardia Paroxística \\ 148 - Flutter e Fibrilação Atrial \\ 149 - Outras Arritmias Cardíacas \\ 150 - Insuficiência Cardíaca \\ 151 - Complicações de Cardiopatias e Doenças Cardíacas Mal Definidas \\ 152 - Outras Afecções Cardíacas em Doenças Classificadas em Outra Parte \\ 160 - Hemorragia Subaracnóide \\ 161 - Hemorragia Intracerebral \\ 162 - Outras Hemorragias Intracranianas Não-traumáticas \\ 163 - Infarto Cerebral \\ 164 - Acidente Vascular Cerebral, Não Especificado Como Hemorrágico ou Isquêmico \\ 165 - Oclusão e Estenose de Artérias Pré-cerebrais Que Não Resultam em Infarto Cerebral \\ 166 - Oclusão e Estenose de Artérias Cerebrais Que Não Resultam em Infarto Cerebral \\ 167 - Outras Doenças Cerebrovasculares
}


168 - Transtornos Cerebrovasculares em Doenças Classificadas em Outra Parte

169 - Seqüelas de Doenças Cerebrovasculares

170 - Aterosclerose

171 - Aneurisma e Dissecção da Aorta

172 - Outros Aneurismas

173 - Outras Doenças Vasculares Periféricas

174 - Embolia e Trombose Arteriais

177 - Outras Afecções Das Artérias e Arteríolas

178 - Doenças Dos Capilares

179 - Transtornos Das Artérias, Das Arteríolas e Dos Capilares em Doenças Classificadas em Outra Parte

180 - Flebite e Tromboflebite

181 - Trombose da Veia Porta

182 - Outra Embolia e Trombose Venosas

183 - Varizes Dos Membros Inferiores

184 - Hemorróidas

185 - Varizes Esofagianas

186 - Varizes de Outras Localizações

187 - Outros Transtornos Das Veias

188 - Linfadenite Inespecífica

189 - Outros Transtornos Não-infecciosos Dos Vasos Linfáticos e Dos Gânglios Linfáticos

195 - Hipotensão

197 - Transtornos do Aparelho Circulatório, Subseqüentes a Procedimentos Não Classificados em Outra Parte

198 - Outros Transtornos do Aparelho Circulatório em Doenças Classificadas em Outra Parte

199 - Outros Transtornos do Aparelho Circulatório e os Não Especificados 